\title{
Aplicação das classificações CID-10 e CIF nas definições de deficiência e incapacidade
}

\author{
Heloisa Brunow Ventura Di Nubila
}

Tese apresentada ao programa de PósGraduação da Faculdade de Saúde Pública da Universidade de São Paulo para obtenção do título de Doutor em Saúde Pública.

Área de concentração: Epidemiologia.

Orientadora: Profa. Dra. Cassia Maria Buchalla

São Paulo 
Autorizo, exclusivamente para fins acadêmicos e científicos, a reprodução total ou parcial desta tese, por processos fotocopiadores.

Assinatura:

Data: 


\section{Dedicatória:}

\section{Dedico esta tese}

Ao meu esposo Carlos, companheiro, revisor paciente e colaborador incansável.

Às minhas filhas Angela e Julia, fonte de motivação, alegria e inspiração.

À memória de meu tio Roberto, que viveu a maior parte de sua vida com epilepsia, internado numa instituição, sem poder decidir o seu destino. 


\section{AGRADECIMENTOS:}

Agradeço a orientação, o apoio e a generosidade da orientadora Prof ${ }^{a}$ Dra. Cassia Maria Buchalla neste trabalho de tese, mas também em outras situações de necessário aprofundamento no uso e no entendimento da CIF.

Ao Professor Ruy Laurenti por me permitir o privilégio do seu convívio e contínuo aprendizado no CBCD (Centro Brasileiro de Classificação de Doenças).

À amiga Lucila Faleiros Neves, que mesmo enfrentando os momentos mais difíceis com a sua surdez no trabalho, me incentivou a "enveredar" pela CIF.

Aos pacientes, familiares, amigos e colegas da AVAPE (Associação para Valorização e Promoção de Excepcionais) que me ensinam todos os dias.

Aos amigos Ana Rita de Paula e Antonio Carlos Munhoz, a quem muito admiro como protagonistas ativistas pelos direitos das pessoas com deficiência.

A Maria Cecília Mathias Coelho Tamantini, querida amiga, cuja ajuda me tornou possível participar dos encontros internacionais da CIF.

À amiga Jacqueline Louise Schefler que me permitiu fazer a primeira aproximação das pessoas escondidas nos "diagnósticos e prognósticos neurológicos".

A todas as maravilhosas pessoas envolvidas com o Movimento de Direitos das Pessoas com Deficiência que tive o prazer de conhecer neste caminho. 


\section{RESUMO}

Di Nubila HBV. Aplicação das classificações CID-10 e CIF nas definições de deficiência e incapacidade [tese de doutorado]. São Paulo: Faculdade de Saúde Pública da Universidade de São Paulo; 2007.

A Organização Mundial de Saúde tem hoje duas classificações de referência para a descrição dos estados de saúde: a CID-10 (Classificação Estatística Internacional de Doenças e Problemas Relacionados à Saúde) e a CIF (Classificação Internacional de Funcionalidade, Incapacidade e Saúde). A utilização da CIF vem sendo aguardada com grande expectativa pelas organizações de pessoas com deficiências e instituições relacionadas. A falta de definição clara de "deficiência" ou "incapacidade" tem sido apontada como um impedimento para a promoção de saúde de pessoas com deficiência. Este trabalho tem como objetivo apresentar definições de deficiência, discutindo a utilização da CID-10 e da CIF e a contribuição da CIF para melhorar a compreensão sobre definições de deficiência a partir do conceito de funcionalidade e dos fatores contextuais. Foram revisados alguns diferentes conceitos/definições de deficiência, bem como publicações envolvendo a aplicação da CIF. São apresentadas algumas categorias de diagnósticos de estados de saúde da CID-10 hoje utilizadas em alguns sistemas, além de elementos da recém-apresentada CIF, que podem contribuir para diferentes campos de aplicabilidade no que diz respeito ao entendimento das definições de deficiência ou incapacidade.

Palavras-chave: Classificações; CID; CIF; Definições; Deficiência; Incapacidade. 


\begin{abstract}
Di Nubila HBV. Aplicação das classificações CID-10 e CIF nas definições de deficiência e incapacidade/ Application of the classifications ICD-10 and ICF on definitions of disability [doctoral thesis]. São Paulo (BR): Faculdade de Saúde Pública da Universidade de São Paulo; 2007.
\end{abstract}

The World Health Organization has nowadays two reference classifications for description of health conditions: ICD-10 (International Statistical Classification of Diseases and Health Related Problems) and ICF (International Classification of Functioning, Disability and Health). Organizations of people with disabilities and related institutions are waiting with high expectation for the ICF utilization. Lack of clear definition of "disability" is being pointed out as a deterrent for promoting the health of people with disabilities. The objective of this work is to evaluate definitions of disability, and discuss the use of ICD-10 and ICF and the contribution of ICF to improve understanding of definitions of disability through functioning and contextual factors. Some different definitions of disability have been reviewed, as well as publications involving ICF application. Diagnostic categories of health conditions of ICD-10 used in some systems are presented, as well as ICF components that could contribute for different fields of applicability regarding the understanding of definitions of disability.

Key-words: Classifications; ICD; ICF; Definitions; Impairment; Disability. 


\section{ÍNDICE}

$\begin{array}{lr}\text { 1. Introdução } & 8\end{array}$

$\begin{array}{ll}1.1-\text { Questões de identidade } & 12\end{array}$

1.2 - Questões de tradução $\quad 21$

2. Objetivo 29

3. Desenvolvimento do tema

3.1 - CID-10 e CIF

3.1.1 - Histórico das duas classificações 29

3.1.2 - CID-10 39

3.1.3- CIF 41

3.1.4 - Definições de deficiência e incapacidade da CIF 46

3.1.5 - Natureza complementar e sobreposições das duas 51 classificações

3.2 - Definições de deficiência ou incapacidade $\quad 54$

3.2.1- Definições nas Leis dos Estados Unidos

3.2.2 - Definições na União Européia 66

3.2.3 - Baremas $\quad 73$

3.2.4 - Definições de Leis no Brasil $\quad 80$

3.3 - CID-10 para definir deficiência ou incapacidade 94

3.4 - Categorias da CIF e da CID-10 relacionadas a deficiência ou 96 incapacidade

$\begin{array}{lr}\text { 4. Considerações finais } & 100\end{array}$

$\begin{array}{ll}\text { 5. Referências } & 104\end{array}$

6. Anexos 


\section{Introdução}

A definição e a mensuração da incapacidade é tema de interesse crescente a partir do momento em que as pessoas começaram a viver por mais tempo e as doenças crônicas e suas consequiências têm-se tornado relativamente mais comuns (CHATERJI e col., 1999).

Queixas médicas, moléstia, enfermidade, doença crônica, distúrbio, limitações funcionais, deficiência e incapacidade para o trabalho são fenômenos complexos e mal definidos. A incapacidade, em particular, é uma categoria escorregadia e potencialmente expansiva, inerentemente subjetiva, ambígua, imprecisa, impalpável e problemática para definir e medir. A deficiência muitas vezes não pode ser observada diretamente, mas pode ser inferida a partir de causas presumidas (prejuízos, danos) com distintas conseqüências, isto é, uma restrição ou incapacidade para desempenhar normalmente vários papéis, principalmente de trabalho. Danos à saúde que causam deficiência ou incapacidade precisam ser certificados medicamente, embora a certificação clínica de dano seja necessária, mas não suficiente para certificar a incapacidade para o trabalho ou elegibilidade para benefícios por incapacidade (MARIN, 2003).

Para LOLLAR (2002), a falta de uma definição clara de "deficiência ou incapacidade" tem sido apresentada como um impedimento para a promoção da saúde de pessoas com deficiência. A vigilância e a intervenção dependeriam da capacidade para identificar as pessoas que deveriam ser incluídas.

Tanto no setor da saúde como em outros setores que necessitam avaliar o estado funcional das pessoas, como é o caso da previdência social, do emprego, da educação e dos transportes, entre outros, a CIF pode desempenhar um papel 
importante. O desenvolvimento das políticas nestes setores requer dados válidos e confiáveis sobre o estado funcional da população. As definições de incapacidade de âmbito legislativo e regulamentar têm de ser consistentes e fundamentarem-se num modelo único e coerente sobre o processo que origina a incapacidade (PORTUGAL, 2006).

O processo de certificação de deficiência ou incapacidade pode às vezes ser bastante litigioso devido a diferenças entre suas definições legais, administrativas, sociais e culturais. Diferentes sistemas definem deficiência ou incapacidade de acordo com suas próprias necessidades e regulações, mas as definições tipicamente carecem de critérios específicos, impossibilitando determinações precisas (BARRON, 2001).

Associar as categorias de diagnósticos de estados de saúde da CID-10 com os elementos da recém-apresentada CIF, oferecendo uma discussão sobre a prática possível a partir das duas classificações, pode contribuir para um melhor entendimento de possíveis definições de deficiência ou incapacidade.

O modelo mais amplo de funcionalidade, incapacidade e saúde oferecido pela CID-10 e pela CIF, quando aplicado para a construção de instrumentos para levantamentos de saúde e incapacidade, poderia reforçar o campo da pesquisa em saúde e incapacidade, na infância (MCDOUGALL \& MILLER, 2003), mas também nas outras etapas do ciclo de vida.

Um estudo sobre elegibilidade para Programas de Intervenção Precoce nos EUA utilizou um sistema de classificação com descritores para condições de saúde, atraso no desenvolvimento e fatores associados com estado de risco, baseado na CID-10 e na CIF (SIMEONSSON e col., 2002). Este estudo pode oferecer um modelo ou um 
ponto de partida para a elaboração de recursos para utilização em outras faixas etárias ou outros sistemas, no que diz respeito não só a definições e elegibilidade, mas também para propostas de intervenção, avaliação, certificação, destinação de recursos em reabilitação e, de modo mais amplo, no estabelecimento de políticas.

A CID registra uma condição anormal de saúde e suas causas, sem registrar o impacto destas condições na qualidade de vida da pessoa ou paciente, e é hoje uma exigência legal para todos os benefícios e atestados relacionados ao paciente (BATTISTELLA e BRITO, 2002). A maioria das leis no Brasil, que concede benefícios a pessoas com deficiência, tem como exigência a apresentação de laudo médico, algumas vezes acompanhado da avaliação e assinatura de outros profissionais de equipes multiprofissionais, com o preenchimento de campos específicos para códigos da CID ou a simples informação destes códigos em atestados médicos em receituário comum assinado por médico.

Para a autora deste trabalho, na posição de médica em um serviço de reabilitação, a questão das definições de deficiência surgiu a partir da responsabilidade de ser quem certifica a condição, para fins de acesso a vários tipos de benefícios. Quem é e quem não é elegível? Acostumada a usar os códigos da CID10 para cobrir exigências legais, a autora participou de um grupo que, no sistema de transporte, discutia quais os limites e prioridades de atendimento, dentro de um conjunto de situações muito vasto e heterogêneo. Mais difícil ainda, como fazer isto usando como parâmetros definições legais vagas, fortemente ancoradas em diagnósticos médicos, com pouquíssima orientação quanto a aspectos funcionais?

A publicação da CIF neste caminho, como classificação complementar à CID, com seu foco sobre a funcionalidade, trouxe o interesse em explorar as sobreposições 
e interfaces das duas classificações, no que tange aos próprios limites a serem desenhados para as definições de deficiência.

Este trabalho terá cumprido sua função se com ele for possível avançar alguns passos nesta discussão e contribuir para maior clareza e justiça, menor arbitrariedade e crença pessoal, no processo de julgar e certificar a condição de incapacidade de uma pessoa, pelos profissionais e pelas próprias pessoas interessadas nestes limites. 


\section{1- Questões de Identidade}

Questões de identidade precisam ser levadas em conta ao discutir definições de deficiência e incapacidade, pois estas definições influenciam o imaginário social, partindo de diferentes instituições, produzindo identidades construídas externamente e em parte incorporadas internamente. É importante discutir as definições, pois elas ao mesmo tempo influenciam e são o reflexo da maneira como pensa a sociedade.

Segundo ROCHA (1999), no seu trabalho de doutoramento, a expansão e o fortalecimento das organizações de pessoas com deficiência dependem, entre outros fatores, principalmente da construção de uma mentalidade em relação ao que seja deficiência, diferente das noções vigentes no senso comum, de excepcional, subnormal, aleijado, incapaz, "coitadinho", que refletem uma visão paternalista e assistencialista. O conceito de deficiência, nos dias atuais, resulta de pelo menos dois séculos de construção teórica.

A deficiência como "categoria científica" só passou a existir no século XIX. Até então, as pessoas consideradas deficientes enquadravam-se no grupo dos "sobrenaturais", aleijados, loucos, "leprosos", contagiosos, delinqüentes, e a deficiência percebida como produção mítica, religiosa ou de ameaça social (SILVA, 1986).

A partir do século XIX, a deficiência passa a ser compreendida como uma patologia na lógica científica da época, tornando-se passível de estudos, classificações e objeto de intervenções específicas, de acordo com os principais problemas de ordem médica. Neste momento, a deficiência adquire uma nova expressão de sua negatividade: a de pertencer ao universo de "anomalia da natureza". 
Esse novo enquadramento na negatividade social, por sua vez, passa a requerer soluções por meio de intervenções normatizadoras, previstas pelas instituições científicas. Assim, as deficiências são classificadas em mental, física, perceptivas/sensoriais (auditiva, visual) e, nesta lógica, são organizados modelos específicos de intervenção para cada tipo de deficiência, em instituições especializadas (ROCHA, 1999), divididas de acordo com seus tipos, fragmentadas e retificadoras.

O avanço da Medicina no conhecimento da etiologia das doenças, dos tipos e manifestações das deficiências, também levou a uma classificação das mesmas, de forma cada vez mais específica. A precisão na determinação da patologia torna-se cada vez mais presente e cumpre a finalidade de observar onde está a causa e agir sobre ela também de forma preventiva. A classificação das deficiências, a partir do olhar científico do século XIX e XX, foi fundamental na constituição de modelos de intervenção. O aprofundamento das causas e dos tipos de deficiência fez com que as práticas de reabilitação passassem a ser cada vez mais especializadas e pautadas pelo modelo médico, com finalidades corretivas. No entanto, mesmo que o conceito de patologia tenha se tornado referência dos projetos de intervenção terapêutica e de organização de serviços, isto não foi capaz de eliminar a versão religiosa da visão da pessoa com deficiência, inclusive nos dias atuais. Ocorreram transformações também sobre o conceito de doença do século XIX para o XX, havendo o deslocamento gradativo da idéia de um corpo doente individual para um conceito de corpo social, aproximando-se cada vez mais da idéia de que as doenças são produções históricosociais. Nessa linha, o conceito de deficiência também passou a ser contemplado com um olhar científico, que amplia seu objeto: de um corpo deficiente individual 
para um corpo deficiente social, com incapacidades e desvantagens, um corpo biológico, individual, incapacitado, excluído do social. No corpo individual está expressa toda a negatividade social da deficiência, justificando-se a intervenção que busca sua “correção". O conceito de desvantagem, introduzido com a CIDID/ICIDH, colocaria o "corpo social" como objeto ampliado das práticas de intervenção em saúde e reabilitação. Com o conceito de desvantagem e a necessidade de intervir no ambiente, nas relações pessoais e sociais, esboça-se a idéia de intervenção no corpo social, que deve ser objeto de mudanças a fim de minorar as incapacidades e perdas da pessoa deficiente, embora o enfoque, a finalidade, ainda esteja no individual, uma vez que visa o desempenho ótimo de cada pessoa com deficiência na sociedade. Com o deslocamento do objeto do corpo individual para o corpo social proposto pela OMS, tem-se uma redefinição da negatividade da deficiência (ROCHA, 1999).

A psicóloga Dra. Ana Rita de Paula, estudando em sua tese o asilamento de pessoas com deficiência, considera a instituição do ponto de vista exclusivamente político (micropolítica), onde geralmente a noção de sujeito é abandonada, privilegiando-se os mecanismos de produção de lugares institucionais/sociais. O objeto do qual se apropria a instituição asilar é o cuidado com aqueles que não são ou deixaram de ser capazes de viver em sociedade. As razões atribuídas a essa impossibilidade, a essa incapacidade social, dizem respeito à situação de dependência, de incapacidade para o autocuidado dessas pessoas, associada, porém, a déficits sociais, isto é, à falta de outras instâncias para suprir essas necessidades de cuidado. Estão associadas à carência econômico-cultural das famílias e às vezes, à limitação de recursos técnicos de assistência, que colocam os serviços disponíveis como privilégio de poucos, ou como bens tão preciosos que não devem ser 
desperdiçados com indivíduos que não podem tirar o máximo de aproveitamento. É diante de um quadro de total dependência, impossibilidade de mudança ou de "progresso", que a instituição asilar vai cuidar daqueles a quem ninguém quer ou ninguém pode cuidar, nem mesmo a própria pessoa. É a instituição da incapacidade social, tanto dos indivíduos internados, quanto da sociedade, de manter uma relação que não a da exclusão e segregação. Em outros termos, a instituição asilar propaga uma representação de duas faces: a de que a pessoa com deficiência é incapaz de cuidar de si mesma e a de que a sociedade é incapaz de conviver com estas pessoas no cotidiano, garantindo sua participação e incluindo-as. Quando se está diante de um caso na área de reabilitação, e se objetiva a promoção de mudanças no sentido da maior autonomia possível, é preciso, antes de mais nada, compreender as interligações existentes entre a deficiência - enquanto incapacidades funcionais concretas - e suas representações no imaginário individual e familiar. Interpretar a demanda feita, conhecer o desenho, a matriz das relações estabelecidas, para, só então, definir-se quem é, ou que são o caso, quais os profissionais que atuarão, no quê, e em quê sentido (PAULA, 2000).

Em seu trabalho de análise do discurso em serviços de reabilitação, NALLIN (1994) argumenta que os contínuos ataques à identidade, que vão configurando um lugar de clientela, podem levar a pessoa deficiente a assumir um modelo de deficiente ideal, proposto pela instituição - o deficiente que persiste, que supera as dificuldades, que se empenha, que constrói uma nova vida, que se cuida, que se inspeciona, que trabalha, num processo de individualização da responsabilidade pela não-integração, e de alienação de si mesmo, contribuindo para que não se rompa com esta padronização e submissão, reforçadas pela Técnica e pelo Saber. Assim, é criado 
um modelo ideal de deficiente - "o reabilitando" -, que opera uma separação entre os deficientes reabilitáveis e os não-rebilitáveis, por uma dupla determinação classificatória. São estabelecidas categorias de pessoas deficientes pela patologia face da ciência - e pelo aspecto moral - face da filantropia. Legitima-se e se reforça, deste modo, um processo social de exclusão, que incide sobre um grupo já excluído pela deficiência.

Pode-se distinguir entre categorização social e identificação de grupo. Uma categoria é definida e reconhecida por outros, enquanto a identificação de grupo ocorre através do auto-reconhecimento e reconhecimento mútuo entre os membros do grupo. Categorização social pode afetar a identificação de grupo porque categorias sociais afetam o modo como as pessoas são tratadas na sociedade, por exemplo, por agências de bem-estar social. A relação entre categorização e identificação não é direta, contudo: grupos podem se rebelar contra e subverter categorias sociais que os afetam. Além disso, não se deve exagerar o impacto da categorização social na identificação de grupo. É possível para pessoas pertencer a uma categoria social sem saber da sua existência, ou do fato de ser membro desta. Definições de deficiência ou incapacidade utilizadas em inquéritos são em geral construídas a posteriori a partir de respostas a perguntas sobre saúde e limitações na vida diária. Os respondentes provavelmente não sabem que as suas respostas serão usadas para classificá-las como "deficientes ou incapacitadas". Algumas vezes as medidas de inquéritos de deficiência ou incapacidade se dizem baseadas em “autodefinição", mas isto é enganoso: elas são baseadas nas limitações na vida diária auto-referidas, não em deficiência ou incapacidade autodefinida. As circunstâncias nas quais pessoas definem a si mesmas como deficientes ou incapacitadas não foram 
muito pesquisadas. Mesmo que as pessoas estejam freqüentemente conscientes das suas categorizações na política social para concessão de benefícios (seu status como detentor de direito ao recebimento de benefícios), elas não necessariamente adotam estas categorizações como identidades. Um sinal da disjunção entre categorias e identidades é terminológico: os termos usados para categorias são freqüentemente rejeitados como termos para identidades precisamente porque seu significado é construído por outros, não pela identidade do grupo por si só (BRUNEL , 2002).

Um estudo de Watson (WATSON, 2002 abstract, apud BRUNEL, 2002) aponta diretamente a questão de auto-identificação como deficiente ou incapacitado. A maioria dos membros de sua amostra de pessoas com deficiências demonstrou considerável resistência para adotar a identidade de uma "pessoa deficiente ou incapacitada". A maioria dos seus respondentes procurou estabelecer identidades sociais que não eram dominadas pelas suas deficiências: identidades como membros de famílias e grupos de amizade, como indivíduos produtivos e cheios de habilidades, como pessoas que levam vidas "normais". Isto pode ser visto como um genuíno reflexo da importância limitada da deficiência (no nível do corpo) ou então como uma forma de "falsa consciência" motivada pelo estigma ligado à deficiência ou incapacidade. As pessoas devem ser capazes de desenvolver e escolher suas próprias identidades, não ter uma identidade imposta a elas com base em algumas características imputadas. Os informantes politicamente ativos do estudo de Watson também rejeitaram uma identidade construída na deficiência, mas eles se identificaram com outras pessoas deficientes ou incapacitadas ao descrever experiências de opressão. Isto sugere que a mobilização política de um grupo com experiências comuns não tem que se colocar sobre definir uma identidade fixa e 
comum. Mobilização política poderia ser vista como envolvendo um terceiro processo ao lado dos processos de identificação e categorização da política social.

Este processo pode ser chamado de "construção social". Construções sociais seriam estereótipos sobre grupos particulares de pessoas que têm sido criados por políticas, culturas, socialização, história, meios de comunicação, literatura, religião e outras, exercendo uma forte influência na formação da política pública. É útil notar as diferenças entre construções sociais e categorias de políticas sociais para concessão de benefícios. Construções sociais caracterizam grupos de pessoas, mas não se preocupam com a tarefa de determinar que indivíduos precisamente estão no grupo que está sendo descrito. De fato, alguma dificuldade em encontrar indivíduos que correspondam a construções sociais é inerente a sua natureza estereotípica. Elas freqüentemente se apóiam sobre casos e análise seletiva. Existem claramente conexões entre construções sociais e categorias de política social para concessão de benefícios: por exemplo, regras que definem categorias podem refletir questões sobre excluir grupos negativamente-construídos tais como "parasitas" ou incluindo pessoas “merecedoras" positivamente-construídas, mas estas conexões são freqüentemente problemáticas devido à natureza retórica das construções sociais. A burocracia que administra categorias pode ser influenciada por esta retórica, mas igualmente pode estar consciente das dissonâncias entre os grupos construídos e as circunstâncias das pessoas realmente encontradas. Muito do debate sobre a definição de deficiência ou incapacidade ocorre sobre a construção social da deficiência ou incapacidade. Este debate preocupa-se com o modo como a imagem pública de deficiência ou incapacidade é formada. Isto é muito importante para o desenvolvimento de políticas de deficiência ou incapacidade. Defensores dos direitos das pessoas com deficiência 
ou incapacidade fizeram avançar diferentes construções sociais de deficiência ou incapacidade no processo de buscar livrar-se da imagem de "merecedor", mas "dependente" da deficiência ou incapacidade no olhar público, e promoveu o desenvolvimento de novos tipos de política com diferentes arrazoamentos para medidas tradicionais de bem-estar social. Entretanto, inovações na construção social de deficiência ou incapacidade não se traduzem num caminho simples no processo de categorização nas políticas sociais (BRUNEL, 2002).

Segundo KAPLAN (2003), as questões da definição de "pessoa com uma deficiência ou incapacidade" e como as pessoas com deficiência ou incapacidade percebem a si mesmas são difíceis e complexas. Não é acidental que estas questões estejam emergindo ao mesmo tempo em que o status das pessoas com deficiência ou incapacidade na sociedade está mudando dramaticamente. Nos Estados Unidos da América, a lei conhecida como ADA ("Americans with Disabilities Act”) é a causa de algumas destas mudanças, mas também o resultado da mudança de direção na política pública. Questões de status e identidade estão no cerne da política de deficiência ou incapacidade. Para Kaplan, um dos objetivos centrais do movimento de direitos na deficiência ou incapacidade, o qual pode chamar para si a responsabilidade política primária pelo ADA, é mover a sociedade americana para um entendimento novo e mais positivo do que significa ter uma deficiência ou incapacidade.

É importante compreender as representações sociais que estão na base das definições. Diferentes instituições propagam estas representações e alimentam as construções sociais das quais derivam as definições. Não há como entender a deficiência ou incapacidade ficando apenas no nível do corpo e do funcionamento, 
sem atingir a compreensão das representações que foram apontadas neste tópico. Uma mudança no modo de trabalhar com estas definições pode produzir mudanças de cultura, que não ocorrem a curto prazo, o que bem pôde ser observado ao longo dos últimos 30 anos, com o movimento de direitos das pessoas com deficiência. 


\section{2- Questões de Tradução}

A CIF foi revisada em vários idiomas considerando o inglês apenas como o idioma operacional. Vários colaboradores da OMS lideraram o trabalho de tradução, análise lingüística e revisão editorial dos idiomas oficiais da OMS. A versão ao português da CIF foi realizada pelo Centro Colaborador da OMS para a Família de Classificações Internacionais na Faculdade de Saúde Pública da Universidade de São Paulo (OMS CIF, 2003).

No anexo sobre questões terminológicas e taxonômicas da CIF, "termos" são definidos como a designação de conceitos e se traduzem em expressões lingüísticas, tais como palavras ou frases. A maioria dos termos que geram confusão é utilizada com um significado baseado no senso comum da linguagem corriqueira, falada e escrita. Os termos "deficiência", "incapacidade" e "limitação" (ou "desvantagem") são usados freqüentemente com o mesmo sentido dos contextos quotidianos. $\mathrm{Na}$ versão de 1980 da CIDID/ICIDH, esses termos já passavam a ter um significado mais preciso. Durante o processo de revisão, o termo "desvantagem" ( ou "limitação", como tradução da palavra "handicap") foi abandonado e o termo "incapacidade" foi utilizado para abranger todas as três perspectivas - corporal, individual e social. Sendo a CIF uma classificação escrita, traduzida em várias línguas, é particularmente importante usar de clareza e precisão para definir os vários conceitos, de maneira que possam ser escolhidos os termos mais apropriados para expressar de maneira não ambígua cada um dos conceitos subjacentes. Também é essencial chegar a um acordo sobre os termos que possam melhor refletir o conteúdo em cada idioma. Com a possibilidade de várias alternativas, é preciso que as decisões 
sejam tomadas com base em princípios de precisão, aceitabilidade e utilidade geral (OMS CIF, 2003).

Dentro do esquema hierárquico de estruturação da CIF, as definições são importantes pois especificam as qualidades, propriedades ou relações (atributos essenciais) do conceito designado para cada categoria. Cada definição estabelece que tipo de coisa ou de fenômeno é designado por um termo, indicando como ele difere de outras coisas ou fenômenos relacionados (OMS CIF, 2003).

Do ponto de vista da terminologia, qualquer classificação tem sua base na distinção fundamental entre os fenômenos que estão sendo classificados e a própria estrutura da classificação. Em geral, é importante distinguir entre o mundo e os termos que utilizamos para descrevê-lo. Por exemplo, os termos 'dimensão' ou ‘domínio' podem ser definidos precisamente para se referir ao mundo e 'componente' e 'categoria' definidos para se referir apenas à classificação. Ao mesmo tempo, há uma correspondência, ou seja, uma função de compatibilidade, entre esses termos e há a possibilidade de que uma grande variedade de usuários possa utilizar esses termos de maneira intercambiável. Para exigências mais especializadas, montagem de bancos de dados e pesquisas, por exemplo, é essencial que os usuários identifiquem separadamente, e com uma terminologia claramente distinta, os elementos do modelo conceitual daqueles da estrutura da classificação. Todavia, chegou-se à conclusão de que a precisão e pureza fornecidas por este tipo de abordagem não valem o preço pago em um nível de abstração que pode solapar a utilidade da CIF ou, mais importante, restringir a faixa de potenciais usuários desta classificação (OMS CIF, 2003). 
Segundo SASSAKI (2006), “à medida que o movimento inclusivo se espalha pelo mundo, palavras e conceituações mais apropriadas ao atual patamar de valorização dos seres humanos estão sendo incorporadas ao discurso dos ativistas de direitos, por exemplo, dos campos da deficiência e da saúde mental”. Este considera, em primeiro lugar, a questão do vocábulo "deficiência", colocando que a tradução correta das palavras (respectivamente, em inglês e espanhol) "disability" e "discapacidad" para o português falado e escrito no Brasil deveria ser "deficiência", pois esta palavra permanece no universo vocabular tanto do movimento das pessoas com deficiência como dos campos da reabilitação e da educação, como uma realidade terminológica histórica. O termo "anormalidade" seria utilizado na CIF estritamente para se referir a uma variação significativa das normas estatísticas estabelecidas (isto é, como um desvio da média da população dentro de normas mensuradas) e ele deveria ser utilizado somente neste sentido.

Para este autor, o conceito de "deficiência" não pode ser confundido com o de "incapacidade", colocando que esta palavra é uma tradução, também histórica, do termo "handicap". O conceito de "incapacidade" denotaria um estado negativo de funcionamento da pessoa, resultante do ambiente humano e físico inadequado ou inacessível, e não um tipo de condição, apontando como exemplos: a incapacidade de uma pessoa cega para ler textos que não estejam em braile, a incapacidade de uma pessoa com baixa visão para ler textos impressos em letras miúdas, a incapacidade de uma pessoa em cadeira de rodas para subir degraus, a incapacidade de uma pessoa com deficiência intelectual para entender explicações conceituais, a incapacidade de uma pessoa surda para captar ruídos e falas. Assim estaria configurada a situação de “desvantagem" imposta às pessoas "com deficiência" através daqueles fatores 
ambientais que não constituem barreiras para as pessoas "sem deficiência", segundo o seu entendimento (SASSAKI, 2006).

Ainda segundo Sassaki, "infelizmente para quem luta há décadas pelo uso de terminologias corretas, a CIF foi oficialmente traduzida para o português como 'Classificação Internacional de Funcionalidade, Incapacidade e Saúde’”. Sassaki critica o fato de ser utilizada apenas a palavra "incapacidade" toda vez que, no texto original, aparece o vocábulo "disability" (que para o português corrente seria “deficiência"). Defende que, do ponto de vista formal, deva-se manter a palavra "deficiência" no singular, apresentando como exemplos: "pessoas com deficiência visual” (e não "pessoas com deficiências visuais"), ou "pessoas com deficiência intelectual" (e não "pessoas com deficiências intelectuais"). Salienta a importância de usar o singular ao nos referirmos à deficiência e/ou ao tipo de deficiência, independentemente de, no idioma inglês, ser utilizado o plural ("persons with disabilities", "persons with intellectual disabilities") ou o singular ("persons with a disability", "persons with an intellectual disability") (SASSAKI, 2006).

Apontando para o comentário sobre o "português corrente" referido no parágrafo anterior, deve-se lembrar que a maioria dos termos que se presta a confusões tem sido utilizada, no dia a dia, com o significado que o senso comum lhes atribui habitualmente (OMS CIDID, 1989). Mesmo muitos profissionais que trabalham na área de reabilitação ainda utilizam termos para se referir à deficiência e incapacidade que fazem parte de vocabulário comum, com pouca diferenciação do seu real significado.

Uma razão fundamental da falta de informação sobre a situação social e sobre outras condições das pessoas com deficiência, inclusive o próprio número de pessoas 
que apresentam deficiência ou incapacidade na população, provém do fato das diversas organizações oficiais implicadas não partilharem de uma definição comum e desprovida de ambigüidade sobre o que constitui a incapacidade, a deficiência e limitação de atividade. Por outro lado, também se verificam incoerências quanto à identificação de problemas. Dentro dos conceitos da CIDID/ICIDH, o problema de fundo provém dos conceitos relacionados com incapacidade e desvantagem não serem suficientemente apreciados, estudados e, conseqüentemente, não ter se desenvolvido uma prática sistemática da linguagem específica referente a estas questões. Embora as distinções semânticas possam ser levadas ao exagero, na verdade o que justifica a opção por determinada nomenclatura é o fato de, com ela, ser possível conseguir vantagens práticas. Tais vantagens devem tornar-se evidentes à medida que uma descrição mais esclarecedora dos processos revelar a forma de solucionar os problemas. Já no manual da CIDID/ICIDH, deu-se muita atenção aos termos descritivos utilizados, de forma a reforçar as distinções de tipo conceitual (OMS CIDID, 1989).

No dicionário Houaiss da língua portuguesa, há uma descrição da origem etimológica da palavra inglesa handicap que remonta ao ano de 1754, explicando o sentido de desvantagem, para uma "corrida ou competição em que uma vantagem é concedida ou uma desvantagem é imposta a um participante para igualar as chances de vitória dos competidores; desvantagem que torna mais difícil alcançar uma meta, deficiência física". O termo provém de handicap, que seria uma alteração de hand in cap descrito como um "tipo de jogo em que o dinheiro pago como penalidade ficava em um chapéu". A descrição como substantivo masculino oferece três significados: (1) na rubrica "esportes" há a explicação "em corridas e outras competições, 
vantagem que se concede a um ou mais competidores (pessoa ou animal) para compensar deficiências de sua parte e igualar as possibilidades de vitória para todos"; (2)como derivação em "sentido figurado" como "qualquer desvantagem que torna mais difícil o sucesso" ou (3) "deficiência física ou mental que dificulta as atividades normais de uma pessoa" (HOUAISS, 2002).

Uma descrição semelhante pode ser encontrada no Dicionário Contemporâneo da Língua Portuguesa de Caldas Aulete para a palavra inglesa "handicap" relacionando-a ao turfe, corrida em que cavalos de diferentes classes recebem pesos proporcionais a suas qualidades, a fim de igualar-lhes suas possibilidades de vitória. Por extensão, nas provas esportivas de força, destreza ou agilidade, descrito como qualquer desvantagem artificial imposta ao concorrente havido como superior; desvantagem (AULETE, 1964).

No Dicionário de Sinônimos "American Century Thesaurus", o termo handicap tem entre vários sinônimos, a palavra "disability". A palavra "disability", por sua vez tem como sinônimos as palavras "handicap", "impairment", “disablement", "inability”, "incapacity” entre outras (URDANG, 1997).

Podemos perceber que a dificuldade com o uso adequado destes termos não é só da língua portuguesa e fazer a tradução dos mesmos acaba por esbarrar no uso intercambiável de termos que se fez por muito tempo, também na língua inglesa. Mesmo reconhecendo as questões de uso das palavras no idioma português, a CIF de alguma maneira dá definições para os termos "impairment" e "disability", tendo sido abandonado o termo "handicap".

Em Portugal, ao ser iniciada a discussão do modelo biopsicossocial da CIF, foi posto em questão o tradicional modelo médico. Este modelo está baseado em 
classificações categoriais e em critérios estritamente médicos, critérios estes assentados sobre terminologias, conceitos e definições que são ancoradas em inferências causais relativas à deficiência e inerentes à pessoa, sem tomar em consideração os fatores externos ou ambientais. O termo "deficiência" (no nível do corpo) não deixa transparecer o papel relevante do meio ambiente e carrega um conceito de conotação eminentemente biológica, própria do modelo médico. Segundo esta discussão, a utilização deste termo seria, ao mesmo tempo, causa e consequiência da permanência de algumas opções de política quanto à organização de recursos, procedimentos e critérios de elegibilidade, bem como de representações sociais e profissionais mais negativas relativas às pessoas com deficiência (PORTUGAL, 2006).

Implementar a CIF como um novo sistema de classificação é complexo e requer esforços conjugados, sobretudo de diferentes setores da Administração Pública, de organizações não governamentais, de pessoas com deficiência ou incapacidade, de universidades e escolas superiores, de profissionais e especialistas de diferentes áreas disciplinares, bem como requer a colaboração internacional, especialmente da OMS e dos seus mecanismos estabelecidos para efeitos de apoio aos diferentes países que queiram implementar tal sistema. Portugal defende que, para incrementar de maneira coerente a sua aplicação progressiva, este novo modelo seja, desde já, o elemento orientador para a reformulação de políticas setoriais, de sistemas de informação e estatística, de quadros legislativos, de procedimentos e de instrumentos de avaliação e de critérios de elegibilidade. Nesta perspectiva, Portugal propõe que todos os esforços sejam empreendidos em diferentes níveis para a adoção do termo "incapacidade", como termo genérico que engloba os diferentes níveis de 
limitações funcionais relacionados com a pessoa e o seu meio ambiente, para referir o estado funcional da pessoa, expressando os aspectos negativos da interação entre um indivíduo com problemas de saúde e o seu meio físico e social, em substituição ao termo "deficiência" (que corresponde apenas às alterações ou anomalias no nível das estruturas e funções do corpo, incluindo as funções mentais) que se configura mais restritivo e menos próximo do modelo social (PORTUGAL, 2006).

No entanto, reconhecendo que "deficiência" ainda é o termo de referência predominante na língua portuguesa, no documento "Plano de Ação para a Integração das Pessoas com Deficiências ou Incapacidades", Portugal opta pela utilização simultânea dos termos "incapacidade" e "deficiência" de modo a estabelecer uma transição, indicando um caminho para a adoção da nova terminologia (PORTUGAL, 2006).

Desta forma, entendendo a questão apresentada por Sassaki, mas também buscando a melhor maneira de aproximar as traduções e os conceitos descritos na CIF, a autora opta por utilizar nesta tese a palavra "pessoa com deficiência ou incapacidade" para traduzir "person with a disability", "pessoa deficiente ou incapacitada" para traduzir "disabled person", "incapacitante" para "disabling", "desvantagem" para "handicap" e apenas "deficiência" onde houver a palavra “impairment", da maneira como Portugal aponta para uma forma de transição. 


\section{Objetivo:}

Apresentar definições de Deficiência e Incapacidade, contidas em bibliografia especializada, bem como em leis brasileiras e de alguns outros países, discutindo a possível contribuição das classificações CID-10 e CIF nesta área.

\section{Desenvolvimento do tema:}

\section{1- CID-10 e CIF}

\subsection{1 - Histórico das duas classificações}

A Décima Revisão da Classificação Internacional de Doenças (CID), denominada "Classificação Estatística Internacional de Doenças e Problemas Relacionados à Saúde", ou de forma abreviada "CID-10", é a mais recente revisão da “Classificação de Bertillon” ou "Lista Internacional de Causas de Morte” de 1893. Os antecedentes históricos dos principais fatos que levaram à classificação, organizada por Bertillon, são apresentados no Volume 2 da CID-10. Com a décima revisão, o título da classificação foi alterado para tornar mais claro o conteúdo e a sua finalidade, mas também para refletir a extensão progressiva da abrangência da classificação além de doenças e lesões, sendo mantida a familiar abreviatura "CID". $\mathrm{Na}$ atualização da classificação, as afecções foram agrupadas de forma a torná-la mais adequada aos objetivos de estudos epidemiológicos gerais e para a avaliação de assistência à saúde (OMS CID-10, 1996).

Em 1983 iniciou-se o trabalho para a Décima Revisão da CID, quando foi realizada uma Reunião Preparatória sobre a CID-10, em Genebra. O programa de trabalho foi conduzido por meio de reuniões periódicas dos Diretores de Centros 
Colaboradores da OMS para a Classificação de Doenças. Foram realizadas várias reuniões para estabelecer o plano de ação, incluindo as reuniões do Comitê de Peritos em Classificação Internacional de Doenças, realizadas em 1984 e 1987. Muitos comentários e sugestões foram provenientes dos Países Membros da OMS e dos Escritórios Regionais da OMS, além das contribuições técnicas oferecidas por vários grupos de especialistas bem como de peritos individuais. Esses comentários e sugestões resultaram na circulação, pelos países, dos rascunhos das propostas da Revisão em 1984 e 1986. Vários modelos alternativos de estrutura foram avaliados seguindo sugestões apresentadas durante a preparação da Nona Revisão da Classificação, pois foram feitas sugestões de que uma estrutura básica diferente poderia atender melhor às necessidades de muitos e variados tipos de usuários. Entretanto, ficou claro que o modelo tradicional de eixo com variável única da classificação, assim como outros aspectos de sua estrutura que davam ênfase a afecções que eram freqüentes, que representavam altos custos ou, por outro lado, eram de importância em saúde pública, resistiu ao tempo e que muitos usuários não se satisfaziam com os modelos apresentados como possíveis substitutos. Assim, foi mantida a tradicional estrutura da CID, com um esquema de código alfanumérico que substituiu o anterior que era apenas numérico. Isso levou a um sistema com muito maior número de códigos deixando espaços para que em futuras revisões não houvesse rompimento da ordenação, como ocorria nas revisões anteriores (OMS CID-10, 1996).

A Classificação foi aprovada pela Conferência Internacional para a Décima Revisão em 1989 e apresentada à Quadragésima Terceira Assembléia Mundial de Saúde. Por meio das recomendações do relatório da Conferência Internacional para a 
Décima Revisão da Classificação Internacional de Doenças, foi adotada a lista detalhada de categorias de três caracteres e subcategorias opcionais de quatro caracteres com as Listas Abreviadas de Tabulação para Mortalidade e para Morbidade, constituindo a Décima Revisão da Classificação Estatística Internacional de Doenças e de Problemas Relacionados à Saúde, para entrar em vigor em $1^{\circ}$ de janeiro de 1993. Foram incluídas as definições, normas e requisitos para informações relacionadas às mortalidades materna, fetal, perinatal, neonatal e infantil, além das regras e instruções para as codificações da causa básica de mortalidade e da causa principal em morbidade. Foi estabelecido um processo de atualização para ocorrer durante o ciclo de dez anos da revisão (OMS CID-10, 1996).

A CID era inicialmente uma classificação de causas de morte. Apenas a partir da Sexta Revisão, passou a ser uma classificação que incluiu todas as doenças e motivos de consultas, possibilitando seu uso em morbidade (LAURENTI, 1991).

A CID-10 retém pontos-chave da Classificação de Bertillon, original do século XIX, e muitas das características da sexta revisão, a CID-6, adotada em 1946. O conteúdo da CID-10 foi desenvolvido a partir de 1983-1989 e reflete o conhecimento e o pensamento daquela época (WHO FDC Bethesda, 2001).

No período de 1984 a 1987, durante o processo de revisão, muitos usuários manifestaram o desejo de que a CID incluísse outros tipos de dados além da "informação diagnóstica" que sempre havia incluído, surgindo o conceito de uma "família" de classificações. Segundo esse conceito, a CID atenderia as necessidades de informação diagnóstica para finalidades gerais, enquanto outras classificações seriam usadas em conjunto com ela, tratando com diferentes enfoques a mesma informação ou tratando de informação diferente (principalmente procedimentos 
médicos e cirúrgicos e as incapacidades). Na Quadragésima Terceira Assembléia Mundial de Saúde foram endossadas as recomendações da Conferência Internacional para a Décima Revisão relativas ao conceito e a implementação de uma família de classificações de doenças e de problemas relacionados à saúde, tendo como núcleo central a Classificação Estatística Internacional de Doenças e de Problemas Relacionados à Saúde, cercada por várias classificações relacionadas ou suplementares a ela e a Nomenclatura Internacional de Doenças. Com base nesta necessidade, a partir da Décima Revisão passa a existir uma "família" de classificações para os mais diversos usos em administração de serviços de saúde e epidemiologia (LAURENTI, 1991; OMS CID-10, 1996).

A CIF (Classificação Internacional de Funcionalidade, Incapacidade e Saúde) pertence a esta "família" de classificações, desenvolvida pela Organização Mundial da Saúde (OMS) para aplicação em vários aspectos da saúde (ÜSTUN, 2002).

A Classificação Internacional das Deficiências, Incapacidades e Desvantagens foi publicada em 1980 (conhecida pela sigla CIDID em português ou ICIDH do nome em inglês, International Classification of Impairments, Disabilities and Handicaps,), em caráter experimental, após sucessivas revisões que foram incorporando categorias correspondentes às conseqüências duradouras das doenças (CASADO, 2001; OMS CIDID, 1989).

A CIF é a segunda revisão da CIDID/ ICIDH de 1980. Como segunda revisão, a CIF foi desenvolvida após estudos de campo sistemáticos e consulta internacional que duraram pelo menos cinco anos, sendo então aprovada em maio de 2001 para uso internacional (ÜSTUN, 2002; OMS CIF, 2003). 
Organizações de pessoas com deficiência, como a Rehabilitation International (RI) e outras, tiveram participação importante em questões conceituais ao longo das revisões sucessivas da CIDID/ICIDH até a versão final da CIF (CASADO, 2001).

O processo de revisão da CIDID/ICIDH começou no início dos anos 90. Após numerosas versões resultantes deste processo de revisão, a CIF sucedeu a CIDID/ICIDH, refletindo o conhecimento e o pensamento de uma década diferente (WHO FDC Bethesda, 2001; EGEA e SARABIA, 2001). Esta década diferente compõe o pano de fundo de importantes mudanças de concepções e no modelo da classificação, com a aprovação e publicação de documentos de extrema relevância para o movimento de direitos das pessoas com deficiência no mundo. É um período que sucede importante movimentação política para democratização, com impacto diferenciado em diferentes países, podendo ser lembrado o período de abertura política no Brasil.

A OMS desenvolveu um esquema relacionado com as conseqüências da doença de natureza preliminar em 1972, sendo, em poucos meses, sugerida uma abordagem mais abrangente. As sugestões foram feitas com base em dois princípios importantes: distinguir entre as deficiências e a sua importância, ou seja, as conseqüências funcionais e sociais, e classificar independentemente, com diferentes códigos, esses vários aspectos ou eixos de informação. Explorou-se a possibilidade de constituir um esquema que fosse compatível com os princípios da estrutura da CID, com tentativas para sistematizar a terminologia aplicada às consequiências das doenças. Em 1973, essas sugestões circularam de modo informal e foi solicitada especial ajuda de grupos do setor da reabilitação. Em 1974, circularam classificações 
distintas para deficiências e para desvantagens e as discussões continuaram, sendo recolhidos comentários para a elaboração de propostas definitivas. Em outubro de 1975, estas propostas foram submetidas à consideração da Conferência Internacional para a Nona Revisão da Classificação Internacional de Doenças que recomendou a sua publicação em caráter experimental (OMS CIF, 2003).

Concomitantemente, em 1975, foi aprovada pela Assembléia Geral da ONU a Resolução que estabeleceu a primeira "Declaração dos Direitos das Pessoas Deficientes". Um ano depois, em 16 de dezembro de 1976, foi aprovada a Resolução que proclamava o ano de 1981 como o "Ano Internacional das Pessoas Deficientes", que agregou grupos de defesa dos direitos das pessoas com deficiência, projetos e recomendações para atividades em nível nacional e internacional, diversas metas a curto, médio e longo prazo, representando uma importante conquista. Este ano teve como tema "Participação plena e igualdade", trazendo o foco para o reconhecimento mundial de que as pessoas com deficiência têm os mesmos direitos de todos os outros cidadãos de se beneficiar dos serviços postos à disposição pelo Estado e pela sociedade em geral a todos os outros cidadãos, entendendo como participação plena a participação em todos os aspectos da vida comunitária, incluindo as atividades políticas, econômicas, sociais e culturais (SILVA, 1987).

Em 1976 a OMS aprovou, para teste, a CIDID/ICIDH como "manual das consequiências da doença", para ser publicada em 1980 na versão oficial em inglês. Em 1987, estabelece-se a rede de centros colaboradores da OMS para aplicação e desenvolvimento da CIDID/ICIDH e neste mesmo ano o Conselho Europeu cria um Comitê de Especialistas para a aplicação da CIDID/ICIDH. Em 1989 o Conselho Europeu cria um documento sobre a utilização da CIDID/ICIDH e em 1992 realiza- 
se uma reunião anual sobre a CIDID/ICIDH na Holanda em que são revisados alguns itens da Classificação, redigida uma nova introdução, com o acordo de levar adiante o processo de revisão, com o estabelecimento de responsabilidades aos distintos centros colaboradores (OMS CIF, 2003; EGEA e SARABIA, 2001).

Em 1992, ano em que se decide efetivamente avançar na revisão da CIDID/ICIDH, foi proclamado o Dia Internacional das Pessoas com Deficiência pela Assembléia Geral das Nações, para ocorrer todos os anos na data de 3 de dezembro, com o objetivo de promover, na população em geral, a compreensão das questões de deficiência e mobilizar o respeito pela dignidade, pelos direitos e pelo bem-estar das pessoas com deficiência.

Na reunião anual de 1993 sobre a CIDID/ICIDH realizada em Washington, programa-se o processo de revisão e são distribuídas tarefas e responsabilidades entre os centros colaboradores. A OMS publica uma reimpressão da CIDID/ICIDH em que aparece a menção "para teste" com o acréscimo um novo prólogo. Neste mesmo ano, as Nações Unidas publicam as Normas Uniformes para a Equiparação de Oportunidades para as Pessoas com Deficiência (OMS CIF, 2003; EGEA e SARABIA, 2001).

Em 1996, foi redigida a versão preliminar "alfa" da nova CIDID/ICIDH, que passa a utilizar a sigla ICIDH-2, por razões históricas, ou seja, indicando que se tratava de uma versão da classificação original, em processo de modificação. De maio de 1996 a fevereiro de 1997 a versão preliminar Alfa circulou entre os centros colaboradores e os grupos de trabalho, sendo centralizados na OMS, em Genebra, todos os comentários e as sugestões coletados. Uma lista de perguntas básicas 
englobando os principais problemas relacionados com a revisão também circulou para facilitar a coleta dos comentários (OMS CIF, 2003; EGEA e SARABIA, 2001).

Em março de 1997, foi elaborada uma versão preliminar Beta-1 que integrava as sugestões recolhidas nos anos anteriores, sendo apresentada na reunião de revisão da CIDID/ICIDH em abril de 1997. Após a incorporação na CIDID/ICIDH das decisões da reunião, foi produzida em junho de 1997 a versão preliminar ICIDH-2 Beta-1, para estudos de campo. Este segundo rascunho "beta-1" da ICIDH-2, recebeu o nome provisório de "Classificação das Deficiências, Atividades e Participação". Entre janeiro e abril de 1999, com base em todos os dados e outras informações provenientes dos estudos de campo da versão Beta-1, foi redigida a versão preliminar Beta-2. A versão resultante foi apresentada e discutida na reunião anual da ICIDH-2 em Londres em abril de 1999. O novo rascunho "beta-2" da ICIDH-2 recebeu o nome de "Classificação do Funcionamento e da Incapacidade". Após a incorporação das decisões da reunião, a versão preliminar Beta-2 foi impressa e publicada em julho de 1999 para ser utilizada em estudos de campo (OMS CIF, 2003; EGEA e SARABIA, 2001).

Os estudos de campo concentraram-se em questões transculturais e multisetoriais, desencadeando uma ampla participação dos Estados Membros da OMS, com diferentes disciplinas, incluindo setores como seguros de saúde, previdência social, trabalho, educação e outros grupos engajados na classificação das condições de saúde. O objetivo era chegar a um consenso, através de definições que fossem claras e operacionais. Os estudos de campo constituíram um processo contínuo de desenvolvimento, consulta, feedback, atualização e teste (OMS CIF, 2003). 
Em 2000, com base nos dados do estudo de campo da versão Beta-2 e com a colaboração dos centros colaboradores e do Comitê de Peritos em Medição e Classificação da OMS, foram feitos dois rascunhos "pré-finais" (em outubro e dezembro, respectivamente) da ICIDH-2, com o nome de "Classificação Internacional de Funcionamento, Incapacidade e Saúde”. Em janeiro de 2001, o Comitê Executivo da OMS decide levar para aprovação na $54^{a}$ Assembléia Mundial da Saúde, o rascunho pré-final de dezembro da ICIDH-2. Em abril, surgiu o rascunho "final" da ICIDH-2 e em 22 de maio foi aprovada a nova versão desta classificação com o nome definitivo de "Classificação Internacional de Funcionalidade, Incapacidade e Saúde" com a sigla CIF. O período de aplicação da CIDID/ICIDH vai além de 20 anos e seu período de revisão se prolongou por quase uma década. Foi um longo processo, com ampla participação internacional (todos os centros colaboradores, grupos de trabalho específicos para algumas partes, instituições internacionais representativas e redes internacionais). Mais de 50 países e de 1800 peritos estiveram envolvidos nos testes de campo, cada um produzindo o seu próprio relatório. Foram utilizadas novas tecnologias da informação e da comunicação (a OMS, em sua página da web, manteve uma parte dedicada à revisão da ICIDH). Ocorreram voltas surpreendentes neste processo de elaboração (termos que apareceram e desapareceram, inclusive o próprio nome da classificação, desdobramento ou agrupamento das diferentes escalas que compõem a Classificação e até uma mudança final nas siglas que a iriam reger desde o momento de sua aprovação pela Assembléia Mundial da Saúde de 2001) (OMS CIF, 2003; EGEA e SARABIA, 2001). 
Uma das razões para as mudanças de nome da classificação durante o processo de revisão e ao final a mudança da sigla para CIF, envolve o entendimento de que a CIDID/ICIDH apresentava apenas os aspectos negativos da deficiência ou incapacidade, buscando com os termos "funcionalidade" e "saúde" reforçar os aspectos positivos e o fato de ser uma classificação de saúde. Houve muitas modificações e, na prática, muito pouco restou da CIDID/ICIDH em termos de conceitos e da terminologia empregada (EGEA e SARABIA, 2001).

A CIF evoluiu a partir de uma classificação de "consequiências de doenças" para uma classificação de "componentes da saúde". "Componentes da saúde" definem o que constitui a saúde, enquanto "conseqüências" focalizam o impacto das doenças ou outras condições que se seguem como um resultado. Neste caminho, a CIF toma um lugar neutro com respeito à etiologia e permite aos pesquisadores chegar a inferências causais com métodos científicos (ÜSTUN, 2002).

A CIF faz um deslocamento paradigmático do eixo da doença para o eixo da saúde, permitindo uma visão diferente da saúde, permitindo entender a condição ou estado de saúde dentro de contextos específicos. Como classificação de saúde, a CIF introduz um novo modo de compreender a situação de saúde de indivíduos ou populações, mais dinâmico e mais complexo, compatível com a complexidade que envolve compreender a experiência completa de saúde.

A versão final da Classificação Internacional de Funcionalidade, Incapacidade e Saúde, foi disponibilizada nos seis idiomas oficiais na página da família de classificações e publicada na língua portuguesa para todos os países lusófonos em novembro de 2003 (OMS CIF, 2003; EGEA e SARABIA, 2001; ICF WHO homepage). 


\subsection{2 - CID-10}

Pode-se definir uma classificação de doenças como um sistema de categorias que são atribuídas a entidades mórbidas segundo algum critério estabelecido, com vários eixos de classificação possíveis. Um determinado eixo pode vir a ser selecionado, dependendo do uso das estatísticas elaboradas. Todas as entidades mórbidas devem ser incluídas dentro de um número manuseável de categorias em uma classificação estatística de doenças (OMS CID-10, 1996).

Ao ser aprovada, a CID-10 passou de dois para três volumes. No volume 1 está a Lista Tabular, que é a Classificação propriamente dita nos níveis de três e quatro caracteres, além da classificação de morfologia das neoplasias, listas especiais de tabulação para mortalidade e para morbidade, as definições e os regulamentos da nomenclatura. No volume 2, que é um Manual de Instruções, são apresentadas notas sobre a certificação médica e sobre a classificação, que estavam antes incluídas no volume 1, agora com maior quantidade de informações e de material de instrução e orientações sobre o uso do volume 1, sobre as tabulações e sobre o planejamento para o uso da CID, o que se julgou que faltava nas revisões anteriores. Inclui também a parte histórica que antes estava na introdução do volume 1 . No volume 3 , que é o Índice Alfabético, consta o índice propriamente dito com uma introdução e maior quantidade de instruções sobre o seu uso (OMS CID-10, 1996).

Como publicação oficial da OMS, a CID-10 foi adotada por todos os países membros para finalidade de apresentações estatísticas das causas de morte (mortalidade) ou das doenças que levam a internações hospitalares ou atendimentos ambulatoriais (morbidade). Até a nona Revisão (CID-9), as revisões da CID eram 
decenais e não havia atualizações entre as revisões. No relatório da Conferência Internacional para a Décima Revisão, em 1989, que aprovou a CID-10, foi lançada a recomendação de que "a OMS endosse o conceito de um processo de atualização no período entre duas revisões e considere os mecanismos para que esta atualização seja colocada em prática" (OMS CID-10,1996).

Hoje é a classificação diagnóstica padrão internacional para propósitos epidemiológicos gerais e administrativos da saúde, incluindo análise de situação geral de saúde de grupos populacionais e o monitoramento da incidência e prevalência de doenças e outros problemas de saúde. Embora a CID seja adequada para estas aplicações, ela nem sempre permite a inclusão de detalhes suficientes para algumas especialidades, e às vezes pode ser necessária a informação acerca de diferentes atributos das afecções classificadas (OMS CID-10, 1996). 


\subsection{3 - CIF}

A CIF organiza a informação em três componentes: (1) O construto do "Corpo", que compreende duas classificações, uma para funções do corpo e uma para estruturas do corpo, cujos capítulos são organizados de acordo com os sistemas do corpo; (2) Os construtos de "Atividade" e "Participação", que cobrem a extensão completa de domínios que denotam aspectos da funcionalidade a partir da perspectiva individual e social; (3) Uma lista de "fatores ambientais". Os fatores ambientais têm um impacto sobre todos os três construtos e são organizados a partir do ambiente mais imediato do indivíduo para o ambiente geral. Os domínios do componente de Atividades e Participação estão incluídos numa lista única que engloba a totalidade das áreas vitais (desde a aprendizagem básica ou a mera observação até áreas mais complexas, tais como, interações interpessoais ou de trabalho). Os domínios deste componente são qualificados pelos dois qualificadores de desempenho e capacidade. O qualificador de desempenho descreve o que um indivíduo faz no seu ambiente real. Devido ao fato de que o ambiente real traz um contexto social, o desempenho pode também ser entendido como "envolvimento em uma situação de vida" ou "a experiência vivida" das pessoas no contexto real nas quais vivem. Este contexto inclui os fatores ambientais - todos os aspectos do mundo físico, social e de atitudes que podem ser codificados usando os Fatores Ambientais. O qualificador de capacidade descreve a capacidade de um individuo para executar uma tarefa ou ação descrita na classificação em um ambiente uniforme. Este construto oferece um entendimento do mais elevado nível provável que uma pessoa pode alcançar em um dado domínio em um dado momento. Um "ambiente uniforme" como um termo específico, cobre os fatores ambientais relevantes para o domínio 
especificado e não deve ter barreiras ou obstáculos, de modo que permita a alguém avaliar a total capacidade do indivíduo. Assume-se que ambiente uniforme seja o mesmo para todas as pessoas em todos os países para permitir comparações internacionais (ÜSTUN, 2002; OMS CIF, 2003).

A CIF cobre todos os componentes possíveis da saúde e alguns componentes de bem-estar relacionados à saúde (tais como educação, trabalho, etc) para descrição e avaliação. Como uma classificação, a CIF sistematicamente agrupa diferentes domínios. Os domínios da CIF são descritos por duas listas básicas: (1) funções e estruturas corporais; (2) atividades e participação (ÜSTUN, 2002).

A CIF descreve estes aspectos da saúde humana e os relacionados à saúde como “domínios da saúde" e "domínios relacionados à saúde”. Os estados de saúde associados com todas doenças, distúrbios, lesões e outras condições de saúde podem ser descritos usando a CIF. A unidade de classificação é, portanto, o "domínio" da saúde e dos estados relacionados à saúde (ÜSTUN, 2002).

A CIF é uma classificação com múltiplos propósitos, idealizada para servir a várias disciplinas e diferentes setores. Seu objetivo específico é prover uma base científica para a compreensão e o estudo de condições de saúde e estados relacionados à saúde e os seus determinantes, além de estabelecer uma linguagem comum para descrever os estados de saúde que permitirão a comparação de dados entre países, disciplinas de cuidados de saúde, entre serviços e ao longo do tempo. Mesmo a CIDID/ICIDH foi utilizada para vários propósitos, tais como estatísticas de saúde, pesquisa, trabalho clínico e política social. A CIF é uma classificação de saúde e de domínios relacionados à saúde e estes são agrupados de acordo com suas características comuns (tais como origem, tipo ou similaridade) e ordenados de um 
modo significativo. A CIF dá definições operacionais dos domínios da saúde ao contrário das definições de saúde "vernaculares" (ou seja, definições próprias dos idiomas dos países a que pertencem). Estas definições operacionais descrevem os atributos essenciais de cada domínio (por exemplo, qualidades, propriedades e relacionamentos) e contêm informação sobre o que está incluído e excluído em cada domínio, com pontos de ancoramento para avaliação, de modo que as definições possam ser traduzidas em questionários, ou de modo inverso, resultados de instrumentos de avaliação possam ser codificados em termos da CIF. Por exemplo, "visão" é definida como uma pessoa poder ver claramente objetos a distâncias variadas, o campo visual e a qualidade da visão, enquanto a gravidade da dificuldade de visão pode ser codificada como de nível leve, moderado, grave ou total (ÜSTUN, 2002; OMS CIF, 2003).

Os códigos da CIF somente são completos pela presença de pelo menos um qualificador, que denota a magnitude do nível de saúde (por exemplo, gravidade do problema) seja em termos do construto "Desempenho" ou do construto “Capacidade”. Os Qualificadores são codificados como um ou dois números após um ponto decimal. O uso de qualquer código deve ser acompanhado por pelo menos um qualificador. Sem os qualificadores, os códigos não têm significado quando usados para indivíduos ou casos (ÜSTUN, 2002; OMS CIF, 2003)

Dificuldades ou problemas nestes domínios podem surgir quando existe uma alteração qualitativa ou quantitativa no modo como as funções nestes domínios são realizadas. Limitações ou restrições são avaliadas contra um padrão geralmente aceito para a população. O padrão em relação ao qual a capacidade e o desempenho de um indivíduo é comparado é aquele de um indivíduo sem uma condição similar de 
saúde (doença, distúrbio ou lesão, etc.). Limitação ou restrição registram a discordância entre o desempenho observado e o esperado. O desempenho esperado é a norma da população, que representa a experiência de pessoas sem a condição específica de saúde. Esta é a mesma norma no qualificador de capacidade, de modo que alguém pode fazer inferências sobre o que pode ser feito ao ambiente da pessoa para melhorar seu desempenho (ÜSTUN, 2002; OMS CIF, 2003).

Os fatores contextuais representam o histórico completo da vida e do estilo de vida de um indivíduo. Incluem fatores ambientais e fatores pessoais que podem ter um impacto sobre o indivíduo com uma condição de saúde e sobre a saúde ou os estados relacionados à saúde do indivíduo. Os fatores ambientais representam o ambiente físico, social e de atitudes nos quais as pessoas vivem e conduzem suas vidas. Estes fatores são externos aos indivíduos e podem ter influência positiva ou negativa sobre a participação de um indivíduo como um membro da sociedade, no seu desempenho de atividades ou sobre a sua função ou estrutura corporal. Os fatores pessoais são o conjunto de características individuais da vida de um indivíduo e da sua existência, compostos por características que não são parte de uma condição de saúde ou estado de saúde. Estas podem incluir idade, raça, gênero, nível educacional, experiências, estilo de caráter e personalidade, aptidões, outras condições de saúde, preparo físico, estilo de vida, hábitos, tipo de criação, estilos de enfrentamento, substrato social, profissão e experiência passada e atual. Os fatores pessoais não são classificados na CIF (ÜSTUN, 2002; OMS CIF, 2003).

$\mathrm{Na}$ CIF, são dados a uma pessoa conjuntos de códigos que compreendem as três partes da classificação. Geralmente a versão mais detalhada de 3 ou 4 níveis é usada por serviços especializados (por exemplo, resultados em reabilitação, geriatria, 
etc) enquanto a classificação de 2 níveis pode ser usada para levantamentos e avaliação de resultados clínicos. No modelo das "Medidas Resumo de Saúde de Populações" - Summary Measures of Population Health (SMPH), a CIF fornece um modelo útil para capturar as múltiplas dimensões de resultados ou desfechos de saúde não fatais (nonfatal health outcomes) (ÜSTUN, 2002).

Descrições de estados de saúde incluem a informação sobre a doença e as habilidades funcionais afetadas em vários domínios. A CIF dá um perfil de tais habilidades funcionais, que são definidas de uma forma padronizada para observação e mensuração (por exemplo, várias funções corporais, mobilidade, autocuidados, cognição, relações interpessoais, etc.). Estas descrições podem ser usadas como um elemento valioso para avaliações do estado de saúde por medidas resumidas de saúde. Como avaliação, é expressa como um único valor numérico e é obtida através de um processo onde a descrição de estados de saúde é dada para elicitar os valores dados em termos de importância, tempo, pessoa, dinheiro, probabilidade ou risco. As descrições a partir da CIF oferecem uma ferramenta útil para chegar a exercícios de avaliação conceitualmente compreensíveis e culturalmente significantes. As descrições da CIF oferecem um modelo comum com definições padrão e pontos de ancoramento, que são factíveis e científicos. Usando o modelo da CIF, pode-se também estudar a mudança após um evento-chave tal como adaptação, enfrentamento, ajustamento e acomodação, uma vez que a CIF permite a codificação e medidas de capacidade, fatores ambientais e fatores pessoais (OMS CIF, 2003; ÜSTUN, 2002). 


\subsection{4 - Definições de deficiência ou incapacidade da CIF}

O desenvolvimento de uma terminologia formal relacionada a funcionalidade e incapacidade apresenta desafios únicos devido à ambigüidade conceitual dentro deste campo. A CIF é uma fonte rica de termos relevantes, conceitos e relações requeridas para terminologias formais, oferecendo um importante ponto de partida para o desenvolvimento destas (HARRIS e col., 2003).

Durante décadas foram disponibilizadas ferramentas úteis para coletar dados sobre causas de morte e modos de estimar a mortalidade da população. Embora as disciplinas da reabilitação tenham produzido incontáveis instrumentos de avaliação e medidas de qualidade de vida, ficou faltando uma classificação completa que pudesse assegurar coleta de dados confiáveis e comparabilidade internacional. Esta foi a primeira motivação para levar ao desenvolvimento da CIF. A CIF agora serve como modelo da OMS para saúde e incapacidade, como uma base conceitual para a definição, medidas e formulações de política para todos os aspectos da deficiência ou incapacidade (MC DOWELL e NEWELL, 1996; BICKENBACH, 2003).

Ao construir as definições das categorias da CIF, foram consideradas características ideais das definições operacionais. São consideradas características ideais das definições terem um significado e serem consistentes do ponto de vista lógico, identificando unicamente o conceito pretendido pela categoria. Ainda segundo características ideais, as definições devem apresentar os atributos essenciais do conceito - tanto na intenção (o que o conceito significa intrinsecamente) como na extensão (a que objetos ou fenômenos ela se refere), além de serem precisas, sem ambigüidades, englobando o significado do termo na sua totalidade. Sua expressão deve utilizar termos operacionais que envolvam gravidade, duração, importância 
relativa e possíveis associações. É importante que seja evitada a circularidade, isto é, o próprio termo, ou qualquer sinônimo, não deve aparecer na definição que também não deve incluir um termo definido noutro local em que se utiliza o primeiro termo na sua definição. Possíveis fatores etiológicos ou interativos devem ser referidos, sempre que for apropriado. Obedecendo a regras de taxonomia, as definições de uma determinada categoria devem-se ajustar aos termos das categorias superiores (um termo do terceiro nível deve incluir as características gerais da categoria de segundo nível à qual pertence) e devem ser consistentes com os atributos dos termos subordinados (os atributos do segundo nível não devem contradizer os termos do terceiro nível subjacente). Além disso, devem ser concretas e operacionais, evitando sentido figurado ou metáforas. É adequado que suas formulações empíricas sejam observáveis, testáveis ou dedutíveis por meios indiretos. Sua formulação deve ser, sempre que possível, em termos neutros sem conotações negativas desnecessárias. Elas devem ser concisas, evitando-se, dentro do possível, os termos técnicos (com exceção de alguns termos das Funções e Estruturas do Corpo). Cada definição deve conter notas de inclusão que forneçam sinônimos e exemplos que levem em consideração a variação e as diferenças culturais ao longo da vida, bem como notas de exclusão que alertem os usuários para possíveis confusões com termos relacionados (OMS CIF, 2003).

A seguir são alistadas as definições dos componentes da CIF.

- Funções Corporais: são as funções fisiológicas ou psicológicas dos sistemas do corpo.

- Estruturas Corporais: são as partes anatômicas do corpo tais como órgãos, membros e outros componentes. 
- Deficiências: são problemas na função ou estrutura corporal, tais como um desvio ou perda significativos.

-Funcionalidade: refere-se a todas as funções do corpo e desempenho de tarefas ou ações como um termo genérico.

- Incapacidade: serve como um termo genérico para deficiências, limitações de atividades e restrições à participação, com os qualificadores de capacidade ou desempenho.

A CIF também alista fatores ambientais que interagem com todos estes construtos (ÜSTUN, 2002).

Funções Corporais e estruturas corporais referem-se ao organismo humano como um todo, incluindo o cérebro e suas funções, isto é, a mente. Portanto, funções mentais (ou psicológicas) são agrupadas sob as funções corporais. Funções e estruturas corporais são classificadas juntamente com sistemas corporais. As deficiências de estrutura podem envolver uma anomalia, defeito, perda ou outro desvio significativo em estruturas corporais. As deficiências representam um desvio de certos padrões geralmente aceitos para a população no estado biomédico do corpo e de suas funções. As deficiências podem ser temporárias ou permanentes; progressivas, regressivas ou estáticas; intermitentes ou contínuas. O desvio da norma pode ser leve ou grave e pode flutuar ao longo do tempo. Estas características são capturadas em descrições ulteriores, principalmente nos códigos, por meio dos qualificadores (ÜSTUN, 2002; OMS CIF, 2003)

$\mathrm{Na}$ CIF, o termo deficiência corresponde, como descrito acima, a alterações nas funções ou estruturas corporais, ou seja, apenas no nível do corpo, enquanto o termo incapacidade seria bem mais abrangente, constituindo um termo genérico para 
deficiências, limitações de atividades e restrições à participação, indicando os aspectos negativos da interação entre um indivíduo (com uma determinada condição de saúde) e seus fatores contextuais (fatores ambientais ou pessoais) (OMS CIF, 2003).

O modelo dinâmico da CIF é mostrado abaixo, na figura 1, incluindo os fatores contextuais.

Figura 1: Interações entre os componentes da CIF

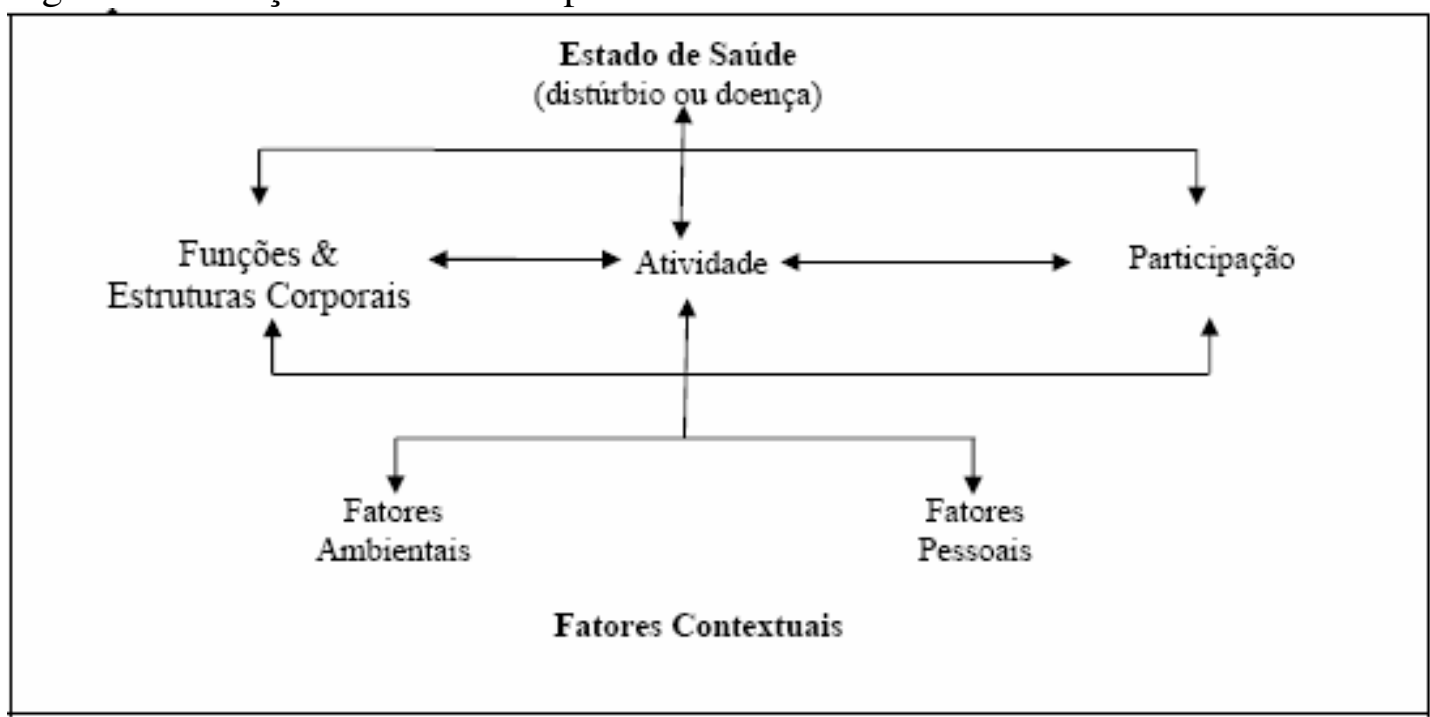

Extraído de: OMS CIF, 2003.

Uma importante característica da abordagem que foi adotada na CIF é a "universalização" do entendimento de deficiência ou incapacidade. Esta abordagem reconhece que a população inteira é "de risco" para as circunstâncias concomitantes de doença crônica e incapacidade ou deficiência. O esquema da CIF não fornece limites para definir quem é deficiente e quem não é. Entretanto, reconhece aspectos e graus de deficiência ou incapacidade passíveis de ocorrer em toda a população. Muitos usos estatísticos de dados de deficiência ou incapacidade não requerem o estabelecimento de limites. Por exemplo, estatísticas que resumem a saúde da população podem incorporar elementos relacionados a deficiência ou incapacidade 
num continuum de estado de saúde. Neste tipo de abordagem, não existe a necessidade de uma definição de quem se conta como deficiente e quem não, de onde se depreende que a comparação internacional de estatísticas de deficiência não necessariamente requer pontos de limite para serem resolvidos (BRUNEL, 2002).

Seus construtos de experiência relacionada à saúde substituem termos anteriormente usados - "deficiência", "incapacidade" e "desvantagem" e estendem seus significados para incluir experiências positivas. Os novos termos são definidos e detalhados dentro da classificação. É importante notar que estes termos são usados com significados específicos que podem diferir do seu uso corriqueiro (ÜSTUN, 2002).

Definindo as rubricas de domínios da saúde e domínios relacionados à saúde (não "da saúde"), a CIF pode ser útil para desenhar a linha entre a saúde e a "nãosaúde" para a descrição de desfechos de saúde não fatais. Funcionaria assim como uma "Pedra de Rosetta" (como uma matriz de tradução) para vários instrumentos de descrição de estados de saúde porque quase todos estes instrumentos poderiam ser mapeados dentro da CIF como um modelo comum (ÜSTUN, 2002). 


\subsection{5- Natureza complementar e sobreposições das duas classificações}

A OMS agora tem duas classificações de referência para a descrição dos estados de saúde, a CID-10 e a CIF (WHO FDC Bethesda, 2001).

Na família de classificações internacionais da OMS, as condições ou estados de saúde propriamente ditos (doenças, distúrbios, lesões, etc.) são classificados principalmente na CID-10, que fornece um modelo basicamente etiológico, embora tenha uma estrutura com diferentes eixos ou grandes linhas de construção, entre estes o etiológico, o anátomo-funcional, anátomo-patológico, clínico e epidemiológico. A funcionalidade e incapacidade associadas aos estados de saúde são classificadas na CIF (OMS CIF, 2003; ÜSTUN, 2002).

A CID-10 e a CIF são consideradas classificações complementares, sendo os usuários estimulados a utilizá-las em conjunto. A CID-10 fornece um "diagnóstico" de doenças, distúrbios ou outras condições de saúde e essas informações são complementadas pelas informações adicionais fornecidas pela CIF sobre funcionalidade. Em conjunto, as informações sobre o diagnóstico e sobre a funcionalidade, fornecem uma imagem mais ampla e mais significativa para descrever a saúde das pessoas ou de populações, que pode ser utilizada, entre outros, para propósitos de tomada de decisão (OMS CIF, 2003; ÜSTUN, 2002).

Enquanto a CID-10 fornece os códigos para mortalidade e morbidade, a CIF fornece os códigos para descrever a variação completa de estados funcionais que capturam a experiência completa de saúde (ÜSTUN e col, 2003).

É importante reconhecer a sobreposição entre a CID-10 e a CIF. As duas classificações começam com os sistemas do corpo. Deficiências, parte essencial da CIF, referem-se às estruturas e funções do corpo que são, em geral, parte do 
"processo de doença" e, portanto também utilizadas na CID-10. Não obstante, a CID10 utiliza as deficiências (como sinais e sintomas) como partes de uma constelação que forma uma "doença" ou, algumas vezes, como as razões para o contato com serviços de saúde, enquanto que o sistema da CIF utiliza as deficiências como problemas das funções e estruturas do corpo associados aos estados de saúde (OMS CIF, 2003).

Podem ser identificadas coincidências de partes, termos ou categorias na CID-10 e sobreposição com a CIF, e estas parecem estar principalmente em componentes da CIF de Estrutura Corporal e Função Corporal com o capítulo de sinais e sintomas da CID-10, com exemplos no quadro 1, apresentado abaixo.

Quadro 1. Sobreposições CID-10 e CIF.

\begin{tabular}{|c|c|c|c|}
\hline CID-10 & Código & CIF & Código \\
\hline Dor & $\begin{array}{l}\text { R52.9 e } \\
\text { vários } \\
\text { códigos }\end{array}$ & Dor & b280-b289 \\
\hline $\begin{array}{l}\text { Sintomas e sinais envolvendo } \\
\text { estados emocionais }\end{array}$ & R45 & Funções emocionais & b152 \\
\hline Distúrbios da Fala & R47 & Funções da voz e da fala & b310-b399 \\
\hline $\begin{array}{l}\text { Doenças do olho e anexos - } \\
\text { cegueira e visão subnormal }\end{array}$ & H54 & $\begin{array}{l}\text { Visão e funções } \\
\text { relacionadas }\end{array}$ & b210-b229 \\
\hline $\begin{array}{l}\text { Doenças do Ouvido e Processo } \\
\text { mastóide - Surdez / Perda } \\
\text { auditiva }\end{array}$ & H91 & $\begin{array}{l}\text { Audição e funções } \\
\text { vestibulares }\end{array}$ & b230-b249 \\
\hline Incontinência Urinária & R32 & Continência Urinária & b6202 \\
\hline Dorsopatias & M40-M54 & $\begin{array}{l}\text { Estrutura da Coluna } \\
\text { Vertebral }\end{array}$ & s7600 \\
\hline Anormalidades da Respiração & R06 & Funções da Respiração & b440 \\
\hline $\begin{array}{l}\text { Sintomas e sinais envolvendo } \\
\text { cognição, percepção, estado } \\
\text { emocional e comportamento - } \\
\text { sonolência, estupor e coma }\end{array}$ & R40 & $\begin{array}{l}\text { Alteração de funções } \\
\text { mentais - Estado de } \\
\text { consciência - Funções } \\
\text { mentais que quando } \\
\text { alteradas produzem } \\
\text { estados como obnubilação } \\
\text { da consciência, estupor ou } \\
\text { coma }\end{array}$ & b100 \\
\hline
\end{tabular}

Fonte: WHO Family Development Committee, Bethesda, 2001

Algumas outras categorias dos componentes "Funções e Estruturas do Corpo" e categorias da CID-10 parecem se sobrepor, principalmente no que se refere aos 
sintomas e sinais. No entanto, os propósitos das duas classificações são diferentes. A CID-10 classifica sintomas em capítulos especiais para documentar morbidade ou utilização de serviços, enquanto que a CIF os mostra como parte das funções do corpo, que podem ser utilizados para prevenção ou identificação das necessidades dos pacientes (OMS CIF, 2003). 


\section{2- Definições de deficiência ou incapacidade}

Segundo Frank Mulcahy, secretário da "Disabled Peoples' International" (DPI), por muitos anos, esta organização e muitas outras organizações nãogovernamentais $(\mathrm{ONG})$ internacionais não adotaram uma definição de deficiência ou incapacidade, devido a várias razões. Muitas circunstâncias levaram a esta opção, entre estas o fato de existirem muitas definições diferentes usadas na legislação em diferentes países, além de que a maioria das definições em uso eram definições médica. Havia problemas com traduções de diferentes definições, bem como a aceitação em alguns países de termos rejeitados em outros. O modelo experimental vigente da CIDID/ICIDH também foi apontado como uma razão para não adotar uma definição de deficiência ou incapacidade (MULCAHY, 2003).

A apresentação da CIDID/ICIDH como um dos motivos para não adotar uma definição de deficiência ou incapacidade, defendida por Mulcahy, possivelmente se deve ao modelo médico no qual se baseava, com a falta de mudança ao longo do tempo e o fluxo unidirecional da deficiência para incapacidade e para desvantagem, $o$ que foi alvo de muitas críticas, segundo descrição do processo de revisão na própria CIF (OMS CIF, 2003), com a sugestão de representações gráficas alternativas, que acabaram por resultar no modelo dinâmico multidirecional e interativo da CIF, apresentado anteriormente nesta tese na figura 1.

Todas as razões apresentadas acima e muitas outras, fizeram com que as ONG internacionais, incluindo a DPI, deixassem a decisão sobre o modo como abordariam a definição usada a cargo das Organizações Membro Nacionais (MULCAHY, 2003). 
Pode-se ter qualquer número de definições sendo usadas para diferentes legislações, e isto cabe particularmente para definições de deficiência ou incapacidade usadas para Pagamentos de Benefícios em comparação com as definições Educacionais, de Treinamento e Emprego. A OMS iniciou a revisão da CIDID/ICIDH nos anos 90 e a DPI foi representada neste processo. O documento final, a CIF, adota uma abordagem que fortalece o modelo social de deficiência ou incapacidade em comparação com o modelo médico previamente usado. A própria DPI se viu requisitada em numerosas ocasiões sobre qual definição de deficiência ou incapacidade gostaria de ver utilizada. Estas questões vieram de organizações membro bem como de outras organizações que apóiam Direitos Humanos com base na abordagem da deficiência ou incapacidade. Até a publicação da CIF, a DPI não tinha uma definição que pudesse ser passada para estas pessoas. Contudo, dentro da CIF, a definição de deficiência ou incapacidade que é usada poderia ser utilizada para os propósitos da DPI. A CIF define incapacidade como "o resultado da interação entre uma pessoa com uma deficiência e as barreiras ambientais e de atitudes que possa enfrentar". Assim, Mulcahy propõe que poderia ser utilizada para o momento como definição preferida esperando que se possa ter uma definição melhorada quando o Conselho Mundial da DPI permitir um debate sobre esta questão (MULCAHY, 2003).

Esta opção pela definição da CIF, com os argumentos apresentados, possivelmente se deve ao importante apoio e participação das ONG de pessoas com deficiência na mudança do modelo da CIDID/ICIDH para o da CIF, mais adequado para o entendimento das situações de incapacidade vividas em diferentes contextos. 
Definições menos baseadas no modelo médico e que reconheçam a significância de contextos sociais e outros contextos na deficiência ou incapacidade vêm sendo defendidas durante anos por apoiadores do modelo social para a deficiência ou incapacidade (JOSLYN, 1999).

Segundo STEPPER e col.(1997), várias definições têm sido usadas para medir o estado de deficiência ou incapacidade, contudo a relação precisa entre a medida ou especificação da deficiência ou incapacidade e as estimativas de custos com cuidados de saúde não têm sido exploradas. A falta de consistência na definição interfere na significância das estimativas na questão de custos em cuidados de saúde para pessoas com deficiência ou incapacidade. Diferentes definições de deficiência ou incapacidade têm sido usadas para caracterizar a população em idade produtiva com deficiências, resultando em padrões de utilização e gastos que normalmente são ininteligíveis.

Para CHATERJI e col.(1999), definições de "deficiência ou incapacidade" não deveriam ser determinadas pelo modo como os dados serão usados. Elas deveriam ser determinadas por um modelo conceitual claro e coerente que se preste a testagem empírica. Definições poderiam ser baseadas em pontos de ancoramento e limites, não meramente aqueles que se referem a dificuldades e assistência, mas àqueles que capturam o impacto na vida do indivíduo e incorporam medidas de preferência individual e social. Referindo-se ao processo de revisão que veio a resultar na CIF, o processo de medida ao avaliar a incapacitação é multidimensional: envolve funções e estruturas corporais bem como as atividades de uma pessoa e o contexto ambiental ou social daquele cujo funcionamento está sendo avaliado. Não existe consenso sobre que construtos deveriam ser empregados no desenvolvimento 
de medidas de incapacidade. A maioria dos instrumentos de avaliação de deficiência ou incapacidade mede uma amálgama de experiências tais como sintomatologia, apoio social, carga sobre a família, satisfação, bem-estar subjetivo e qualidade de vida. O modelo da CIF deverá servir como base para futuras definições de referência para o fenômeno da incapacitação e deve prover o padrão para medidas para melhor informar a política pública, alocação de recursos, gerenciamento de cuidados de saúde e muitos outros aspectos da necessária resposta social à incapacitação.

Para GARRAD e BENNETT (1971), o conceito popular de uma pessoa "deficiente" é de alguém que tem a perda de um membro ou que é fisicamente deformado de alguma maneira evidente e é um conceito é amplamente baseado na apreciação de dano estrutural. A gravidade é considerada dependente da extensão do dano e os critérios baseados nesta abordagem governam a avaliação e a concessão de pensões por incapacidade disponíveis no presente. Segundo uma outra abordagem, a deficiência ou incapacidade pode ser pensada em termos de comportamento e desempenho de um indivíduo, quando comparado com uma pessoa sã ou capaz e este conceito considera a deficiência como um distúrbio na função mais que uma perda ou anormalidade estrutural.

Nos Estados Unidos, relatos do Comitê de Recenseamento Médico de Deficiência Física de 1958 já distinguiam estas duas abordagens. O conceito de perda funcional total é considerado incapacidade enquanto a anormalidade anatômica ou estrutural é descrita como deficiência. GARRAD e BENETT (1971) adotam esta distinção, mas definem estes dois termos mais estritamente, incapacidade como limitação de desempenho em uma ou mais atividades que são geralmente aceitas como componentes básicos essenciais da vida diária, tais como incapacidade para 
realizá-las, necessitando da dependência de outra pessoa. A gravidade da incapacidade seria assim proporcional ao grau de dependência, para as áreas de atividade essencial consideradas: (1) mobilidade: caminhar, utilizando escadas, transferir-se para cima e para fora da cama ou cadeira, e viajar; (2) autocuidados: alimentação, vestuário e cuidados de toalete; (3) tarefas domésticas: fazer compras, preparar e cozinhar a comida, limpar a casa e lavar as roupas; e/ou (4) ocupação: capacidade de manter o mesmo emprego em indústria aberta consistente com a idade, sexo e habilitação individual. Deficiência seria definida como um distúrbio anatômico, patológico ou psicológico que pode ser descrito em termos diagnósticos ou sintomáticos. Isto poderia causar ou estar associado com incapacidade de modo que enquanto toda pessoa incapacitada tem uma deficiência, nem toda a pessoa com deficiência é necessariamente incapacitada. A deficiência poderia ser classificada em 4 categorias: aquelas afetando a locomoção ou qualquer atividade motora; aquelas de origem sensorial; aquelas relacionadas aos órgãos internos, ou seja, distúrbios cardíacos e respiratórios; e aquelas de origem primariamente psicológica juntamente com transtornos orgânicos inclassificáveis (GARRAD e BENNETT, 1971).

$\mathrm{Na}$ ausência de um esquema conceitual bem aceito, a literatura científica sobre deficiência ou incapacidade contém um vocabulário confuso. Termos foram inventados e operacionalizados numa miríade de maneiras. Termos comuns tais como incapacidade, deficiências e limitações funcionais têm significados variados e sobrepostos (VERBRUGGE e JETTE, 1994).

Muitas medidas de incapacidade funcional prestam pouco mais que um apoio superficial à idéia de uma abordagem conceitual para o tópico de diferenciação entre termos na área de deficiência ou incapacidade (MCDOWELL e NEWELL, 1996). 
A dificuldade em delimitar o universo da deficiência no Brasil pode ser observada em levantamentos de pessoas com deficiências por diferentes estruturas (IBGE, Censo 2000; Relatório sobre Prevalência de deficiências, incapacidades e desvantagens- estudos realizados em 21 cidades brasileiras com a Metodologia de Entrevistas Domiciliares da OPS, CORDE/AFR 2004; Perfil das Pessoas com Deficiências no Rio de Janeiro, 2002). Em São Paulo, algumas equipes de reabilitação em Programas de Saúde da Família (ROCHA, 2006) utilizaram conceitos da CIDID/ICIDH em levantamento da população de pessoas com deficiências em suas áreas. Isto em parte poderia ser explicado pelo fato de que os levantamentos para estudos de morbidade têm uma história mais longa, enquanto os estudos de deficiência ou incapacidade usando tais levantamentos seriam um fenômeno bem mais recente (MCDOUGALL e MILLER, 2003).

Quando a definição de deficiência precisa ser aplicada para a infância, a questão adquire uma complexidade própria. A experiência de uma condição de saúde crônica e incapacidade para crianças e jovens não é a mesma dos adultos. Devido à variável natureza do desenvolvimento, é particularmente difícil medir incapacidade em crianças muito pequenas. Uma consideração importante é que o status de incapacidade tem sido tradicionalmente igualado com o status de morbidade, e esta ambigüidade de definições faz com que os dois conceitos, de condição de saúde crônica e deficiência ou incapacidade, sejam freqüentemente medidos e identificados de modo incorreto. Levantamentos que incluam instrumentos baseados na CID-10 e na CIF que distintamente medem condições de saúde crônicas, os domínios de incapacidade e fatores ambientais que têm impacto sobre a incapacidade, poderiam facilitar um entendimento da incapacidade e saúde nas crianças, no contexto do 
modelo de saúde internacional corrente oferecido pela OMS (MCDOUGALL e MILLER, 2003).

Segundo AMIRALIAN e col.(2000), existem imprecisões dos conceitos na pesquisa e na prática da área da deficiência, com variações relacionadas ao modelo médico e ao modelo social, que resultam em dificuldades na aplicação e utilização do conhecimento produzido. Embora a discussão destes autores ainda tenha sido construída sobre os conceitos da CIDID/ICIDH, mantém-se o foco sobre a importância de esclarecer melhor a conceituação, com a identificação de pontos comuns e divergentes das principais posições teóricas, para a utilização de uma linguagem comum e bem especificada, para melhorar a comunicação entre os profissionais e na troca de informações nas discussões de pesquisa e no planejamento e execução de ações.

A Convenção Internacional de Direitos das Pessoas com Deficiência (ou Incapacidade), no documento produzido na oitava reunião em agosto de 2006, apresenta o seu propósito no Artigo 1, que é o de promover, proteger e assegurar o igual e pleno gozo de todos os direitos humanos e liberdades fundamentais por todas as pessoas com deficiência ou incapacidade, e promover o respeito por sua inerente dignidade. Além disso, este mesmo Artigo define de alguma maneira que pessoas com deficiência ou incapacidade incluem aquelas que têm deficiências física, mental, intelectual ou sensorial, de longa duração, deficiências estas que em interação com várias barreiras podem impedir a sua participação completa e efetiva na sociedade em base de igualdade com outros (UNITED NATIONS CONVENTION, 2006).

O relato de participantes da oitava Reunião de discussão do texto da Convenção apontam entre os temas mais difíceis de serem tratados a definição de 
Deficiência e de Pessoa com Deficiência, além dos temas Situação de Risco, Capacidade legal, Proibição a Tratamentos Forçados, Proteção à Integridade da Pessoa, Saúde Sexual e Reprodutiva e Monitoramento. Nos momentos finais, chegou a ser veiculado em comunicado diário que seria melhor não ter uma definição a ter uma definição muito ruim, pois alguns países não admitiam uma redação de Definição de pessoa com Deficiência que incluísse a interação dos fatores externos como parte do conceito. Após muitas discussões, conseguiu-se chegar a uma definição, que não foi considerada a ideal por este grupo de participantes, mas uma com a qual é possível conviver (ATALLA, 2006). 


\subsection{1- Definições nas Leis dos Estados Unidos}

A lista de "definições" estabelecidas em nível federal nos EUA é enorme. Mesmo os profissionais de saúde pública interessados em assuntos de deficiência ou incapacidade sentem-se assoberbados, pois existem cerca de 50 definições legislativas diferentes (LOLLAR, 2002).

Os Estados Unidos da América possuem uma coleção de definições estatutárias federais de deficiência ou incapacidade (disability) incluídas no Código de Leis dos Estados.

No anexo 1, é apresentada uma lista de definições traduzidas, que não pretende ser uma descrição exaustiva de programas para pessoas com deficiências, mas sim uma referência para as várias definições de deficiência ou incapacidade (disability) contidas nesse Código de Leis. O Código é a compilação oficial dos estatutos federais que estão em vigor e está dividido em 50 títulos por tipo de assunto, sendo cada título dividido em seções. A compilação foi feita pelo Escritório do Conselho de revisão de Leis na Casa de Representantes dos Estados Unidos.

Foram encontrados 67 lugares onde é definida deficiência ou incapacidade. Isto inclui definições de deficiência ou incapacidade, pessoa deficiente ou incapacitada, indivíduo com uma deficiência ou incapacidade, desvantagem, ou outras variações do termo deficiência ou incapacidade.

Nesta lista, o estatutos estão organizados em nove títulos: Direitos Civis, Educação, Emprego, Moradia, Código de Renda Interno (Internal Revenue Code), Seguridade Social, Serviços Sociais, Veteranos e Forças Armadas, e Miscelânea. 
Dentro destes títulos, as definições foram organizadas por título de Código e número de seção.

No anexo 1 são identificadas as leis (por exemplo, Americans with Disabilities Act) ou programas (por exemplo, Bilhete para Trabalho e Programa de Auto-Suficiência) pelos nomes com sua tradução mais aproximada, mantendo-se o termo em inglês entre parênteses. As leis são referidas pelo título contido no estatuto (por exemplo, Lei de Boa Moradia - Fair Housing Act) e os programas estão referidos pelo seu nome (por exemplo, Programa de Moradia Apoiada - Supportive Housing Program) mais que pela lei que o autoriza. Uma questão complicada é saber quantas definições diferentes existem, pois há sobreposição entre definições e alguns estatutos têm mais de uma definição. Por exemplo, o ADA define não somente "deficiência ou incapacidade", mas também "indivíduo qualificado com uma deficiência ou incapacidade" para propósitos de emprego e serviços públicos. O ADA também especifica certas condições que não são consideradas deficiências ou incapacidades. Da mesma maneira, a "Lei de Reabilitação" ("Rehabilitation Act”) de 1973 tem várias definições, incluindo uma definição de duas partes para "indivíduo com uma deficiência ou incapacidade", uma das quais é a definição do ADA. Há ao todo 67 leis ou programas que definem deficiência ou incapacidade, 35 destas têm definições próprias (embora algumas destas 35 contenham mais de uma definição e três usem a linguagem do ADA), 26 usam definições provenientes de uma outra seção do Código, e seis usam definições provenientes de mais de uma seção do Código.

É interessante observar as notas de exclusão de algumas definições, como por exemplo, nas leis apontadas nos itens de número 4, 16 e 38 (Anexo 1). São excluídas 
"homossexualidade e bissexualidade, travestismo, transsexualismo, pedofilia, exibicionismo, voyeurismo, distúrbios de identidade de gênero não resultante de alterações físicas ou outros distúrbios do comportamento sexual, jogo compulsivo, cleptomania ou piromania, distúrbios pelo uso de substâncias psicoativas"; “exclusão indivíduos envolvidos em uso de drogas"; "para emprego, exclusão de alcoolista cujo uso corrente de álcool impeça tal indivíduo de realizar as obrigações do emprego em questão ou cujo emprego, em razão de tal abuso de álcool corrente, constituiria uma ameaça direta à propriedade ou à segurança de outros"; "para emprego exclusão do indivíduo que tenha uma doença contagiosa ou infecção correntemente e que, em razão de tal doença ou infecção, constituiria uma ameaça direta à saúde ou segurança de outros indivíduos ou que, em razão da sua infecção ou doença contagiosa atual, é incapaz de realizar as obrigações do seu emprego ou trabalho" (STATUTORY DEFINITIONS, 2002).

Um número tão grande de definições pode refletir o modo fragmentado como são elaboradas as leis, levando em conta diferentes momentos históricos, refletindo diferentes entendimentos da questão da deficiência e incapacidade. Há definições compartilhadas e algumas definições muito semelhantes, mas dificilmente se imaginaria a homogeneização de todo este conjunto de definições em diferentes leis.

Segundo CWICKEL (1999), em um artigo que discute definições de deficiência ou incapacidade para avaliação de custos em cuidados de saúde, o uso de uma única definição como referência não é recomendado para avaliar ou definir as necessidades de um grupo muito heterogêneo de adultos com deficiência ou incapacidade. Isto possivelmente reforça a idéia que poderia explicar o número tão 
grande de definições existentes nos EUA, em que leis diferentes implicariam em definições diferentes e avalizações diferentes. 


\subsection{2 - Definições na União Européia}

Um estudo realizado pela Universidade de Brunel no Reino Unido, e encomendado pela Direção Geral da Comissão Européia de Emprego e Assuntos Sociais, envolveu relatores de 14 estados da União Européia e Noruega na discussão das definições de deficiência ou incapacidade na Europa (BRUNEL, 2002). Em razão de ser um estudo muito abrangente, que contou inclusive com especialistas que participaram do processo de revisão da CIF, é importante que alguns conceitos e impressões do estudo sejam apresentados. Os diferentes tipos de definições usados nos 14 países europeus do estudo, mostram como é universalmente difícil homogeneizar ou unificar definições de deficiência ou incapacidade, pelo menos do modo como são construídas e avaliadas.

O projeto de pesquisa da Universidade de Brunel revisou as definições de deficiência ou incapacidade usadas na previdência social, emprego e políticas antidiscriminação. Foi coletada informação sobre definições, cobrindo métodos de avaliação, instituições e pessoal, bem como diferentes entendimentos da política a respeito das situações que a deficiência ou incapacidade acarreta. O relato sublinhou os modelos para interpretar as definições que poderiam contribuir para o debate e o desenvolvimento da política social para a concessão de benefícios. O estudo sobre definições de deficiência ou incapacidade na Europa encontrou quatro métodos gerais de avaliar a deficiência ou incapacidade em uso: 1) o método "barema", 2) avaliação de necessidades de cuidados, 3) medida da capacidade funcional e 4) cálculo da perda econômica. (BRUNEL, 2002).

Uma grande diferença inicial nas definições encontra-se naquelas apresentadas em leis antidiscriminação e nas leis de políticas sociais que envolvem 
concessão de benefícios, especialmente com relação ao trabalho. As questões relacionadas ao trabalho parecem constituir-se em uma preocupação mais antiga, surgindo mais recentemente a discussão dos aspectos de discriminação. Do mesmo modo, as definições de deficiência usadas para as leis de políticas sociais que envolvem pagamento de benefícios, em geral são mais restritivas que aquelas usadas nas leis que envolvem situações de discriminação.

É importante apresentar alguns termos usados neste estudo, que podem ser alistados e definidos, com algumas de suas características apontadas como vantagens ou desvantagens, como segue:

1) Definições contingentes: são aquelas que são aplicadas somente em contextos específicos, onde fatores particulares pessoais, sociais e ambientais são realçados. Tem o sentido de "condicional" da palavra "contingente", ou seja, as definições dependem do contexto.

2) Definições essencialistas: são aquelas que se atêm apenas a uma característica essencial da definição, não levando em conta os contextos. Tem o sentido de “absoluto" da palavra "essencial”, ou seja, as definições não se modificam em qualquer circunstância ou contexto.

A gravidade de deficiências (no nível do corpo) é freqüentemente avaliada observando os seus efeitos incapacitantes, e estes efeitos incapacitantes surgem em contextos específicos, de modo que a avaliação da deficiência não é tão essencial quanto parece. Uma pessoa pode ser avaliada como mais gravemente deficiente em um local de trabalho que em outro, ou menos deficiente em casa que no trabalho. $\mathrm{Ou}$ seja, embora utilizando para definição apenas a alteração no nível do corpo, o que 
faria pensar numa definição essencialista, a mudança de valoração em diferentes contextos, tende para uma definição contingente.

3) Coerência: corresponde ao nexo do que está descrito numa definição de deficiência ou incapacidade com o que é entendido ou avaliado como deficiência (no nível do corpo) ou incapacidade, não levando em conta questões de gravidade do problema relacionadas com a relevância.

4) Relevância: corresponde à importância contida naquilo que está descrito numa definição de deficiência ou incapacidade, relacionada à gravidade e à extensão na qual uma determinada condição afeta a vida do indivíduo para ser objeto de políticas de proteção social.

Utilizando as noções de coerência e relevância, as definições baseadas apenas no nível do corpo (deficiências) que poderiam parecer identificar o ingrediente essencial da deficiência ou incapacidade, não preenchem por si só a questão da relevância. A idéia de relevância poderia ser considerada um requisito fundamental para a definição operacional de uma categoria de política social para concessão de benefícios, mas não o único requisito. Avaliações relevantes podem diferir dependendo do tipo de política envolvida, tornando as categorizações inconsistentes em diferentes áreas de políticas. Por exemplo, uma pessoa que é deficiente ou incapacitada para os propósitos de uma medida de emprego pode não ser deficiente ou incapacitada para a provisão de assistência com as AVD, ou seja, uma pessoa pode se defrontar com problemas para obter emprego sem concomitantemente ter limitações (suficientemente graves) na vida diária.

A idéia de "coerência" poderia sugerir que se estabelecesse um status de deficiência ou incapacidade, fornecendo uma certificação ampla e ligando condições 
de elegibilidade. Entretanto, podem surgir conflitos entre coerência e relevância se isto for feito de um modo sistemático, colocando-se como uma questão problemática que método de avaliação poderia ser usado para estabelecer um status coerente de deficiência ou incapacidade, e se tal status poderia ser relevante.

5) Categorias integradas: diferentes categorias são agrupadas para a definição de elegibilidade para concessão de benefícios (por exemplo, desempregado, deficiente ou incapacitado e aposentado), utilizando definições de deficiência ou incapacidade de modo mais flexível do que quando as categorias são fragmentadas. Os sistemas que têm categorias integradas costumam usar menos abordagens médicas para definir deficiência ou incapacidade, especialmente se não há interesse em defender limites definidos no aspecto médico. Sistemas integrados que são centralizados tendem a ser orientados para o uso de instrumentos e regras desenhadas para atingir consistência na tomada de decisão. Dados médicos podem ser incluídos nestes instrumentos, até onde eles pareçam ser objetivos e confiáveis. Uma desvantagem apontada é que demandas aumentadas em qualquer uma das políticas relativas a uma das categorias, podem afetar a disponibilidade de recursos para as outras.

6) Categorias fragmentadas: são adotadas categorias isoladas nas definições usadas para elegibilidade em políticas de concessão de benefícios e proteção social. Sistemas que têm categorias fragmentadas costumam defender limites médicos e nestes sistemas os médicos exercem um papel central na avaliação. Estes sistemas são freqüentemente caracterizados pelo uso de tabelas de deficiências e baremas. As definições de deficiência ou incapacidade são menos susceptíveis de serem influenciadas por mudanças no ambiente da política social nestes sistemas. Há uma 
crítica sobre a existência questões sobre a relevância da política das definições de deficiência ou incapacidade geradas desta maneira.

\section{7) Modelos de avaliação:}

7. a) Com elevada evidência médica e baixo arbítrio: $O$ modelo de elevada evidência médica - baixo arbítrio, envolvendo o uso de tabelas de deficiências ou baremas, é amplamente encontrado em políticas regulatórias, incluindo esquemas de quotas. É menos comum nas políticas sociais orçamentárias, mas é usado em alguns estados como um instrumento de administração de recursos em múltiplos níveis, onde o governo central regula a provisão através de governos locais ou regionais ou instituições de seguro.

\section{7. b) Com elevada evidência médica e elevado arbítrio (médico e não-médico):}

Modelos de elevado arbítrio (tanto médico como não-médico) são mais freqüentemente encontrados em áreas de provisão onde o controle sobre a política e a responsabilidade pelo financiamento está localizada no mesmo nível de governo.

7. c) Com baixa evidência médica e elevado arbítrio: $O$ modelo baixa evidência médica - elevado arbítrio é mais freqüentemente encontrado na provisão de assistência social e serviço de emprego. Os administradores costumam ter uma considerável flexibilidade para classificar pessoas como deficientes ou incapacitadas para medidas de emprego. Quando as dificuldades de uma pessoa para conseguir um emprego são devidas a limitações sociais e de saúde, medidas gerais (mainstream) podem ser mais apropriadas que medidas especiais para o deficiente ou incapacitado. Contudo, os Serviço de Emprego em geral possuem um orçamento maior para a colocação de pessoas que procuram emprego que classificadas como deficientes ou incapacitadas. Nesta lógica, metas para colocação de pessoas deficientes ou 
incapacitadas podem criar um incentivo institucional para designar pessoas como deficientes ou incapacitadas, ou seja, "construir" pessoas deficientes ou incapacitadas.

8) Deficiência ou Incapacidade acarretando problemas em AVD's: Nos sistemas para a provisão de assistência em Atividades da Vida Diária (AVD), a deficiência ou incapacidade pode ser vista como acarretando custos extras para a vida e necessidades de cuidado e apoio Algumas destas visões sobre o que a deficiência ou incapacidade acarreta tem uma afinidade com a abordagem particular adotada para avaliar a deficiência ou incapacidade. Isto é mais evidente na provisão de assistência com AVD, em que a deficiência ou incapacidade que acarreta custos e necessidades extra, corresponde estreitamente ao uso de avaliações orientadas à capacidade da pessoa para realizar atividades da vida diária.

9) Deficiência ou Incapacidade acarretando problemas para o trabalho: $\mathrm{Na}$ área de manutenção de salário ou renda, a deficiência ou incapacidade pode ser vista como acarretando incapacidade total ou parcial para o trabalho. Na política de emprego, a deficiência ou incapacidade pode ser vista como acarretando produtividade reduzida, como um aspecto da desvantagem na entrada do emprego, ou como um fator levando a discriminação na entrada ou retenção do emprego.

10) Deficiência ou Incapacidade acarretando problemas de discriminação: Uma abordagem proposta neste tipo de situação é adotar uma definição "expansiva" e que dificilmente requer avaliação. A intervenção em geral inclui remediar as situações de discriminação assim que elas surjam, não envolvendo políticas de concessão de benefícios nestes casos. As situações em que é necessária uma definição de categoria, como a administração de medidas de ação positiva tais como quotas, esta 
abordagem não pode ser usada. Encontrar uma avaliação de deficiência ou incapacidade que seja relevante para o "risco de discriminação" mostrou-se uma área problemática.

Utilizar os conceitos mostrados neste tópico, ajudando a identificar como são construídas as definições de deficiência ou incapacidade em diferentes leis, buscando maneiras de torná-las operacionais de modo coerente e relevante, pode ser um ponto de partida para avaliações mais justas e claras. A CIF, como classificação de saúde, pode, pela sua abrangência, contribuir com as questões de coerência e, por meio dos seus qualificadores, com as questões de relevância. 


\subsection{3 - Baremas}

Informação muito detalhada é fornecida em diferentes baremas nacionais na União Européia (tabelas mostrando uma certa percentagem de deficiência ou incapacidade correspondendo a deficiências especificadas) (BRUNEL, 2002).

A palavra "barema" é descrita no dicionário da língua portuguesa como um substantivo masculino, sob a rubrica matemática, significando "conjunto de quadros ou de dados numéricos que apresentam o resultado de certos cálculos" e tem origem da palavra francesa barème, de 1796 (HOUAISS, 2001).

Na Europa, segundo Bernd Marin (2003), “antes da CIF, esta visão mais ampla, mais complexa e dinâmica da deficiência ser adotada, a avaliação de deficiência era reduzida a mensurar as incapacidades em um modo pseudocientífico através dos assim chamados Baremas. Baremas são escalas para compensação de lesões que datam de período anterior à idade média. A lei germânica relacionava somas de dinheiro para a perda de partes do corpo para 'wergeld' ou 'manngeld' a serem pagas como uma compensação por matar um homem livre. Mais tarde, o matemático francês François Bareme transpôs tais escalas para percentagens, que foram denominadas 'Baremas', ou (mais dramaticamente em alemão) 'Knochentaxe' ('bone-rate' ou 'taxa de ossos')” (MARIN, 2003).

Originalmente, anormalidade ou perda estava restrita a pessoas que eram cegas ou surdas ou paralisadas, ou sem um órgão ou sem uma perna. Estes eram os dias de apogeu dos assim chamados "Baremas". A partir daí, os médicos criaram o equivalente a uma "taxa de membro" (limb-rate) (ou "gliedertaxe" em alemão) também para "distúrbios neuropsiquiátricos" ou mentais ou psicológicos, com ainda maior imprecisão (MARIN, 2003). 
Um olhar sobre os Baremas europeus e as suas variações entre países (mesmo em vizinhanças como, por exemplo, a Escandinávia) mostra um código estranho e inteiramente arbitrário de níveis particulares de incapacidade, variando muito entre os países - e ao longo do tempo nos mesmos países, e dentro dos mesmos países entre diferentes grupos assegurados, principalmente ocupacionais, isto é, distinções corporativas que não têm nada a fazer com capacidades de trabalho residuais ou estruturas de risco - para as muitas mesmas perdas ou deficiências, permitindo uma grande variação e decisão arbitrária dentro das mesmas categorias de danos, e estranhas comparações entre lesões e entre grupos de interesse especial corporativo (MARIN, 2003).

No Reino Unido, nos anos 60, por exemplo, a perdas dos dedos e de uma perna amputada abaixo do joelho constituía uma deficiência ou incapacidade de $50 \%$, enquanto a perda de três dedos e a amputação de um pé ou a perda de um olho era traduzida numa taxa de $30 \%$ de incapacidade; hoje, a mesma perda do pé é avaliada como $100 \%$ de incapacidade no mesmo país, enquanto a amputação de um pé como somente $30 \%$ na Alemanha, 50\% para a Bélgica contra os $100 \%$ na Inglaterra, mas ambos os pés somente $70 \%$ na Itália. Hoje, uma amputação no nível do quadril constitui $35 \%$ de incapacidade na Islândia, mas $90 \%$ na Inglaterra e na Bélgica, a amputação no nível do tornozelo 30\% na Dinamarca, mas somente 9\% na Suécia. Dentro dos mesmos países, na Áustria por exemplo, a mesma perda física de um membro amputado abaixo do joelho conta como um grau de $50 \%$ de redução da capacidade para trabalho remunerado se isto aconteceu a alguém durante a guerra, enquanto a mesma deficiência conta como $40 \%$ se isto ocorre a um fazendeiro hoje, mas somente $30 \%$ se isto afeta um trabalhador de escritório ou de fábrica. Um infarto 
ou uma doença coronariana corresponde a $100 \%$ de deficiência na Itália, mas somente 30 a $60 \%$ na Bélgica. Fraturas na coluna vertebral com conseqüências neurológicas são avaliadas entre $20 \%$ (e 25\%) e $100 \%$ dentro dos mesmos países incluindo Dinamarca, Noruega e Suécia. Fenômenos inflamatórios e degenerativos da coluna vertebral podem variar entre $5 \%$ e $100 \%$ na Bélgica, deixando todo o arbítrio aos médicos. Diabetes mellitus insulino-dependente instável conta como 5075\% na França, 60-100\% na Bélgica, 30-100\% na Lituânia, 51-60\% na Itália, 50$80 \%$ na Estônia, $75-100 \%$ na Irlanda, mas somente até $40 \%$ na Islândia, e um 50\% mínimo na Alemanha. Uma perda total da visão em ambos os olhos corresponde a 100\% de deficiência na Alemanha, Dinamarca e Noruega, 95\% na França, mas somente a $68 \%$ na Suécia. "Desfiguração facial grave" é avaliada como $100 \%$ de deficiência na Inglaterra, 80-100\% na Itália ("boca de lobo" wolf-mouth, síndrome de Binder), enquanto "desfiguração visualmente repulsiva" conta somente como $50 \%$ na Alemanha, e entre 10 a 100\% na Bélgica - deixando todo o espaço para o julgamento arbitrário sobre a "feiúra" (ugliness) e os benefícios correspondentes por incapacidade para burocratas. A França, por outro lado, não conhece tal desfiguração facial repulsiva no todo, mas operacionaliza "deficiência maior" por "distúrbios prejudicando seriamente ou impedindo a alimentação, controle da cabeça e retenção de saliva" (50-70\%), com dependência de uma terceira pessoa como 80\% (MARIN, 2003).

Ao longo do tempo, para comparação internacional, bem como quando para comparar lesões umas com as outras, esta abordagem mecanística de atribuir figuras resumidas singulares para benefícios baseados em Baremas demonstra um caráter arbitrário e estranho, com os seguintes problemas: O problema dos Pontos - como se 
compara uma perna fraturada com esquizofrenia; o problema dos órgãos remanescentes - o que se faz na situação de um homem que só tem um olho e perde seu olho remanescente; o problema do corpo todo - se a perda de um dedo é $10 \%$, dor lombar é $20 \%$, depressão é $40 \%$, qual é o prêmio total para um indivíduo com todas as três condições; o problema do Limiar - se o benefício é concedido em um limite (tal como 30\% para uma pensão por incapacidade parcial e $80 \%$ para uma completa), como decidir se alguém cai em 29\%, 30\% ou 31\%?” (MARIN, 2003).

Algumas vezes, Baremas nacionais refletem simplesmente preconceitos ou estigmatização de longa duração, se eles forem compartilhados pela profissão médica. Na Áustria, por exemplo, cerca de 60.000 pessoas com esquizofrenia são totalmente excluídas do trabalho devido ao estigma ligado a sua condição de saúde, ainda amplamente vista, também por especialistas médicos nos comitês de avaliação, como equivalente a psicose e como uma doença mental. Como a primeira incidência da doença ocorre ao redor dos 20 anos para homens (que, na média, têm pequeno ou nenhum registro profissional nesta idade), e ao redor da idade de 30 anos para as mulheres, a maioria das pessoas diagnosticadas com esquizofrenia estarão em uma pensão por invalidez por toda a vida por cerca da metade de um século - a despeito do fato de que $70 \%$ deles serem capazes e desejosos de trabalhar. Mesmo sendo a incidência da esquizofrenia de $1 \%$, significantemente mais baixa que aquela de outras doenças psiquiátricas - cujo compartilhamento dos benefícios gerais por incapacidade está aumentando rapidamente em todos os lugares da Europa - esta é a maneira de exclusão, do trabalho e da vida, de vários milhões de europeus que apresentam esta única condição de saúde mental; e isto irá preocupar dúzias de milhões de europeus de todas as idades quando ocorrer por alcoolismo, ataques de 
pânico e fobias sociais, ou depressão, incluindo aqueles muito graves (MARIN, 2003).

A despeito destes sérios problemas com os Baremas, eles ainda são amplamente usados para prêmios de compensação por lesões. Este uso possível mais amplo do mais problemático e mais amplamente criticado método de avaliação deve ser menos surpreendente do que seria num primeiro olhar: ele é um sistema muito antigo e bem estabelecido, datando de séculos atrás; ele tem uma vantagem institucional de precedência por ter sido estabelecido nos primeiros dias da evolução do sistema de bem-estar (welfare) para deficiência ou incapacidade; ele parece difícil de aplicar, requerendo testes "científicos" e exames conhecidos somente pelos profissionais; por atribuir números a fenômenos altamente complexos e multidimensionais, ele dá a impressão de objetividade (pelo menos para pessoas leigas, enquanto pode ser ridicularizado por outros profissionais pela ultraprecisão mal colocada), comparabilidade e assim, eqüidade (ou justiça) social; ele deve ser usado muito flexivelmente para concessão de benefícios tanto para deficiências como para incapacidades advindas de deficiências, de modo que tanto as lesões propriamente ditas ou somente as deficiências resultantes das lesões podem vir a ser compensadas, deixando amplo espaço para os formuladores de leis bem como para administradores sociais desenhar e redesenhar práticas de acordo com os humores públicos cambiantes, constrangimentos fiscais e solicitações políticas; a autonomia profissional e o arbítrio tanto dos médicos como dos burocratas permanece extremamente elevada, dado a latitude inerente aos Baremas baseados na deficiência, de modo que eles seguram um monopólio da decisão sobre o status de trabalho de pessoas com deficiências ou incapacidades, salário, tipos de benefícios e direitos a 
serviços, em resumo: um controle de grande alcance sobre as vidas das pessoas (MARIN, 2003).

Quadro 2 - Baremas para amputação baixo do joelho na Áustria

\begin{tabular}{|l|l|}
\hline Áustria & Perda física de um membro amputado abaixo do joelho \\
\hline Durante a guerra & $50 \%$ \\
\hline Fazendeiro & $40 \%$ \\
\hline $\begin{array}{l}\text { Trabalhador empregado } \\
\text { em escritório ou fábrica }\end{array}$ & $30 \%$ \\
\hline
\end{tabular}

Fonte: MARIN, 2003. 


\subsection{4 - Definições de leis no Brasil}

Leis que concedem benefícios às pessoas com deficiências (leis de gratuidade em transporte, leis de quotas para trabalho, leis para concessão de benefícios continuados) são de difícil operacionalização no que diz respeito à definição de quem tem deficiência. Algumas leis e suas regulamentações tiveram sua operacionalização com base em diagnósticos da CID-10, porém com várias ressalvas do ponto de vista da função.

No Brasil, a utilização da CIF vem sendo aguardada com grande expectativa pelas organizações de pessoas com deficiência e instituições relacionadas. A CIF foi incluída, mesmo antes da sua edição, como padrão para caracterização da deficiência na proposta do Estatuto da Pessoa com Deficiência, apresentada em consulta pública ao Senado Federal (Título I -art.2º, embora esta menção tenha desaparecido numa minuta subseqüente. No processo de discussão de um novo substitutivo que fosse compatível com a recém-aprovada Convenção da Organização das Nações Unidas sobre os Direitos das Pessoas com Deficiência, a CIF voltou a fazer parte do texto do Estatuto em dezembro de 2006, conforme apontado adiante.

Numa das primeiras versões após consulta pública (quando foi abandonado o termo "portador" de deficiência) o projeto de Lei do Senado No 429, de 2003, continha o seguinte texto nas disposições preliminares, incluindo a CIF no seu artigo segundo: "Institui o Estatuto da Pessoa com Deficiência e dá outras providências. TÍTULO I - Das Disposições Preliminares Art. $1^{\text {o }}$. Esta lei institui o Estatuto da Pessoa com Deficiência, destinado a assegurar a integração e a inclusão social e o pleno exercício dos direitos individuais e coletivos das pessoas que apresentam limitação em suas atividades devido à sua deficiência. Parágrafo Único. Para efeito 
desta lei entende-se por pessoa com deficiência aquele tipificado na Constituição Federal e nos termos da lei, como "portador de deficiência". Art. $2^{\circ}$. Para fins deste Estatuto serão considerados os conceitos de deficiência, atividade, limitação na atividade, participação e restrição na participação daqueles que estão conforme definidos pelo documento CIF (Classificação Internacional de Funcionalidades ) da OMS, que passa a ser o padrão para a caracterização feita por quaisquer instituições oficiais brasileiras ou, no caso de somente ali não constar, conforme documento assinado por dois profissionais especializados.”.

No entanto, o Substitutivo do Estatuto da Pessoa com Deficiência, levado a discussão em março de 2006, deixou de mencionar a CIF, nem mesmo como um modelo a ser explorado ou para servir como apoio nas avaliações, reproduzindo definições de documentos anteriores como os decretos 3298 e 5296. Segue-se a reprodução das definições apresentadas neste substitutivo: "Art. $2^{\circ}$ Considera-se deficiência toda restrição física, mental ou sensorial, de natureza permanente ou transitória, que limita a capacidade de exercer uma ou mais atividades essenciais da vida diária e/ou atividade remunerada, estando enquadrada em uma das seguintes categorias: I - Deficiência Física - alteração completa ou parcial de um ou mais segmentos do corpo humano, acarretando limitação da função física, apresentando-se sob a forma de paraplegia, paraparesia, monoplegia, monoparesia, tetraplegia, tetraparesia, triplegia, triparesia, hemiplegia, hemiparesia, ostomia, amputação ou ausência de membro, paralisia cerebral, nanismo, membros ou face com deformidade congênita ou adquirida; II - Deficiência Auditiva - perda bilateral, parcial ou total média de $41 \mathrm{~dB}$ (quarenta e um decibéis) ou mais, aferida por audiograma nas frequiências de 500HZ, $1.000 \mathrm{HZ}, 2.000 \mathrm{~Hz}$ e $3.000 \mathrm{~Hz}$; III - Deficiência Visual - 
compreende a cegueira, na qual a acuidade visual é igual ou menor que 0,05 no melhor olho, com a melhor correção óptica; a baixa visão, que significa acuidade visual entre 0,5 e 0,05 no melhor olho e com a melhor correção óptica; os casos nos quais a somatória da medida do campo visual em ambos os olhos for igual ou menor que $60^{\circ}$; ou a ocorrência simultânea de qualquer uma das condições anteriores; IV Deficiência Mental - funcionamento intelectual significativamente inferior à média, com manifestação no período de desenvolvimento humano e limitações associadas a duas ou mais áreas de habilidades adaptativas, tais como:

a) comunicação;

b) cuidado pessoal;

c) habilidades sociais;

d) utilização dos recursos da comunidade;

e) saúde e segurança;

f) habilidades acadêmicas;

g) lazer; e

V - Surdo - cegueira: compreende a perda concomitante da audição e da visão, cuja combinação causa dificuldades severas de comunicação e compreensão das informações, prejudicando as atividades educacionais, vocacionais, sociais e de lazer, necessitando de atendimentos específicos, distintos de iniciativas organizadas para pessoas com surdez ou cegueira.; VI - Autismo: comprometimento global do desenvolvimento, que se manifesta tipicamente antes dos três anos, causando dificuldades significativas de comunicação, interação social e de comportamento, caracterizando-se freqüentemente por movimentos estereotipados, atividades repetitivas, respostas, mecânicas, resistência a mudanças nas rotinas diárias ou no 
ambiente e a experiências sensoriais. VII - Condutas Típicas: comprometimento psicossocial, com características específicas ou combinadas, de síndromes e quadros psicológicos, neurológicos e/ou psiquiátricos, que causam atrasos no desenvolvimento e prejuízos no relacionamento social, em grau que requeira atenção e cuidados específicos; VIII - Lesão Cerebral Traumática - compreende uma lesão adquirida, causada por força física externa, resultando em deficiência funcional total ou parcial ou deficiência psicomotora, ou ambas, e que comprometem o desenvolvimento e/ o desempenho social da pessoa; IX - Deficiência Múltipla compreende a associação de duas ou mais deficiências, cuja combinação acarreta comprometimentos no desenvolvimento global e desempenho funcional da pessoa e que não podem ser atendidas em uma só área de deficiência. $§ 1^{\circ}$ Para efeitos da presente lei equipara-se a pessoa superdotada à pessoa com deficiência, sendo superdotada a pessoa que apresenta notável desempenho e elevada habilidade de natureza intelectual, física, social e de liderança em uma ou mais áreas da atividade humana. $\S 2^{\circ}$ Entende-se como deficiência permanente aquela que ocorreu ou se estabilizou durante um período de tempo suficiente para não permitir recuperação ou ter probabilidade de que se altere, apesar de novos tratamentos".

ANDRADE (2006), em mensagem ao grupo DEfNEt, argumenta que "o conceito ora utilizado é uma repetição e construto ainda duplamente alicerçado no complexo deficiência/doença, utilizando-se uma visão questionável caso tenhamos como parâmetro a definição da Convenção Interamericana para a Eliminação de Todas as Formas de Discriminação Contra as Pessoas com Deficiência, chamada Convenção da Guatemala, onde se conceitua "deficiência" por "uma restrição física, mental ou sensorial, de natureza que limita a capacidade de exercer uma ou mais 
atividades essenciais da vida diária, CAUSADA OU AGRAVADA PELO AMBIENTE ECONÔMICO OU SOCIAL"(art. 1, n 1), sendo estes termos e afirmações grifados excluídos da atual minuta em apreciação. Pergunto e não encontro a justificativa imediata desta supressão, já que o restante da conceituação da Convenção encontrase reproduzido na minuta, porém ao se verificar os demais termos das 'disposições preliminares', ficam claras as inclusões de condições médicas e de doença que mais estão para a inclusão na Classificação Internacional de Doenças e situações relacionadas à Saúde, do que da atual Classificação Internacional de Funcionalidade, Incapacidade e Saúde (CIF - ICF) da OMS (2001), que trouxe um possível reforço para a determinação causal de deficiências a partir das questões ambientais e da situação econômico social dos cidadãos e cidadãs que passam pelos caminhos excludentes das deficiências, incapacidades e desvantagens, ressignificando e esclarecendo o conceito de doença associado às deficiências, mudando radicalmente a concepção para uma visão da funcionalidade e da Saúde, como parâmetros para a atenção, cuidados e, quiçá para a aplicação das leis em nosso País. Lembro, portanto, que se o Direito permanecer na superfície apenas das deficiências, com uma postura ainda vitimizada e tutelada das pessoas com deficiência, sem um aprofundado debate sobre a sua heterogeneidade e multiplicidade, sem perceber a questão imprescindível da construção histórica de estigmas e preconceitos, formados pela lógica da exclusão social, ocorrerá, a meu ver, como está ocorrendo, a construção de mais um documento para cidadãos e cidadãs "de papel", posto que as deficiências, e, consequientemente as pessoas com deficiência, por mais que se lute para sua inclusão, são e serão parte de um sistema de exclusão, pois somos remetidos sempre 
à questão da diferença, embora sejam tratadas no campo das diversidades humanas" (ANDRADE, 2006).

Um novo Substitutivo ao Projeto de Lei do Estatuto da Pessoa com Deficiência foi elaborado levando em conta novas opiniões e sugestões, especialmente da sociedade civil, a legislação vigente no país e a recém aprovada Convenção Internacional sobre os Direitos das Pessoas com Deficiência e aprovado no dia 6 de dezembro de 2006 pela Comissão de Direitos e Legislação Participativa do Senado. Este documento deve seguir para a Câmara Federal, onde continuará a ser debatido, havendo ainda a possibilidade de aprimoramento do seu conteúdo.

Foram mantidas as definições de categorias contidas no substitutivo anterior, de março de 2006, dentro do Artigo $2^{\circ}$, mas modificada a definição do que se considera deficiência, entrando na redação a questão de ser causada ou agravada pelo ambiente econômico e social, de acordo com o comentário de ANDRADE (2006) reproduzido acima. Foram acrescentados três parágrafos a este Artigo e reintegrada a menção à CIF, como segue: “Artigo $2^{\circ}$ Considera-se deficiência toda restrição física, intelectual ou sensorial, de natureza permanente ou transitória, que limita a capacidade de exercer uma ou mais atividades essenciais da vida diária e/ou atividades remuneradas, causada ou agravada pelo ambiente econômico e social, dificultando sua inclusão social, enquadrada em uma das seguintes categorias: ....”. “...§ $1^{\circ}$ Considera-se também deficiência a incapacidade conceituada e tipificada pela Classificação Internacional de Funcionalidade, Incapacidade e Saúde - CIF. $\S 2^{\circ}$ Entende-se como deficiência permanente aquela definida em uma das categorias dos incisos ou do parágrafo $1^{\circ}$ deste artigo e que se estabilizou durante um período de tempo suficiente para não permitir recuperação ou ter probabilidade de que se altere, 
apesar de novos tratamentos. $\S 3^{\circ}$ As categorias e suas definições expressas nos incisos e parágrafo $1^{\circ}$ não excluem outras decorrentes de normas regulamentares a serem estabelecidas pelo Poder Executivo, ouvido o Conselho Nacional da Pessoa com Deficiência."

No que diz respeito ao terceiro parágrafo acima reproduzido, pode-se ter uma idéia de como são construídas algumas definições e leis nesta área, a partir da lista de componentes da sociedade civil do Conselho Nacional da Pessoa com Deficiência CONADE. Fazem parte do CONADE: Federação Nacional das Sociedades Pestalozzi, União Brasileira de Cegos, Federação Nacional de Educação e Integração de Surdos - FENEIS, Federação Brasileira das Associações de Síndrome de Down, Associação Brasileira de Ostomizados - ABRASO, Organização Nacional de Entidades de Deficientes Físicos - ONEDEF, Associação Brasileira de Autismo ABRA, Associação de Pais e Amigos de Pessoas Portadoras de Deficiência dos Funcionários do Banco do Brasil - APABB, Ordem dos Advogados do Brasil OAB, Confederação Nacional do Comércio, Confederação Federal de Engenharia, Arquitetura e Agronomia - CONFEA, Sociedade Brasileira de medicina Física e Reabilitação, Central Única dos Trabalhadores - CUT, Federação Brasileira de Entidades De e Para Cegos - FEBEC, Conselho Nacional dos Centros de Vida Independente - CVI, Federação das Associações de Renais e Transplantados do Brasil - FARBRA, Movimento de Reabilitação dos Portadores de Hanseníase MORHAN e Associação Nacional do Ministério Público de defesa dos Direitos das pessoas Idosas e com Deficiência - AMPID.

O Decreto 5296, de 2 de dezembro de 2004, que "regulamenta as Leis nos 10.048, de 8 de novembro de 2000, que dá prioridade de atendimento às pessoas que 
especifica, e 10.098, de 19 de dezembro de 2000, que estabelece normas gerais e critérios básicos para a promoção da acessibilidade das pessoas portadoras de deficiência ou com mobilidade reduzida, e dá outras providências", no capítulo II, que determina o atendimento prioritário para pessoas com deficiência, enumera uma lista de definições que se assemelha à utilizada na minuta do estatuto da pessoa com deficiência, e que por sua vez, reproduz as definições categoriais, com listas de diagnósticos, do próprio Decreto 3298, apenas com alguns acréscimos, com o agravante de continuar a utilizar o termo "pessoa portadora de deficiência" ao invés de "pessoa com deficiência" num documento do final de 2004, quando muito já se havia discutido nos grupos de pessoas com deficiência sobre a inadequação do termo "portador". Apenas para observação, são reproduzidas as definições citadas: "I pessoa portadora de deficiência, além daquelas previstas na Lei n⿳0 10.690 , de 16 de junho de 2003, a que possui limitação ou incapacidade para o desempenho de atividade e se enquadra nas seguintes categorias: a) deficiência física: alteração completa ou parcial de um ou mais segmentos do corpo humano, acarretando o comprometimento da função física, apresentando-se sob a forma de paraplegia, paraparesia, monoplegia, monoparesia, tetraplegia, tetraparesia, triplegia, triparesia, hemiplegia, hemiparesia, ostomia, amputação ou ausência de membro, paralisia cerebral, nanismo, membros com deformidade congênita ou adquirida, exceto as deformidades estéticas e as que não produzam dificuldades para o desempenho de funções; b) deficiência auditiva: perda bilateral, parcial ou total, de quarenta e um decibéis $(\mathrm{dB})$ ou mais, aferida por audiograma nas frequiências de $500 \mathrm{~Hz}, 1.000 \mathrm{~Hz}$, $2.000 \mathrm{~Hz}$ e $3.000 \mathrm{~Hz}$; c) deficiência visual: cegueira, na qual a acuidade visual é igual ou menor que 0,05 no melhor olho, com a melhor correção óptica; a baixa visão, que 
significa acuidade visual entre 0,3 e 0,05 no melhor olho, com a melhor correção óptica; os casos nos quais a somatória da medida do campo visual em ambos os olhos for igual ou menor que $60^{\circ}$; ou a ocorrência simultânea de quaisquer das condições anteriores; d) deficiência mental: funcionamento intelectual significativamente inferior à média, com manifestação antes dos dezoito anos e limitações associadas a duas ou mais áreas de habilidades adaptativas, tais como: 1. comunicação; 2 . cuidado pessoal; 3. habilidades sociais; 4. utilização dos recursos da comunidade; 5. saúde e segurança; 6. habilidades acadêmicas; 7. lazer; e 8. trabalho; e) deficiência múltipla associação de duas ou mais deficiências; e II - pessoa com mobilidade reduzida, aquela que, não se enquadrando no conceito de pessoa portadora de deficiência, tenha, por qualquer motivo, dificuldade de movimentar-se, permanente ou temporariamente, gerando redução efetiva da mobilidade, flexibilidade, coordenação motora e percepção".

O Decreto 3.298, de 20 de dezembro de 1999, que "regulamenta a Lei no 7.853, de 24 de outubro de 1989, dispõe sobre a Política Nacional para a Integração da Pessoa Portadora de Deficiência, consolida as normas de proteção, e dá outras providências", no seu capítulo I, das Disposições Gerais, no seu artigo terceiro, apresenta as seguintes definições: "I - deficiência - toda perda ou anormalidade de uma estrutura ou função psicológica, fisiológica ou anatômica que gere incapacidade para o desempenho de atividade, dentro do padrão considerado normal para o ser humano; II - deficiência permanente - aquela que ocorreu ou se estabilizou durante um período de tempo suficiente para não permitir recuperação ou ter probabilidade de que se altere, apesar de novos tratamentos; e III - incapacidade - uma redução efetiva e acentuada da capacidade de integração social, com necessidade de 
equipamentos, adaptações, meios ou recursos especiais para que a pessoa portadora de deficiência possa receber ou transmitir informações necessárias ao seu bem-estar pessoal e ao desempenho de função ou atividade a ser exercida". No seu artigo quarto, as definições foram todas modificadas pelo Decreto 5296 acima citado.

É interessante observar que, além das inclusões de novas situações como as ostomias e o nanismo, foram mais bem especificadas as definições para as condições de deficiência auditiva e visual. A definição de deficiência auditiva contida no item II do artigo $4^{\text {o }}$ do decreto 3298 não fazia menção ao fato de ser a alteração auditiva uni ou bilateral, reproduzindo a escala de perdas usada por audiologistas, como "perda parcial ou total das possibilidades auditivas sonoras, variando de graus e níveis na forma seguinte; a) de 25 a 40 decibéis(dB)- surdez leve; b) de 41 a $55 \mathrm{~dB}$ surdez moderada; c) de 56 a $70 \mathrm{~dB}$ - surdez acentuada; d) de 71 a $90 \mathrm{~dB}$ - surdez severa; e) acima de $91 \mathrm{~dB}$ - surdez profunda; e f) anacusia”. Especialmente em relação às quotas para colocação profissional de pessoas com deficiência, muitas empresas passaram a contratar pessoas com deficiência auditiva leve ou unilateral, alegando ao Ministério Público do Trabalho estarem cumprindo a Lei, excluindo mais uma vez as pessoas com maior dificuldade que deveriam ser o alvo desta colocação especial. Com isto, a definição no decreto 5296 passou a ser "deficiência auditiva: perda bilateral, parcial ou total, de quarenta e um decibéis $(\mathrm{dB})$ ou mais, aferida por audiograma nas frequiências de $500 \mathrm{~Hz}, 1.000 \mathrm{~Hz}, 2.000 \mathrm{~Hz}$ e $3.000 \mathrm{~Hz}$ ”.

A situação descrita no parágrafo anterior é um exemplo que aponta para as idéias de coerência e relevância apresentadas no tópico sobre as definições da União Européia. Ao contratar pessoas com quadros leves, as empresas podiam estar 
coerentes com o texto da lei, mas não alcançavam a relevância do espírito desta mesma lei.

A Portaria do Ministério da Saúde n.1060, de 5 de junho de 2002, que estabelece a "Política Nacional de Saúde da Pessoa Portadora de deficiência", adota o conceito fixado pelo Decreto 3298 que considera "pessoa portadora de deficiência aquela que apresenta, em caráter permanente, perdas ou anormalidades de sua estrutura ou função psicológica, fisiológica ou anatômica, que gerem incapacidade para o desempenho de atividades dentro do padrão considerado normal para o ser humano". O documento salienta a evolução do conceito com o passar dos tempos, colocando como marco a década de 60 , em cujo período teve início o processo de formulação de um conceito de deficiência, no qual é refletida a estreita relação existente entre as limitações que experimentam as pessoas com deficiência, a concepção e a estrutura do meio ambiente e a atitude da população em geral com relação à questão. A Portaria 1060 também faz referência às definições da CIDID/ ICIDH, "deficiência" como toda perda ou anormalidade de uma estrutura ou função psicológica, fisiológica ou anatômica; "incapacidade" como toda restrição ou falta devida a uma deficiência - da capacidade de realizar uma atividade na forma ou na medida que se considera normal para um ser humano; e "desvantagem" como uma situação prejudicial para um determinado indivíduo, em conseqüência de uma deficiência ou uma incapacidade, que limita ou impede o desempenho de um papel que é normal em seu caso (em função da idade, sexo e fatores sociais e culturais). Mais adiante, está referida a ICIDH-2, que já concebe a deficiência como uma perda ou anormalidade de uma parte do corpo (estrutura) ou função corporal (fisiológica), incluindo as funções mentais. Há, no documento, uma nota sobre o termo 
incapacidade "não ser mais utilizado porque poderia ser tomado como uma desqualificação social”, que pode merecer questionamentos. Mais adiante, está definido que "em alguns países, como os Estados Unidos e o Canadá, são consideradas pessoas com incapacidades todas aquelas que têm alguma desvantagem e ou dificuldade de desempenho funcional, o que engloba a população de idosos e de portadores de doenças crônicas potencialmente incapacitantes. No Brasil, a cultura vigente e a definição legal consideram pessoas com deficiência aquelas pertencentes aos segmentos com deficiências mental, motora, sensorial e múltipla”. Também são mencionadas as doenças que, embora não estejam enquadradas nestas categorias de deficiência, produzem, direta ou indiretamente, graus de limitação variados e que seriam "as condutas típicas, os distúrbios comportamentais, os distúrbios da fala e da linguagem e os transtornos orgânicos". Na seqüência, observa-se que "a despeito de as doenças crônicas apresentarem uma alta probabilidade de gerarem incapacidades, não configuram objeto desta Política na sua prevenção primária, considerando que estão sendo contempladas em políticas específicas. No entanto, as doenças cardiovasculares, a hipertensão arterial, a insuficiência coronária, as doenças do aparelho respiratório (como o enfisema), as doenças metabólicas (como o diabetes mellitus e as nefropatias), as doenças hematológicas (a anemia falciforme, as hemoglobinopatias e as hemofilias), bem como o reumatismo e a hanseníase constituem campo de intervenção desta Política a partir de desvantagens e incapacidades delas decorrentes”. Há também uma nota sobre as pessoas com ostomias, que foram incluídas na lista de deficiências do decreto 5296, referindo que "representam um segmento que pode ser classificado como portador de deficiência, na medida em que houve uma doença prévia que deixou uma deficiência do sistema 
excretor, que produz limitações em várias esferas da vida, tanto social, quanto pessoal”.

A Lei 8742 de 07 de dezembro de 1993, chamada Lei Orgânica da Assistência Social (LOAS) estabelece, entre os objetivos da assistência social, no item V do seu artigo $2^{\circ}$, a garantia de um salário mínimo de benefício mensal, conhecido hoje como Benefício de Prestação Continuada - BPC, à pessoa com deficiência e ao idoso que comprovem não possuir meios de prover a própria manutenção ou de tê-la provida por sua família. Neste sistema, a pessoa com deficiência foi definida no Decreto 1744 de 8 de dezembro de 1995 como aquela incapacitada para a vida independente e para o trabalho, em razão de anomalias ou lesões irreversíveis de natureza hereditária, congênitas ou adquiridas, que impeçam o desempenho das atividades da vida diária e do trabalho. A Resolução do INSS 324 de 15 de dezembro de 1995, ao estabelecer normas e procedimentos para a operacionalização do BPC, acrescentou uma lista de diagnósticos para orientar os médicos peritos responsáveis pelas avaliações dos candidatos. Esta lista foi apresentada como "relação das situações em que a pessoa com deficiência terá o direito ao benefício desde que preenchidas as demais condições, não devendo, no entanto, os profissionais se restringirem somente ao discriminado a seguir: 1) Tetraplegia, Paraplegia e Hemiplegia; 2) Cegueira Total; 3) Surdez Total; 4) Distúrbio psicomotor de natureza grave e irreversível; 5) Deficiência/Doenças que impeçam o desempenho das atividades da vida e do trabalho e/ou exijam permanência contínua no leito; 6) Grande lesionado, com perda de membros, quando a prótese for impossível; 7) Deficiência Mental com grave perturbação da vida orgânica e social; 8) Alteração das faculdades mentais com grave perturbação da vida orgânica e social (Síndrome e quadros de origem 
neurológica e/ou psiquiátrica)”.

Estas definições e listas seguem fortemente o modelo médico de entendimento da deficiência, embora a concessão do BPC esteja também estritamente vinculada à condição sócio-econômica do indivíduo. O Ministério do Desenvolvimento Social e Combate à Fome, pela Portaria Interministerial $n^{\circ} 1$ de 15 de junho de 2005, criou um Grupo de Trabalho Interministerial, para a proposição de novos parâmetros e procedimentos de avaliação das pessoas com deficiência para acesso ao BPC. Este Grupo de Trabalho optou por elaborar novos instrumentos de avaliação com base no modelo da CIF e realizou estudo piloto com grupos de médicos peritos do INSS. As razões para tais mudanças no sistema de avaliação para concessão do BPC possivelmente sejam semelhantes às que levaram a União Européia a rever suas definições de deficiência, com especial foco sobre as políticas sociais para concessão de benefícios, como um campo para muitos litígios, em que o modelo médico não consegue alcançar toda a complexidade da questão. 


\subsection{Categorias da CID-10 usadas para definir deficiência}

Na cidade de São Paulo e no estado de São Paulo, em função das dificuldades de operacionalização do processo de concessão da gratuidade em transporte às pessoas com deficiência, foram estabelecidas listas de diagnósticos de condições de saúde potencialmente incapacitantes, acompanhadas dos respectivos códigos da CID-10, com a exigência de apresentação de atestado médico. Na cidade de São Paulo a gratuidade é determinada pela lei municipal $\mathrm{n}^{\circ} 11.250$ de $1^{\circ}$ de outubro de 1992 e regulamentada pela Portaria 140/93 - SMT.GAB. No Estado de São Paulo, em região metropolitana (atualmente em número de três: São Paulo, Baixada Santista e Campinas), a gratuidade para pessoas com deficiência é definida pela Lei Complementar no 666 de 1991 e regulamentada pelo Decreto Estadual 34.753 de 1992, normatizadas pelas Resoluções SS no 366 de 13 de junho de 1994 SES, SS no 53 de 22 de abril de 2002 e SS/STM n 2 de 23 de outubro de 2003 (AZEVEDO e col., 2005).

O grupo constituído de profissionais para discutir modos de operacionalização para a concessão deste tipo de benefício dispunha à época apenas da CID-10, com as restrições das características próprias da classificação para refletir a condição de deficiência, de modo que foram incluídas ressalvas quanto à funcionalidade em algumas categorias, como pode ser vista na lista reproduzida no anexo 2. O grupo de profissionais citado acima vem estudando a possibilidade de utilizar a CIF para definir de modo mais claro a elegibilidade para este benefício.

Embora possam ser feitas críticas ao uso da CID-10 neste sistema, pelo seu pouco alcance para as questões de funcionalidade ou graus de deficiência ou incapacidade, além da sua finalidade de uso mandatório para estatísticas de 
mortalidade e morbidade, o uso de seus códigos permitiu que fosse minimamente mapeada a concessão do benefício, pois este era concedido sem nenhuma condição de auditagem, sem critérios definidos. Foi possível perceber situações de concessão provavelmente indevida ou mesmo picos de uso indiscriminado de diagnósticos de determinadas patologias de difícil comprovação, como por exemplo, a Esquizofrenia (código F20 pela CID-10) que teria sua prevalência estimada pela OMS em torno de $5 \%$ no mundo, mas representa entre $35 \%$ a $40 \%$ dos laudos médicos analisados para concessão do benefício da gratuidade no transporte metropolitano no estado de São Paulo(AZEVEDO e col., 2005). 


\subsection{Categorias da CIF e da CID-10 relacionadas a deficiência ou incapacidade}

Razões para elegibilidade podem ser classificadas como fenômenos dimensionais desenhados na CIF. Um estudo sobre elegibilidade para Programas de Intervenção Precoce nos EUA utiliza um sistema de classificação com descritores para condições de saúde, atraso no desenvolvimento e fatores associados com estado de risco, baseado na CID-10 e CIF (SIMEONSSON e col., 2001).

O uso comum da CIF e da CID formou a base para o sistema de classificação que envolveu quatro categorias maiores (I-IV) sob as quais foram colocadas 28 subcategorias (A-BB). As quatro categorias maiores para a escolha de códigos da CIF ou da CID aplicáveis a (I) alterações de estrutura ou função corporal; (II) limitações da atividade ou do desempenho; (III) condições de saúde; e (IV) fatores ambientais. O uso deste sistema de classificação de códigos descritores da elegibilidade da criança e a distribuição das razões para elegibilidade na amostra. A utilidade desta abordagem para classificar as razões para elegibilidade em intervenção precoce foi examinada através de uma análise da lista de amostra de 5668 crianças no "National Early Intervention Longitudinal Study - NEILS'. Como um estudo longitudinal, o NEILS acompanha crianças e famílias a partir do momento da sua primeira entrada na intervenção precoce até pelo menos o jardim de infância. Os algoritmos de Codificação e a Lista Numérica de Termos Codificados utilizados neste estudo podem ser observados no anexo3 (SIMEONSSON e col., 2001).

O uso dos códigos da CID-10 e da CIF para documentar o status de saúde e incapacidade de uma dada criança pode recorrer a informação derivada de um número de fontes, incluindo avaliação direta, entrevista com cuidadores, bem como revisão de registros. O valor da documentação conjunta usando a CID-10 e a CIF é 
que a informação etiológica de morbidade é registrada em conjunto com a informação funcional de relevância potencial para o planejamento de intervenção. Morbidade e incapacidade costumam ser confundidas, podendo ser melhor diferenciadas com esta abordagem. Além de documentar a natureza dinâmica em constante modificação da funcionalidade em diferentes idades de uma criança, o uso conjunto da CID-10 e da CIF pode também gerar perfis funcionais de crianças com condições diagnosticadas semelhantes ou diferentes. O uso combinado da CID-10 e da CIF oferece o compromisso de uma linguagem comum para documentar a natureza e distribuição da incapacidade em crianças em sistemas de serviços de intervenção precoce ou outros serviços mais gerais para crianças (SIMEONSSON e col., 2006).

$\mathrm{Na}$ CIF, é sugerida uma lista mínima para sistemas ou pesquisas de informações de saúde ideais e mínimos, que podem ser pontos de partida para a exploração de categorias da CIF para definições de deficiência ou incapacidade.

Quadro 3 - * Itens candidatos para uma lista mínima para sistemas ou pesquisas de informações de saúde ideais e mínimos

\begin{tabular}{|l|l|l|l|}
\hline Dor $*$ & Cap. 2 & b280 & Dor \\
\hline Afeto $*$ & Cap.1 & b152-b180 & Funções mentais específicas \\
\hline Cognição * & Cap.1 & b140, b144, b164 & $\begin{array}{l}\text { Atenção, memória e funções } \\
\text { cognitivas de nível superior }\end{array}$ \\
\hline Mobilidade * & Cap.4 & b450-b465 & Andar e deslocar-se \\
\hline Cuidado Pessoal * & Cap.5 & b510-b570 & Cuidado pessoal \\
\hline Atividades usuais * & $\begin{array}{l}\text { Cap.6 } \\
\text { e } 8\end{array}$ & & $\begin{array}{l}\text { Vida doméstica: Principais áreas } \\
\text { da vida }\end{array}$ \\
\hline
\end{tabular}

Fonte: CIF, 2003.

Um exemplo do "Guia Australiano do Usuário da CIF" (ICF Australian User

Guide) (2002), é apresentado abaixo, de três maneiras, evidenciando as diferentes dimensões alcançadas ao codificar de acordo com o entendimento da CID-10 para mortalidade e morbidade, ou com a CIF para incapacidade e funcionalidade. 
a) O Sr. M.B. sofreu atropelamento por automóvel na via pública e fícou tetraplégico, em razão de uma lesão cervical grave, vindo a falecer.

Para a elaboração de estatísticas de mortalidade, interessa a circunstância da morte que precisa ser prevenida, e não a lesão o que ocorreu com o corpo. Deste modo o código selecionado da CID-10 seria o da causa básica da morte V03.1 ("pedestre traumatizado em colisão com um automóvel, como acidente de trânsito")

\section{Morte por atropelamento \\ Tetraplegia \\ Lesão Cervical Grave}

Figura 2 - Representação de Causa de Morte

a) O Sr. M.B. sofreu atropelamento por automóvel na via pública e ficou $\underline{\text { tetraplégico, }}$ em razão de uma lesão cervical grave, sendo internado em hospital para tratamento.

Para a elaboração de estatísticas de morbidade, o foco de interesse é deslocado para as lesões que vão requerer tratamento hospitalar específico e outros recursos. Nesta situação, o código a ser selecionado da CID-10 passa ser o das lesões, como razão para internação ou cuidados de saúde S12.9 ("fratura do pescoço") e G82.5 ("tetraplegia").

Lesão Cervical Grave
Tetraplegia

Figura 3 - Representação de Causas para internação ou cuidados de saúde b) O Sr. M.B. é tetraplégico como resultado de uma lesão cervical grave. Ele não tem força suficiente para realizar os movimentos básicos necessários para dirigir um carro comum. Entretanto, com seu veículo adaptado ele consegue dirigir de modo seguro. Infelizmente, uma lei em seu país o proíbe de dirigir veículos. 
Para avaliar questões de funcionalidade e incapacidade, há um outro deslocamento de foco para as situações relevantes vividas pelo indivíduo, com os facilitadores ambientais que melhoram a funcionalidade ou barreiras que causam incapacidade. Nesta situação, os códigos da CID-10 que correspondem à condição de saúde não se modificam, mas são apontados pelo menos mais cinco códigos da CIF, com os respectivos qualificadores, para descrever a situação de incapacidade produzida por uma barreira ambiental, o que é compatível com a maior complexidade do que se está querendo descrever ( b730.3 - deficiência grave de função corporal força, s120.3 - deficiência grave de estrutura corporal medula, d475.0 - nenhuma dificuldade para dirigir um carro adaptado codificado como facilitador completo e120+4, exceto pela barreira completa representada pela lei e540.4).

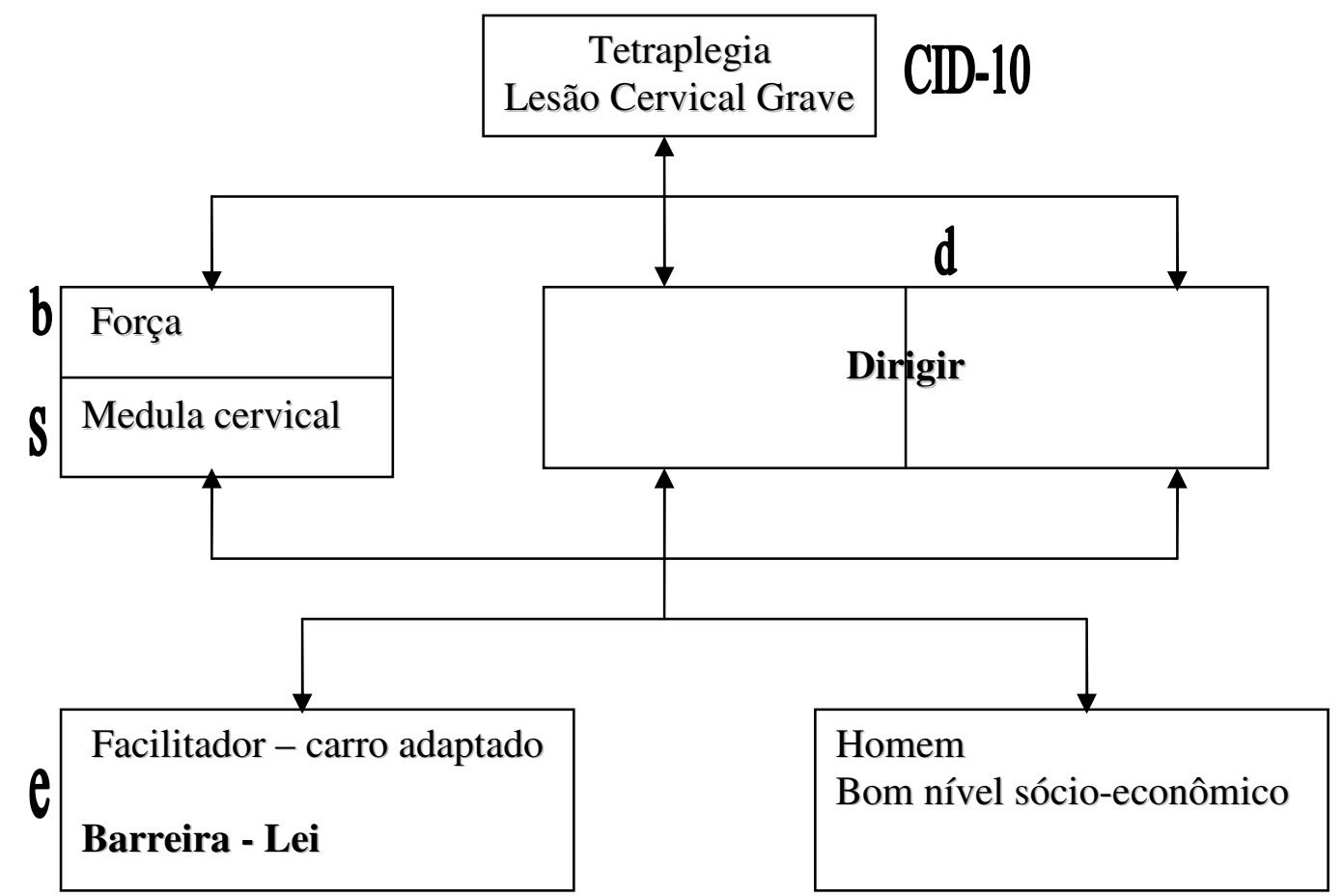

Figura 4 - Representação de situação de Incapacidade no modelo da CIF 


\section{Considerações finais}

A utilização da CIF pode contribuir de forma positiva para o estabelecimento de políticas públicas voltadas para as pessoas com deficiência ou incapacidade. O novo modelo trazido pela CIF, ao ser utilizado, pode fornecer informações que ajudem a estabelecer políticas de saúde, a promover a igualdade de oportunidades para todos e a apoiar a luta contra a discriminação das pessoas com deficiência ou incapacidade.

As questões de tradução ao português da CIF merecem um comentário em relação ao uso do termo "pessoa com deficiência" historicamente para traduzir "person with disability", como forma de permitir uma reflexão sobre a possibilidade de vir a modificar o uso das palavras, para conseguir um entendimento e uma comunicação mais uniforme entre as pessoas interessadas nesta área, buscando alcançar as vantagens de sua terminologia padronizada.

A dificuldade com o tema das definições de deficiência ou incapacidade ocorre no mundo todo, o que bem se manifesta pelo modo como se mostrou problemático o estabelecimento de uma definição de consenso para a primeira convenção de direitos humanos do século XXI, a Convenção Internacional dos Direitos das Pessoas com Deficiência da ONU.

No Brasil, algumas leis já contêm elementos de definição da CIDID/ICIDH, mas ainda pouco se avançou para a incorporação da CIF. Algumas discussões ainda são pautadas sobre definições da CIDID/ICIDH, com o uso do seu modelo linear negativo e da idéia de "handicap" ou "desvantagem". Isto possivelmente se deve ao fato de o modelo experimental da CIDID/ICIDH ter vigorado por muitos anos antes de ser revisado resultando na CIF, sendo o modelo da CIF ainda pouco conhecido e 
entendido. Isto aponta para a necessidade de que seja apresentado aos profissionais, grupos de pessoas com deficiência, ativistas de direitos, enfim a quantos grupos mais possam se tornar interlocutores e agentes multiplicadores com especial senso crítico, para fazer avançar no caminho de políticas mais justas e mais claras para pessoas com deficiência ou incapacidade.

Neste sentido é importante ressaltar o papel da instituições acadêmicas na difusão deste modelo, acolhendo progressivamente trabalhos sobre a CIF, apresentando a nova classificação na formação de profissionais e na pesquisa. Agências fomentadoras de pesquisa também têm apoiado projetos envolvendo formação e divulgação da CIF.

A CID-10 e a CIF são classificações amplas, que podem descrever qualquer estado de saúde ou de funcionalidade. Na realidade, a CID-10 faz parte do modelo da CIF, estando colocada no primeiro módulo da figura que representa o seu modelo dinâmico, no lugar reservado às condições ou estados de saúde, que incluem os distúrbios ou doenças. Os profissionais envolvidos com as questões de deficiência ou incapacidade devem compreender a natureza complementar das duas classificações. Acostumados a trabalhar apenas com a CID-10, estes podem queixar-se da complexidade da CIF. No entanto, é preciso aceitar esta complexidade, assim como é complexa a condição de qualquer indivíduo que enfrenta uma situação de incapacidade em algum momento de sua vida, ou como são complexas as intervenções, a produção de doença, a vida moderna, enfim. Não há como continuar avaliando estas situações apenas com o olhar do modelo médico, biológico, estritamente focado no corpo, quando a CIF se apresenta como uma ferramenta mais adequada e abrangente. A CIF é uma classificação do século XXI, tendo a vantagem 
de dispor de todos os recursos e avanços em termos de informática, o que permite trabalhar eficazmente com um grande volume de dados.

Para o futuro, há a proposta de desenvolvimento e aplicação da CIF para identificar algoritmos que pudessem determinar direitos para benefícios e pensões, sendo necessário um melhor entendimento das definições de deficiência ou incapacidade para as questões de elegibilidade. Definições e limites desenhados a partir da CIF para esta finalidade possivelmente devem conter elementos de deficiência (no nível do corpo) associados com incapacidade (aspecto negativo de interação entre a condição de saúde e fatores contextuais) para cobrir a questão de coerência, com qualificadores de gravidade para cobrir a questão de relevância.

No entanto, deve-se lembrar dos aspectos éticos expostos na própria CIF, alertando que todas as informações derivadas do seu uso não sejam empregadas para negar direitos estabelecidos ou restringir direitos legítimos a benefícios para indivíduos ou grupos, assim como as leis e regulamentações resultantes não pressuponham mais homogeneidade do que o desejado, garantindo que aqueles cujos níveis de funcionalidade estejam sendo classificados sejam considerados como indivíduos.

É importante que o poder público e os formuladores de políticas participem da discussão quanto a ter definições e avaliações mais claras e talvez mais justas da deficiência ou incapacidade.

A CIF é de propriedade de todos os seus usuários. A sociedade interessada, em especial as pessoas com deficiência, as organizações sociais e os formuladores de políticas, devem apropriar-se do conhecimento sobre os usos potenciais da CID- 
10 e da CIF. Por meio do uso destas classificações como instrumentos, as reais condições de vida das pessoas com deficiência poderão vir a fazer parte das estatísticas, permitindo guiar ações e decisões, delinear políticas, definir intervenções e destinar orçamentos, entre outras. 


\section{Referências}

- Amiralian MLT, Pinto EB, Ghirardi MIG, Lichtig I, Massini EFS, Pasqualin L. Conceituando deficiência. Rev Saúde Pública. 2000; 34(1): 97-103

- Andrade JMP. Projeto de Lei 06/2003 - Do Estatuto da Pessoa com Deficiência: Algumas Contribuições para uma Necessária Discussão Continuada. Infoativo Defnet No 2440 - Ano 10 - 29 de março de 2006. Em: www.defnet.org.br, acessado em 03 de setembro de 2006.

- Associação Fluminense de Reabilitação / CORDE. Relatório sobre a prevalência de deficiências, incapacidades e desvantagens. Sistematização dos estudos realizados em 21 cidades brasileiras, com metodologia de Entrevistas Domiciliares da Organização Pan-americana de Saúde - OPS, 2004. Em: www.mj.gov.br/sedh/ct/corde/dpdh/sicorde/Rel_Pesquisa.pdf. Acessado em 2 de agosto de 2005.

- Atalla R. Convenção Internacional dos Direitos das Pessoas com Deficiência é concluída com a participação histórica da sociedade civil. Em: http://bengalalegal.com/onu.php . Acessado em: 27 de janeiro de 2007.

- Aulete C. Dicionário Contemporâneo da Língua Portuguesa. 2 ed., Rio de Janeiro: Delta; 1964.

- Azevedo E, Chiesa R, Barbosa MB, Nosow E. Gratuidade nos transportes Tese do grupo de Trabalho de acessibilidade da Comissão Metroferroviária da ANTP. Revista dos Transportes públicos - ANTP. 2005; 107/108: 109-118.

- Barron BA. Disability Certifications in Adult Workers: A Practical Approach. American Family Physician. 2001; 64(9): 1579-86. 
- Battistella LR, Brito CMM. Classificação Internacional de Funcionalidade (CIF) International Classification of Functioning Disability and Health (ICF). Acta Fisiatrica. 2002; 9: 98-101.

- Bickenbach JE. Functional Status and Health Information in Canada: Proposals and Prospects. Health Care Financing Review. 2003; 24: 89102.

- Brasil. Decreto 1744 de 8 de dezembro de 1995. "Regulamenta o benefício de prestação continuada devido à pessoa com deficiência e ao idoso, de que trata a Lei 8742 de 7 de dezembro de 1993, e dáoutras providências".

- $\quad$ Brasil. Decreto ${ }^{\circ}$ 3298, de 20 de dezembro de 1999. "Regulamenta a Lei $\mathrm{n}^{\circ} 7853$, de 24 de outubro de 1989, dispõe sobre a Política Nacional para a Integração da Pessoa Portadora de deficiência, consolida as normas de proteção, e dá outras providências".

- Brasil. Instrução Normativa SRF n. 367, de 12 de novembro de 2003. "Disciplina a aquisição de automóveis com isenção do Imposto sobre Produtos Industrializados (IPI) por pessoas portadoras de deficiência física, visual, mental severa ou profunda, ou autistas".

- Brasil. Lei 874, de 7 de dezembro de 1993. Dispõe sobre a Lei Orgânica da Assistência Social.

- Brasil. Portaria Interministerial no 1 , de 15 de junho de 2005 do Ministério do Desenvolvimento Social e Combate à Fome e do Ministério da Previdência Social. "Cria um Grupo de Trabalho Interministerial, com vistas à proposição de novos parâmetros e procedimentos de avaliação das pessoas 
com deficiência para acesso ao Benefício de Prestação Continuada BPC".

- Brasil. Portaria Ministério da Saúde n 1060, de 05 de junho 2002 - Política Nacional de Saúde da Pessoa Portadora de Deficiência.

- Brasil. Proposta de Estatuto da Pessoa com Deficiência em Consulta Pública ao Projeto de Lei do Senado Federal n 429 de 2003.

- Brunel University, UK. Definitions of Disability in Europe: A Comparative Analysis - Final Report . September 2002. Em: http://ec.europa.eu/employment_social/publications/2004/cev502004_en.p df . Acessado em: 21 de novembro de 2003.

- Casado D. Conceptos sobre la Discapacidad. Boletín del Real Patronato sobre Discapacidad. 2001; 50:5-13.

- Censo Demográfico 2000, IBGE. Brasil, População residente, por tipo de deficiência, segundo as regiões metropolitanas.

- Chaterji S, Üstun B, Bickenbach JE. What is disability after all? Disability and Rehabilitation. 1999; 21: 396-8.

- Cwikel J. Different strokes for different folks: is one standard of disability possible? Disability and Rehabilitation. 1999; 21:379-381.

- Egea C., Sarabia A. Classificaciones de la OMS sobre Discapacidad. Boletín del Real Patronato sobre discapacidad. 2001; 50:14-30.

- Estado de São Paulo. Lei Complementar Estadual $n^{\circ}$ 666, de 26 de novembro de 1991 “Autoriza o Poder Executivo a conceder a isenção de tarifas do transporte coletivo regular às pessoas portadoras de deficiência”. 
- Estado de São Paulo. Resolução Conjunta SS/STM n ${ }^{\circ}$, de 21 de agosto de 2003 ”Disciplina as medidas administrativas e operacionais referentes à isenção do pagamento de tarifas de transporte coletivo regular de âmbito metropolitano, sob responsabilidade do Estado, concedida às pessoas portadoras de deficiência".

- $\quad$ Estado de São Paulo. Resolução Conjunta SS/STM n², de 30 de outubro de 2003 ”Disciplina as medidas administrativas e operacionais referentes à isenção do pagamento de tarifas de transporte coletivo regular de âmbito metropolitano, sob responsabilidade do Estado, concedida às pessoas portadoras de deficiência”.

- Federal Statutory Definitions of Disability. Prepared for the Interagency Committeee on Disability Research, by CESSI, Virginia, Julho, 2003. Em: http://www.icdr.us/documents/definitions.htm , acessado em $10 \mathrm{de}$ fevereiro de 2004.

- FUNLAR - Secretaria de Desenvolvimento Social do município do Rio de Janeiro / Fundação Osvaldo Cruz. Perfil das Pessoas Portadoras de Deficiência da cidade do Rio de Janeiro. Rio de Janeiro; 2002.

- Garrad J, Bennett AE. A validated Interview Schedule for use in Population Surveys of Chronic Disease and Disability. Br J Prev Soc Med. 1971; 25 : 97-104.

- Harris MR, Ruggieri AP, Chute CG. From Clinical Records to Regulatory Reporting: Formal Terminologies as Foundation. Health Care Financing Review. 2003; 24: 103-120.

- Houaiss A. Dicionário Eletrônico Houaiss da Língua Portuguesa, 2002. 
- ICF Australian User Guide. Australian Institute of Health and Welfare, Meeting of Heads of WHO Collaborating Centres for the Classification of Diseases. Brisbane, Australia: October, 2002.

- International Classification of Functioning, Disability and Health Home Page http: //www3.who.int/icf/icftemplate.cfm

- Joslyn E. Disability and health care expenditure data: a wide range of user experience is more important than standard definitions of disability. Disability and Rehabilitation. 1999; 21: 382-384.

- Kaplan D. The Definition of Disability. The Center for an Accessible Society - World Institute on Disability. Em:

http://www.accessiblesociety.org/topics/demographicsidentity/dkaplanpaper.htm, acessado em 10 de fevereiro de 2004.

- Laurenti R. Análise da informação em saúde: 1893-1993, cem anos da Classificação Internacional de Doenças. Rev. Saúde Públ. 1991; 25: 40717.

- Lollar DJ. Public Health and Disability: Emerging Opportunities. Public Health Reports. 2002; 117: 131-6.

- Marin B. Transforming Disability Welfare Policy. Completing a Paradigm Shift. In "European Disability Pension Policies. Eleven Country Trends 1970-2002” Prinz, C. (ed.). Vienna: Ashgate; 2003.

- McDougall J, Miller L. Measuring chronic health condition and disability as distinct concepts in national surveys of school-aged children in Canada: a comprehensive review with recommendations based on the ICD-10 and ICF. Disability and Rehabilitation. 2003; 25: 922-939. 
- McDowell I, Newell C. Measuring Health: A Guide to Rating Scales and Questionnaires. 2 ed. New York (NY): Oxford University Press, 1996.

- Mulcahy F. Position Paper on Definition of Disability. Disabled People's International. Em http://www.dpi.org/en/resources/pdfs/03-04-08definiton_dis.pdf, acessado em 17 de outubro de 2006.

- Município de São Paulo. Lei n 11250, de 01 de outubro de 1992 "Dispõe sobre a isenção de tarifa no sistema de transporte coletivo do Município aos deficientes físicos e mentais, e dá outras providências”.

- Nallin A. Reabilitação em Instituição: suas razões procedimentos. Análise de Representação do Discurso. Coordenadoria Nacional para Integração da Pessoa Portadora de Deficiência - CORDE. Brasília; 1994.

- Organização Mundial da Saúde. CIF: Classificação Internacional de Funcionalidade, Incapacidade e Saúde / Centro Colaborador da Organização Mundial da Saúde para a Família de Classificações Internacionais. São Paulo: EDUSP - Editora da Universidade de São Paulo; 2003.

- Organização Mundial da Saúde. Classificação Estatística Internacional de Doenças e Problemas Relacionados à Saúde / CID-10 Décima revisão. Tradução do Centro Colaborador da OMS para a Classificação de Doenças em Português. 3 ed. São Paulo: EDUSP - Editora da Universidade de São Paulo; 1996.

- Organização Mundial da Saúde. Classificação Internacional das Deficiências, Incapacidades e Desvantagens (handicaps).Um Manual de Classificaçàao das Conseqüências das Doenças. Tradução de International Classification 
of Impairments, Disabilities, and Handicaps. A Manual of Classification Relating of the Consequences of Disease (Geneva,1980). Lisboa, 1989.

- Organización Panamericana de la Salud. Oficina Sanitária Panamericana, Oficina Regional de la Organizacion Mundial de La Salud . Determinacion de Prevalencia de Discapacidades. Manual de Encuestas Domiciliarias, 1990.

- Paula, A.R. Asilamento de Pessoas com Deficiência - Institucionalização da Incapacidade Social.. [Tese de Doutorado]. São Paulo: Instituto de Psicologia da Universidade de São Paulo; 2000.

- Portugal. I Plano de Acção para a Integração das Pessoas com Deficiências ou Incapacidade para os anos de 2006 a 2009 - Resolução do Conselho de Ministros $n^{\circ}$ 120/ 2006, de 21 de setembro. Em http://www.lerparaver.com/book/export/html/536, acessado em $16 \mathrm{de}$ outubro de 2006.

- Rocha EF. Do corpo orgânico ao corpo relacional: uma proposta de deslocamento dos fundamentos e práticas de reabilitação da deficiência. [Tese de Doutorado]. São Paulo: Instituto de Psicologia da Universidade de São Paulo; 1999.

- Rocha EF. Atenção à Saúde da Pessoa com Deficiência no Programa de Saúde da Família no Município de São Paulo - Parceria com a Fundação Zerbini: 2000 a 2006. Cap. 3 Experiências em Reabilitação: Discutindo a Organização de Serviços e os Modelos Assistenciais, em Reabilitação de Pessoas com Deficiência - A Intervenção em Discussão. São Paulo: Roca; 2006. 
- Sassaki RK. Inclusão. Construindo uma sociedade para todos 7 ed. Rio de Janeiro: WVA Editora; 2006

- Silva OM. A Epopéia ignorada: a pessoa deficiente na história do mundo de ontem e de hoje. São Paulo: CEDAS- Centro São Camilo de Desenvolvimento em Administração da Saúde; 1987

- Simeonsson R J, Scarborough AA, Hebbeler KM, Brown S. Using the ICD10 and ICF to code dimensions of health and disability in young children. WHO Collaborating Center for the Family of International Classifications for North America. Meeting of Heads of WHO Collaborating Centres for the Family of International Classifications - Bethesda, October - 2001 [mimeo] [WHO/GPE/CAS/C/01.87].

- Simeonsson R J, Scarborough AA, Hebbeler KM. ICF and ICD codes provide a standard language of disability in young children. Journal of Clinical Epidemiology. 2006; 59: 365-373.

- Stepper S, Sutton J, Beaty P, DeJong G. Alternative definitions of disability: relationship to health-care expenditures. Disability and rehabilitation. 1997; 19: 556-8.

- United Nations. Draft Convention on the Rights of Persons with Disabilities. Ad Hoc Committee on a Comprehensive and Integral Convention on the Protection and Promotion of the Rights and Dignity of Persons with Disabilities. $8^{\text {th }}$ Session, New York, 14-25 August 2006. Disponível em: http://www.un.org/esa/socdev/enable/rights/ahc8adart.htm\#art1. Acessado em: 23 de janeiro de 2007. 
- Urdang L. The American Century Thesaurus. New York (NY): Warner Books Inc.; 1997.

- Üstun T B, Chaterji S, Kostansjek N, Bickenbach J. WHO's ICF and Functional Status Information in Health Records. Health Care Financing Review. 2003, 24: 77- 88.

- Üstun T B. The International Classification of Functioning, Disability and Health - A common framework for describing Health States. In "Summary Measures of Population Health - Concepts, Ethics, Measurement and Applications" Murray CJL, Solomon JA, Mathers CD and Lopez AD eds. Chapter 7.3, p. 344-348. Geneva: WHO; 2002.

- Verbrugge LM, Jette AM. The disablement process. Soc Sci Med. 1994; 38: $1-14$.

- Watson N. Well, I Know this is Going to Sound Very Strange to You, but I Don't See Myself as a Disabled Person: Identity and disability (abstract). Disability \&Society. 2002; 17: 509-527

- World Health Organization - Family Development Committee. Implications for the ICD of the ICF. Meeting of Heads of WHO Collaborating Centres for the Family of International Classifications - Bethesda, October - 2001 [mimeo] [WHO/GPE/CAS/C/01.55]. 


\section{Anexos}

\section{Anexo 1 - DEFINIÇÕeS ESTATUTÁRIAS FEDERAIS AMERICANAS DE DEFICIÊNCIA OU INCAPACIDADE (DISABILITY)}

\section{I) RELACIONADAS A DIREITOS CIVIS}

\section{Lei para Moradia Apoiada (Fair Housing Act) -}

(h) Desvantagem ("Handicap") significa, com respeito a uma pessoa -

h.1- uma deficiência (impairment) física ou mental que limita substancialmente uma ou mais atividades maiores da vida de tal pessoa,

h.2- um registro de ter algo como uma deficiência (impairment), ou

h.3- ser visto como tendo algo como uma deficiência (impairment), mas tal termo não inclui o uso ilegal corrente ou adição a uma substância controlada (como definido na seção 802 do título 21).

\section{Lei para Serviço Doméstico Voluntário de 1973 (Domestic Volunteer Service Act)}

(2) Definição

Como usado no parágrafo (1), o termo "indivíduo qualificado com uma deficiência ou incapacidade - disability" tem o significado dado para o termo na seção 12111(8) deste título.

\section{Lei de Assistência às Deficiências - Incapacidades do Desenvolvimento e Conjunto de Direitos (Developmental Disabilities Assistance and Bill of Rights Act)}

Deficiência ou Incapacidade do desenvolvimento (Developmental disability)

O termo "deficiência ou incapacidade do desenvolvimento" ("developmental disability”) significa uma deficiência ou incapacidade grave, crônica em um indivíduo com 5 anos de idade ou mais que -

(A) é atribuível a uma deficiência física ou mental ou combinação de deficiências mental e física;

(B) é manifestada antes de o indivíduo atingir a idade de 22 anos;

(C) é provável que continue indefinidamente;

(D) resulta em limitações funcionais substanciais em três ou mais das seguintes áreas maiores de atividade da vida -

- (i) auto-cuidados;

- (ii) linguagem receptiva e expressiva;

- (iii) aprendizagem; 
- (iv) mobilidade;

- (v) auto-determinação;

- (vi) capacidade para vida independente; e

- (vii) auto-suficiência econômica; e

(E) reflete a necessidade do indivíduo de uma combinação e seqüência de serviços especiais, interdisciplinares, ou genéricos, apoios, ou outra assistência, que é de duração por toda a vida ou de duração prolongada, e é individualmente planejada e coordenada, exceto que tal termo, quando aplicado a lactentes e crianças pequenas significa indivíduos do nascimento até a idade de 5 anos, inclusive, que tenham atraso substancial do desenvolvimento ou afecções específicas congênitas ou adquiridas com uma elevada probabilidade de resultar em deficiências incapacidades do desenvolvimento se não forem oferecidos tais serviços.

\section{Lei dos Americanos com Deficiência ou Incapacidade de 1990 (Americans with Disabilities Act of 1990)}

- (2) O termo "deficiência ou incapacidade" - "disability" significa, com respeito a um indivíduo-

(A) uma deficiência física ou mental que limita substancialmente uma ou mais das atividades maiores da vida de tal indivíduo;

(B) um registro de algo como uma deficiência; ou

(C) ser considerado como tendo algo como uma deficiência.

- (8) Indivíduo qualificado com uma deficiência ou incapacidade ("disability”)

O termo "indivíduo qualificado com uma deficiência ou incapacidade - disability" significa um indivíduo com uma deficiência ou incapacidade - disability o qual, com ou sem acomodação razoável, pode realizar as funções essenciais da posição de emprego que tal indivíduo tem ou deseja. Para os propósitos deste sub-capítulo, consideração deve ser dada ao julgamento do empregador de que funções de um emprego são essenciais, e se um empregador tem preparada uma descrição escrita antes de anunciar ou entrevistar candidatos para o emprego, esta descrição deve ser considerada evidência das funções essenciais do emprego. 42 U.S.C. §12111(8) Título I, Emprego

- (2) Indivíduo qualificado com uma deficiência ou incapacidade - disability

O termo "indivíduo qualificado com uma deficiência ou incapacidade - disability" significa um indivíduo com uma deficiência ou incapacidade - disability o qual, com ou sem modificações razoáveis das regras, políticas ou práticas, a remoção de barreiras arquitetônicas, de comunicação ou de transporte, ou o provimento de ajudas e serviços auxiliares, preenche os requisitos essenciais de elegibilidade para o recebimento de serviços ou a participação em programas ou atividades oferecidas por uma entidade pública. Título II, Serviços Públicos 
- Para os propósitos deste capítulo, o termo deficiente ou incapacitado - "disabled" ou deficiência ou incapacidade - "disability" não deve ser aplicado a um indivíduo somente porque aquele indivíduo é um travestido.

(a) Homossexualidade e bissexualidade

Para os propósitos da definição de defici6encia ou incapacidade- "disability" na seção 12102(2) deste título, homossexualidade e bissexualidade não são deficiências (impairments) e assim sendo não são deficiências/incapacidades disabilities sob este capítulo.

(b) Certas condições

Sob este capítulo, o termo "deficiência ou incapacidade"- "disability" não deve incluir -

(1) travestismo, transsexualismo, pedofilia, exibicionismo, voyeurismo, distúrbios de identidade de gênero não resultante de alterações físicas (from physical impairments), ou outros distúrbios do comportamento sexual;

(2) jogo compulsivo, cleptomania, ou piromania; ou

(3) distúrbios pelo uso de substâncias psicoativas resultante do uso ilegal corrente de drogas.

\section{Lei de Acesso em Transporte Aéreo de 1986 (Air Carrier Access Act of 1986)}

Discriminação contra indivíduos deficientes (handicapped)

- Ao fornecer transporte aéreo, uma empresa de transporte aéreo não pode discriminar contra um diferente indivíduo qualificado nas seguintes bases:

(1) o indivíduo tem uma deficiência (impairment) física ou mental que limita substancialmente uma ou mais atividades maiores da vida.

(2) o indivíduo tem um registro de algo tal como uma deficiência (of such an impairment).

(3) o indivíduo é considerado como tento algo tal como uma deficiência (such an impairment). 49 U.S.C. $\$ 41705$

\section{II) RELACIONADAS A EDUCAÇÃO}

\section{Lei de Educação Superior (Higher Education Act)}

(3) Deficiência ou Incapacidade (Disability)

O termo "deficiência ou incapacidade" - "disability" tem o mesmo significado dado ao termo sob a seção 12102(2) do título 42.

\section{Empréstimos Federais Perkins (Federal Perkins loans).}

(c) Lactentes, pré-escolares, crianças e jovens com deficiência ou incapacidade (infants, toddlers, children, and youth with disabilities) 
- Para os propósitos desta parte, o termo "lactentes, pré-escolares, crianças e jovens com deficiência ou incapacidade" ("infants, toddlers, children, and youth with disabilities") significa crianças com deficiência ou incapacidade (children with disabilities) e lactentes e pré-escolares com deficiência ou incapacidade (infants and toddlers with disabilities) como definido nas seções 1401(a)(1) e 1472(1)* deste título.

*A seção 1472 deste título era uma referência para a seção 672 da Lei de Educação para indivíduos com deficiência ou incapacidade (Individuals with Disabilities Education Act). A seção 1472 não mais define "lactentes e pré-escolares com deficiência ou incapacidade" ("infants and toddlers with disabilities").

\section{Lei de Provisões para Educação geral (General Education Provisions Act)}

(1) Deficiência ou Incapacidade - Disability

O termo deficiência ou incapacidade - "disability" tem o mesmo significado dado a tal termo pela seção 12102(2) do título 42.

\section{Lei para a Educação de Indivíduos com Deficiências ou Incapacidades (Individuals with Disabilities Education Act) (IDEA)}

(3) Criança com uma deficiência ou incapacidade (Child with a disability)

- (A) Em geral. O termo "criança com uma deficiência ou incapacidade"- "child with a disability" significa uma criança -

(i) com retardamento mental, deficiências (impairments) da audição (incluindo surdez), deficiências (impairments) da fala ou da linguagem, deficiências (impairments) visuais (incluindo cegueira), distúrbio emocional sério (daqui por diante referido como um "distúrbio emocional" - "emotional disturbance"), deficiências (impairments) ortopédicas, autismo, lesão cerebral traumática, outras deficiências (impairments) de saúde, ou deficiências ou incapacidades específicas da aprendizagem (specific learning disabilities); e

(ii) aquela que, em razão disto, necessita educação especial e serviços relacionados.

- (B) Criança com idade de 3 a 9 anos. O termo "criança com uma deficiência ou incapacidade" - "child with a disability" para uma criança com idade de 3 a 9 anos pode, no arbítrio do Estado e da agência educacional local, incluir uma criança -

(i) que experimenta atrasos no desenvolvimento, como definido pelo Estado e como medido por instrumentos e procedimentos diagnósticos apropriados, em uma ou mais das seguintes áreas: desenvolvimento físico, desenvolvimento cognitivo, desenvolvimento da comunicação, desenvolvimento social ou emocional, ou adaptativo; e

(ii) aquela que, por tais razões, necessita educação especial e serviços relacionados.

(5) Lactente ou pré-escolar com uma deficiência ou incapacidade (Infant or toddler with a disability) 
O termo "lactente ou pré-escolar com uma deficiência ou incapacidade" ("infant or toddler with a disability") -

- (A) significa um indivíduo abaixo de 3 anos de idade que necessita serviços de intervenção precoce porque o indivíduo -

(i) está apresentando atrasos no desenvolvimento, tal como é mensurado por procedimentos e instrumentos diagnósticos apropriados, em uma ou mais áreas do desenvolvimento cognitivo, desenvolvimento físico, desenvolvimento da comunicação, desenvolvimento social ou emocional e adaptativo; ou

(ii) teve uma afecção física ou mental diagnosticada que tem uma elevada probabilidade de resultar em retardo no desenvolvimento; e

- (B) pode também incluir, ao arbítrio do Estado, lactentes e pré-escolares de risco.

10. Lei de Educação Técnica Aplicada e Vocacional de Carl D. Perkins de 1998 (Carl D. Perkins Vocational and Applied Technical Education Act of 1998)

(14) Indivíduo com uma deficiência ou incapacidade -disability

- (A) Em geral

O termo "indivíduo com uma deficiência ou incapacidade" - "individual with a disability" significa um indivíduo com qualquer deficiência ou incapacidade disability (como definido na seção 12102 do título 42).

11. Lei de Educação de Adultos e Alfabetização da família (Adult Education and Family Literacy Act)

(9) Indivíduo com uma deficiência ou incapacidade - disability

Em geral. O termo "indivíduo com uma deficiência ou incapacidade"-"individual with a disability" significa um indivíduo com qualquer deficiência ou incapacidade disability (como definido na seção 12102 do título 42).

12. Lei Nacional do Almoço ou Merenda Escolar (Richard B. Russell National School Lunch Act)

(8) Deficiência ou incapacidade - Disability -

O termo "deficiência ou incapacidade" - "disability" tem o significado dado ao termo na Lei de Reabilitação de 1973 para os propósitos do título II daquela Lei (29 U.S.C 760 et seq.).

\section{Lei da Nutrição Infantil de 1966 (Child Nutrition Act of 1966)}

(7) Deficiência ou incapacidade - Disability-

O termo "deficiência ou incapacidade" - "disability" tem o significado dado ao termo na Lei de Reabilitação de 1973 para os propósitos do título II daquela Lei (29 U.S.C 760 et seq.).

\section{Head Start Act}


Para os propósitos deste sub-capítulo:

(1) O termo "criança com uma deficiência ou incapacidade" - "child with a disability" significa -

- (A) uma criança com uma deficiência ou incapacidade - disability, como definido na seção 1401(3) do título 20; e

- (B) e um lactente ou pré-escolar com uma deficiência ou incapacidade - disability, como definido na seção 1432(5) do título 20.

\section{III) RELACIONADAS AO EMPREGO}

15. Emprego de assistentes pessoais para empregados deficientes (Employment of personal assistants for handicapped employees)

(2) "empregado deficiente" - "handicapped employee" significa um indivíduo empregado por uma agência que é cego ou surdo ou aquele que se qualifica como um indivíduo deficiente (handicapped) dentro do significado da seção 501 da lei de Reabilitação de 1973.

\section{Lei da Reabilitação de 1973 (Rehabilitation Act of 1973)}

(9) Deficiência ou Incapacidade - Disability

O termo "deficiência ou incapacidade" - "disability” significa -

- (A) exceto como em outra parte apresentado no subparágrafo (B), uma deficiência ou incapacidade física ou mental que constitui ou resulta em um impedimento substancial para o emprego; ou

- (B) para os propósitos das seções 701, 711, e 712 deste título, e subcapítulos II, IV, $\mathrm{V}$, e VII deste capítulo, uma deficiência física ou mental que limita substancialmente uma ou mais atividades maiores da vida.

(20) Indivíduo com uma deficiência ou incapacidade - disability

\section{- (A) Em geral}

Exceto como apresentado em outro lugar no subparágrafo (B), o termo "indivíduo com uma deficiência ou incapacidade" - "individual with a disability" significa qualquer indivíduo que

- (i) tenha uma deficiência física ou mental que para tal indivíduo constitua ou resulte em um impedimento substancial para o emprego; e

- (ii) pode se beneficiar em termos de um emprego como resultado de serviços de reabilitação vocacional oferecidos de acordo com os subcapítulos I, III, ou VI deste capítulo.

- (B) Certos programas; limitações em atividades maiores da vida 
Sujeito aos subparágrafos (C), (D), (E), e (F), o termo "indivíduo com uma deficiência ou incapacidade" - "individual with a disability" significa, para os propósitos das seções 701, 711, e 712 deste título, e subcapítulos II, IV, V, e VII deste capítulo, qualquer pessoa que -

- (i) tem uma deficiência física ou mental que limita substancialmente uma ou mais atividades maiores da vida de tal pessoa;

- (ii) tem um registro de algo como uma deficiência (such an impairment); ou

- (iii) é considerada como tendo algo como uma deficiência (such an impairment).

- (C) Cláusulas de Direitos e Advocacia (Rights and advocacy provisions)

- (i) Em geral; exclusão de indivíduos envolvidos em uso de drogas

Para os propósitos do subcapítulo V deste capítulo, o termo "indivíduo com uma deficiência ou incapacidade" - "individual with a disability" não inclui um indivíduo que está atualmente envolvido no uso ilegal de drogas, quando uma entidade coberta age na base de tal uso.

- (ii) Exceção para os indivíduos não mais envolvidos no uso de drogas

Nada na cláusula (i) deve ser construído para excluir da definição como um indivíduo com uma deficiência ou incapacidade (individual with a disability) um indivíduo que

(I) tenha completado com sucesso um programa supervisionado de reabilitação do uso de drogas que não está mais envolvido no uso ilegal de drogas, ou tenha de qualquer outro modo sido reabilitado com sucesso e não esteja mais envolvido em tal uso;

(II) está participando de um programa supervisionado de reabilitação e não está mais envolvido em tal uso; ou

(III) é considerado erroneamente como envolvido em tal uso, mas não está envolvido em tal uso; exceto que não deva ser uma violação deste capítulo para uma entidade coberta para adotar ou administrar políticas ou procedimentos razoáveis, que incluem, mas não se limitam à testagem para drogas, designadas para assegurar que um indivíduo descrito na subcláusula (I) ou (II) não está mais envolvido no uso ilegal de drogas.

- (iii) Exclusão para certos serviços

Não obstante a cláusula (i), para os propósitos de programas e atividades que prestam serviços de saúde e serviços oferecidos sob os subcapítulos I, II, e III deste capítulo, um indivíduo não deve ser excluído dos benefícios de tais programas ou atividades com base no seu atual uso ilegal de drogas se o indivíduo está de outro modo denominado para tais serviços

- (iv) Ação disciplinar 
Para os propósitos de programas e atividades que prestam serviços educacionais, agências educacionais locais podem tomar ações disciplinares pertinentes ao uso ou posse de drogas ilegais ou álcool contra qualquer estudante que seja um indivíduo com uma deficiência ou incapacidade (disability) e que esteja atualmente envolvido no uso ilegal de drogas ou no uso de álcool para a mesma extensão de tal ação disciplinar que for tomada contra estudantes que não sejam indivíduos com deficiências ou incapacidades (disabilities). Além disso, os devido procedimentos de processo na seção 104.36 do título 34, Código de Regulações Federais (ou qualquer regulação ou regramento correspondente ou similar) não devem se aplicar para tais ações disciplinares.

- (v) Emprego; exclusão de alcoolistas

Para os propósitos das seções 793 e 794 deste título como tais seções relacionam-se a emprego, o termo "indivíduo com uma deficiência ou incapacidade" - "with a disability" não inclui nenhum indivíduo que seja um alcoolista cujo uso corrente de álcool impeça tal indivíduo de realizar as obrigações emprego em questão ou cujo emprego, em razão de tal abuso de álcool corrente, constituiria uma direta ameaça à propriedade ou à segurança de outros.

(D) Emprego; exclusão de indivíduos com certas doenças ou infecções

Para os propósitos das seções 793 e 794 deste título, uma vez que estas seções se relacionam a emprego, tal termo não inclui um indivíduo que tenha uma doença contagiosa ou infecção correntemente e que, em razão de tal doença ou infecção, constituiria uma ameaça direta à saúde ou segurança de outros indivíduos ou que, em razão da sua infecção ou doença contagiosa atual, é incapaz de realizar as obrigações do seu emprego ou trabalho.

(E) Cláusulas de Direitos; exclusão de indivíduos com base em homossexualidade ou bissexualidade

Para os propósitos das seções 791, 793, e 794 deste título -

- (i) para propósitos da aplicação do subparágrafo (B) a tais seções, o termo "deficiência" - "impairment" não inclui homossexualidade ou bissexualidade; e

- (ii) por essa razão o termo "indivíduo com uma deficiência ou incapacidade" "individual with a disability" não inclui um indivíduo com base em homossexualidade ou bissexualidade.

(F) Cláusulas de Direitos; exclusão de indivíduos com base em certos distúrbios

Para os propósitos das seções 791, 793, e 794 deste título, o termo "indivíduo com uma deficiência ou incapacidade" - "individual with a disability" não inclui um indivíduo com base em -

- (i) travestismo, transsexualismo, pedofilia, exibicionismo, voyeurismo, transtornos de identidade de gênero não resultante de deficiências - impairments físicas, ou outros distúrbios do comportamento sexual; 
- (ii) jogo compulsivo, cleptomania, ou piromania; ou

- (iii) distúrbios pelo uso de substância psicoativa resultante do uso corrente ilegal de drogas.

(21) Indivíduo com uma deficiência ou incapacidade - disability significante

(A) Em geral

Exceto como apresentado no subparágrafo (B) ou (C), o termo "indivíduo com uma deficiência ou incapacidade significante" - "individual with a significant disability" significa um indivíduo com uma deficiência ou incapacidade - disability :

- (i) que tenha uma deficiência - impairment grave física ou mental que limita seriamente uma ou mais capacidades funcionais (tais como mobilidade, comunicação, auto-cuidados, auto-determinação, habilidades interpessoais, tolerância ao trabalho, ou habilidades para o trabalho) em termos de um desempenho no emprego;

- (ii) aquele cuja reabilitação vocacional pode ser esperada como requerendo múltiplos serviços de reabilitação vocacional ao longo de um período extenso de tempo; e

- (iii) aquele que tem uma tenha uma ou mais deficiências/incapacidades - disabilities física ou mental resultante de amputação, artrite, autismo, cegueira, lesão por queimadura, câncer, paralisia cerebral, fibrose cística, surdez, lesão encefálica, doença cardíaca, hemiplegia, hemofilia, disfunção respiratória ou pulmonar, retardamento mental, doença mental, esclerose múltipla, distrofia muscular, distúrbios músculo-esqueléticos, distúrbios neurológicos (incluindo acidentes vasculares encefálicos e epilepsia), paraplegia, quadriplegia, e outras afecções da medula espinhal, anemia falciforme, deficiência ou incapacidade - disability específica da aprendizagem, doença renal em estágio final, ou uma outra deficiência ou incapacidade - disability ou combinação de deficiências ou incapacidades disabilities determinada com base em uma avaliação para determinar a elegibilidade e necessidades de reabilitação vocacional descrita nos subparágrafos (A) e (B) do parágrafo (2) para causar comparável e substancial limitação funcional.

(B) Serviços para Vida Independente e Centros para Vida Independente

Para os propósitos do subcapítulo VII deste capítulo, o termo "indivíduo com uma deficiência ou incapacidade significante" - "individual with a significant disability" significa um indivíduo com uma grave deficiência - impairment física ou mental cuja capacidade para funcionar independentemente na família ou comunidade ou cuja capacidade para obter, manter ou progredir no emprego está substancialmente limitada e para quem a oferta de serviços para a vida independente melhorará a capacidade para funcionar, continuar funcionando ou progredir adiante funcionando independentemente na família ou comunidade ou para continuar no emprego, respectivamente.

(C) Pesquisa e treinamento 
Para os propósitos do subcapítulo II deste capítulo, o termo "indivíduo com uma deficiência ou incapacidade significante"- "significant disability" inclui um indivíduo descrito no subparágrafo (A) ou (B).

(E) Indivíduo com uma deficiência ou incapacidade mais significante "Individual with a most significant disability”

- (i) Em geral

O termo "indivíduo com uma deficiência ou incapacidade mais significante" "individual with a most significant disability", usado com respeito a um indivíduo em um Estado, significa um indivíduo com uma significante deficiência ou incapacidade - disability que preenche critérios estabelecidos pelo Estado sob a seção 721(a)(5)(C) deste título.

\section{Lei do Centro Nacional Helen Keller (Helen Keller National Center Act)}

(2) o termo "indivíduo que é surdo-cego" - "individual who is deaf-blind" significa qualquer indivíduo -

\section{(A)}

- (i) que tem acuidade visual central de 20/200 ou menos no melhor olho com lentes corretivas, ou um defeito de campo tal que o diâmetro periférico do campo visual subtende uma distância angular não maior que 20 graus, ou uma perda visual progressiva tendo um prognóstico que leva a uma ou ambas as condições;

- (ii) aquele que tem uma deficiência - impairment (alteração) crônica da audição tão grave que a maior parte de sua fala não pode ser compreendida com uma amplificação máxima, ou uma perda auditiva progressiva tendo um prognóstico que leva a esta condição; e

- (iii) para quem a combinação de deficiências - impairments descritas nas cláusulas (i) e (ii) causa extrema dificuldade para alcançar independência em atividades da vida diária, adquirir ajustamento psicossocial, ou obter uma vocação;

(B) aquele que a despeito da impossibilidade de ser avaliado acuradamente pela sua perda de audição e visão devido a problemas cognitivos ou comportamentais, ou ambos, pode ser determinado através de avaliação funcional e de desempenho como tendo graves deficiências ou incapacidades auditivas e visuais que causam extrema dificuldade para alcançar independência em atividades da vida diária, adquirir ajustamento psicossocial, ou obter objetivos vocacionais; ou

(C) aquele que preenche outros requisitos tais como a Secretaria pode prescrever por regulação;

\section{Sistemas de Investimento em Força de Trabalho (Workforce Investment Systems)}

(17) Indivíduo com uma deficiência ou incapacidade (Individual with a disability)

(A) Em geral 
O termo "indivíduo com uma deficiência ou incapacidade" - (disability) significa um indivíduo com qualquer deficiência ou incapacidade - disability (como definido na seção 12102 do título 42).

\section{Lei da Compensação dos Trabalhadores da Estiva e do Porto (Longshore and Harbor Workers' Compensation Act)}

(10) "Deficiência ou Incapacidade" - "Disability" significa incapacidade devido a uma lesão para receber os salários que o empregado estava recebendo à época da lesão no mesmo ou em qualquer outro emprego; mas tal termo deve significar deficiência - impairment permanente, determinada (para a extensão coberta deste modo) sob os manuais para a avaliação de deficiência - impairment permanente promulgados e modificados de tempos em tempos pela Associação Médica Americana (American Medical Association), no caso de um indivíduo cujo objeto de reivindicação está descrito na seção $910(d)(2)$ deste título.

\section{Lei do Dia de Javits-Wagner-O (Javits-Wagner-O'Day Act)}

(2) Os termos "outros gravemente deficientes ou prejudicados" - "other severely handicapped" ou "indivíduos gravemente deficientes ou prejudicados" - "severely handicapped individuals" significam um indivíduo ou classe de indivíduos sob uma deficiência/incapacidade física ou mental, diferentes da cegueira, as quais (de acordo com critérios estabelecidos pelo Comitê após consulta com entidades apropriadas do Governo e levar em conta como visões de entidades não-governamentais representando o deficiente - handicapped) constitui uma desvantagem (handicap) substancial para emprego e é de uma tal natureza que impede o indivíduo sob tal deficiência ou incapacidade - disability de correntemente engajar-se em emprego normal competitivo.

\section{Programa de Ingresso ao Trabalho e Auto-suficiência (Ticket to Work and Self- Sufficiency Program)}

(2) Beneficiário deficiente ou incapacitado (Disabled beneficiary)

O termo "beneficiário deficiente" - "disabled beneficiary" significa um título II beneficiário por deficiência ou incapacidade (disability beneficiary) ou um título XVI beneficiário por deficiência ou incapacidade (disability beneficiary).

(3) Título II beneficiário por deficiência ou incapacidade (disability beneficiary)

O termo "título II beneficiário por deficiência ou incapacidade (disability beneficiary)" significa um indivíduo intitulado para benefícios de seguro por deficiência/incapacidade - disability sob a seção 423 deste título ou benefícios mensais de seguro sob a seção 402 deste título com base em tal deficiência/incapacidade do indivíduo- "individual's disability” (como definido na seção 423(d) deste título). Um indivíduo está em um título II beneficiário por deficiência ou incapacidade (disability beneficiary) para cada mês para o qual tal indivíduo estiver intitulado para tais benefícios.

(4) Título XVI beneficiário por deficiência ou incapacidade (disability beneficiary) 
O termo "título XVI beneficiário por deficiência ou incapacidade (disability beneficiary)" significa um indivíduo elegível para o recebimento de benefícios para seguridade suplementar sob o subcapítulo XVI deste capítulo na base de cegueira (dentro do significado da seção 1382c(a)(2) deste título) ou deficiência/incapacidade disability (dentro do significado da seção 1382c(a)(3) deste título). Um indivíduo está em um título XVI beneficiário por deficiência ou incapacidade (disability beneficiary) para cada mês para o qual tal indivíduo for elegível para tais benefícios.

22. Programa de Extensão de Incentivos ao Trabalho da Seguridade Social (Social Security Work Incentives Outreach Program)

(2) Beneficiário deficiente ou incapacitado (Disabled beneficiary)

O termo "beneficiário deficiente ou incapacitado"-"disabled beneficiary" tem o significado dado àquele termo na seção 1320b-19(k)(2) deste título.

23. Subvenções do Estado Para Incentivos de Assistência ao Trabalho Para Beneficiários Deficientes (Work Incentives Assistance To Disabled Beneficiaries)

(2) Beneficiário deficiente ou incapacitado (Disabled beneficiary)

O termo "beneficiário deficiente ou incapacitado" - "disabled beneficiary" tem o significado dado ao termo na seção 1320b-19(k)(2) deste título.

\section{IV) RELACIONADAS A MORADIA}

\section{Lei de Assistência a Moradia e Auto-Determinação para Americanos Nativos de 1996 (Native American Housing Assistance and Self-Determination Act of 1996)}

(17) Pessoa com deficiências/incapacidades (Person with disabilities)

O termo "pessoa com deficências/incapacidades" - "person with disabilities" significa uma pessoa que -

(A) tem uma deficiência ou incapacidade - disability como definido na seção 423 do título 42;

(B) é determinada, conforme regulações emitidas pelo Secretário, como tendo uma deficiência - impairment física, mental ou emocional que

- (i) é esperado que seja de duração indefinida ou de longa duração e;

- (ii) impeça substancialmente a sua capacidade para viver independentemente; e

- (iii) seja de tal natureza que aquela capacidade poderia ser melhorada por condições de moradia mais adequadas; ou

(C) tenha um deficiência ou incapacidade do desenvolvimento - developmental disability como definido na seção 15002 do título 42.

Tal termo não deve excluir pessoas que têm a doença da síndrome da imunodeficiência adquirida ou quaisquer condições que se originam do agente etiológico da síndrome de imunodeficiência adquirida. Não obstante qualquer outra 
provisão da lei, nenhum indivíduo deve ser considerado uma pessoa com deficiência ou incapacidade (person with disabilities), para propósitos de elegibilidade para moradia assistida sob este capítulo, somente com base em qualquer dependência de drogas ou álcool. O Secretário deve consultar-se com outras agências Federais apropriadas para implementar a sentença precedente.

\section{Lei de Moradia dos Estados Unidos de 1937 (United States Housing Act of 1937)}

(E) Pessoa com deficiência ou incapacidade (Person with disabilities). -

O termo "pessoas com deficiência ou incapacidade" - "person with disabilities" significa uma pessoa que -

- (i) tem uma deficiência/incapacidade - disability como definido na seção 423 deste título,

- (ii) está determinada, de acordo com as regulações publicadas pelo Secretário, por ter uma deficiência - impairment física, mental ou emocional que:

(I) é esperado que seja de longa duração ou duração ou duração indefinida,

(II) impede substantialmente a sua capacidade para viver independentemente, e

(III) é de uma natureza que tal capacidade poderia ser melhorada por condições de moradia adequadas, ou

- (iii) tem uma deficiência ou incapacidade do desenvolvimento (developmental disability) como definido na seção 6001 deste título.

Tal termo não deve excluir pessoas que têm a doença da síndrome de imunodeficiência adquirida ou quaisquer condições originadas do agente etiológico da síndrome da imunodeficiência adquirida. Não obstante qualquer outra provisão da lei, nenhum indivíduo deve ser considerado uma pessoa com deficiências/incapacidades - disabilities, para propósitos de eligibilidade para moradia por critério de baixa renda (low-income) sob este subcapítulo, somente com base na dependência de álcool ou qualquer droga. O Secretário deve consultar-se com outras agências Federais apropriadas para implementar a sentença precedente.

\section{Assistência Financeira para Moradia de Fazenda (Farm Housing Financial Assistance)}

(3) Para os propósitos deste subcapítulo, o termo "Pessoas deficientes ou idosas ou famílias" - "elderly or handicapped persons or families" significa famílias que consistem de duas ou mais pessoas, em que o chefe da mesma (ou o seu cônjuge) tem pelo menos sessenta e dois anos de idade ou é deficiente - handicapped. Tal termo também significa uma única pessoa que tem pelo menos sessenta e dois anos de idade ou é deficiente - handicapped. Uma pessoa deve ser considerada deficiente handicapped se tal pessoa está determinada, de acordo com as regulações publicadas pelo Secretário, por ter uma deficiência - impairment que

(A) é esperado que seja de longa duração e duração indefinida, 
(B) impede substancialmente a sua capacidade - ability para viver independentemente, $\mathrm{e}$

(C) é de natureza que tal capacidade - ability poderia ser melhorada por condições de moradia mais adequadas, o sei tal pessoa tem uma deficiência ou incapacidade do desenvolvimento (developmental disability) como definido na seção 6001(7)* deste título.

* A seção 6001(7) deste título foi subsequentemente alterada, e a seção 6001(7) não mais define o termo deficiência/incapacidade do desenvolvimento - "developmental disability”. Contudo, tal termo está definido em outra parte naquela seção.

\section{Lei de Serviços de Moradia Coletiva de 1978 (Congregate Housing Services Act of} 1978)

(5) o termo "deficiente" - "handicapped" significa ter uma deficiência - impairment que

(A) é esperado que seja de longa duração e duração indefinida, e

(B) impede substancialmente uma capacidade (ability) do indivíduo para viver independentemente a menos que o indivíduo receba serviços coletivos de apoio; tal deficiência - impairment pode incluir uma deficiência/incapacidade funcional (disability) ou fragilidade que seja uma consequiência normal do processo de envelhecimento humano;

\section{Serviços de Moradia Coletiva Revisados (Revised Congregate Housing Services)}

14) O termo "pessoa com deficiência ou incapacidade" - "person with disabilities" tem o significado dado ao termo pela seção 8013 deste título.

\section{Moradia Apoiada para Pessoas com Deficiências ou Incapacidades (Supportive Housing For Persons With Disabilities)}

(2) O termo "pessoa com deficiência ou incapacidade" - "person with disabilities" significa um grupo familiar composto de uma ou mais pessoas em que pelo menos uma delas é um adulto que tem uma deficiência ou incapacidade. Uma pessoa deve ser considerada como tendo uma deficiência/incapacidade - disability se tal pessoa está determinada, de acordo com as regulações publicadas pelo Secretário, por ter uma deficiência - impairment física, mental ou emocional que

(A) é esperado que seja de longa duração e de duração indefinida,

(B) impede substancialmente a sua capacidade para viver independentemente, e

(C) é de uma natureza que tal capacidade poderia ser melhorada por condições de moradia mais apropriadas. Uma pessoa deve também ser considerada como tendo uma deficiência/incapacidade - disability se tal pessoa tem uma deficiência ou incapacidade do desenvolvimento como definido na seção 6001(7)* deste título. O Secretário deve prescrever tais regulações, pois pode ser necessário para prevenir abusos na determinação, sob as definições contidas neste parágrafo, da eligibilidade de famílias e pessoas para admissão e ocupação de moradia assistida sob esta seção. 
Não obstante as provisões precedentes deste parágrafo, o termo "pessoa com deficiências/incapacidades" - "person with disabilities" inclui duas ou mais pessoas com deficiências/incapacidades - disabilities vivendo juntas, uma ou mais de tais pessoas vivendo com uma outra pessoa que é determinado (sob regulações prescritas pelo Secretário) ser importante para o seu cuidado ou bem estar, e o membro ou membros sobreviventes de qualquer grupo familiar descrito na primeira sentença deste parágrafo que estiverem vivendo ou morando, em uma unidade assistida sob esta seção, com o membro falecido da família no momento da sua morte.

* A Seção 6001(7) deste título foi subseqüentemente modificada, e a seção 6001(7) não mais define o termo "deficiência ou incapacidade do desenvolvimento "developmental disability”. Contudo, tal termo está definido em outro lugar naquela seção.

\section{Programa de Moradia Apoiada (Supportive Housing Program)}

(2) O termo "deficiência/incapacidade" - "disability" significa -

(A) uma deficiência/incapacidade - disability como definido na seção 423 deste título,

(B) ser determinada por ter, de acordo com regulações publicadas pelo Secretário, uma deficiência - impairment física, mental ou emocional que:

- (i) é esperado que seja de longa duração e duração indefinida,

- (ii) impede substancialmente a capacidade de um indivíduo para viver independentemente, $\mathrm{e}$

- (iii) de uma natureza que tal capacidade poderia ser melhorada por condições de moradia mais apropriadas,

(C) uma deficiência/incapacidade do desenvolvimento - developmental disability como definido na seção 6001 deste título, ou

(D) a doença da síndrome de imunodeficiência adquirida ou quaisquer condições originadas do agente etiológico da síndrome de imunodeficiência adquirida.

O subparágrafo (D) não deve ser interpretado para limitar a elegibilidade sob os subparágrafos $(\mathrm{A})$ até $(\mathrm{C})$ ou as provisões referidas nos subparágrafos $(\mathrm{A})$ até $(\mathrm{C})$.

\section{Programa Abrigo Mais Cuidado (Shelter Plus Care Program)}

(6) O termo "pessoa com deficiências/incapacidades"- "person with disabilities" tem o mesmo significado dado ao termo na seção 8013 deste título.

\section{V) RELACIONADAS AO CÓDIGO DE RENDA INTERNO}

32. Crédito para o idoso e para o permanentemente e totalmente deficiente (Credit for the elderly and the permanently and totally disabled)

(3) Deficiência/Incapacidade - disability permanente e total definida 
Um indivíduo é permanentemente e totalmente deficiente/incapacitado - disabled se ele é incapaz (unable) de se colocar em qualquer atividade substancial que lhe dê ganhos, em razão de qualquer deficiência (impairment) física ou mental medicamente determinável que pode ser esperado que resulte em morte ou que tenha terminado ou pode ser esperado que perdure por um período contínuo de não menos que 12 meses. Um indivíduo não deve ser considerado como sendo permanentemente e totalmente deficiente/incapacitado - disabled a menos que ele forneça prova da existência disto em tal forma e maneira, e em tais tempos, que o Secretário pode requerer.

33. Despesas para prover acesso a indivíduos deficientes (Expenditures to provide access to disabled individuals)

(1) O termo "deficiência/incapacidade" - "disability" tem o mesmo significado como quando usado na Lei dos Americanos com Deficiências /Incapacidades (Americans With Disabilities Act) de 1990 (como no efeito sobre a data da redação desta seção).

34. Anuidades; certos procedimentos de contratos de seguro de vida e dotação (Annuities; certain proceeds of endowment and life insurance contracts)

(7) Significado de deficiente / disabled

Para os propósitos desta seção, um indivíduo deve ser considerado como sendo deficiente / disabled se ele é incapaz (unable) de se engajar em qualquer atividade substancial que lhe dê ganho, em razão de qualquer deficiência - impairment física ou mental medicamente determinável que pode ser esperada que resulte na morte ou que seja de duração longa ou indefinida. Um indivíduo não deve ser considerado como sendo deficiente - disabled a menos que forneça prova da existência desta em tal forma e maneira como o Secretário pode requerer.

\section{Isenção pessoal por deficiência /incapacidade permanete (Personal exemption for permanent and total disability)}

(C) Um indivíduo deve ser tratado como permanentemente e totalmente deficiente/incapaz - disabled para os propósitos deste parágrafo se tal indivíduo for tratado sob o parágrafo (3) da seção 22(e).

36. Gastos para remover barreiras de transportes e arquitetônicas para o deficiente e idosos (Expenditures to remove architectural and transportation barriers to the handicapped and elderly)

(3) Indivíduo deficiente - handicapped

O termo "indivíduo deficiente" - "handicapped individual" significa qualquer indivíduo que tem uma deficiência/incapacidade disability física ou mental (incluindo, mas não limitado a, cegueria ou surdez) que para tal indivíduo constitui ou resulta em uma limitação funcional para emprego, ou que tem qualquer deficiênciaimpairment física ou mental (incluindo, mas não limitado a, uma deficiênciaimpairment de visão ou audição) que limita substancialmente uma ou mais atividades maiores da vida de tal indivíduo. 
37. Regras especiais para descendentes deficientes e esposas sobreviventes, valor estimado ou fixo de propriedade imobiliária, taxa do estado (Special rules for retired or disabled decedents and surviving spouses, valuation or certain real property, estate tax)

(B) Um indivíduo deve ser deficiente-disabled se tal indivíduo tem uma deficiênciaimpairment mental ou física que o torna incapaz de participar materialmente na operação da fazenda ou outro tipo de negócio.

\section{VI) RELACIONADAS A SEGURIDADE SOCIAL}

\section{Seguro de Garantia Social por Deficiência/Incapacidade [Social Security Disability Insurance (SSDI)]}

Seções 201 \& 220-225 da Lei de Seguridade Social (Social Security Act)

(d) "Deficiência ou Incapacidade" - "Disability" definida

(1) O termo "deficiência ou incapacidade"- "disability" significa -

- (A) incapacidade de se envolver em qualquer atividade que possa lhe dar ganho substancial em razão de qualquer deficiência-impairment física ou mental medicamente determinável que seja esperado que resulte na morte ou que tenha durado ou que seja esperado que dure por um período contínuo de não menos que 12 meses; ou

- (B) no caso de um indivíduo que atingiu a idade de 55 anos e é cego (dentro do significado de "cegueira" como definido na seção 416(i)(1) deste título), incapacidade (inability) em razão de tal cegueira para se envolver em atividade que lhe proporcione ganho substancial e requirendo destreza ou habilidade comparáveis àquelas de qualquer atividade remunerada na qual ele tenha previamente se envolvido com alguma regularidade e durante um período de tempo substancial.

(2) Para os propósitos do parágrafo (1)(A) -

- (A) Um indivíduo deve ser determinado estar sob uma condição de deficiência/incapacidade (to be under a disability) somente se a sua deficiência ou deficiências (impairment or impairments) física ou mental forem de tal gravidade que ele não é somente incapaz (unable) para fazer o seu trabalho prévio, mas não pode, considerando sua idade, educação e experiência de trabalho, envolver-se em qualquer outro tipo de trabalho que lhe proporciona ganho substancial que exista na economia nacional, independentemente se tal trabalho existir na área imediata na qual ele vive, ou se uma vaga de emprego específico exista para ele, ou se ele seria admitido se ele se candidatasse ao trabalho. Para os propósitos da sentença precedente (com respeito a qualquer indivíduo), "trabalho que exista na economia nacional" ("work which exists in the national economy") significa trabalho que existe em números significantes seja na região onde tal indivíduo vive ou em várias regiões do país.

- (B) Ao determinar se uma deficiência ou deficiências (impairment or impairments) física ou mental de um indivíduo são de gravidade médica suficiente, de modo que tal deficiência ou deficiências (impairment or impairments) poderiam ser a base para a elegibilidade sob esta seção, o Comissário da Securidade Social deve considerar o efeito combinado de todas as deficiências-impairments do indivíduo, sem considerar 
se qualquer deficiência-impairment, se considerada separadamente, seria de tal gravidade. Se o Comissário da Securidade Social encontrar uma combinação de deficiências-impairments grave do ponto de vista médico, o impacto combinado das deficiências-impairments deve ser considerado ao longo do processo de determinação da incapacidade/deficiência-disability.

- (C) Um indivíduo não deve ser considerado como sendo deficiente-disabled para os propósitos deste subcapítulo se alcoolismo ou drogadição forem (para este subparágrafo) um fator contribuinte material para a determinação do Comissário de que o indivíduo é deficiente-disabled.

(3) Para os propósitos desta subseção, uma "deficiência física ou mental"- "physical or mental impairment" é uma deficiência - impairment que resulta de anormalidades anatômicas, fisiológicas ou psicológicas que são demonstráveis por técnicas diagnósticas clínicas e laboratoriais aceitáveis do ponto de vista médico.

39. Seguridade Social - definições adicionais (Social Security - additional definitions) Seção 216 da Lei de Seguridade Social (Social Security Act)

(1) Exceto para os propósitos das seções 402(d), 402(e), 402(f), 423, e 425 deste título, o termo "deficiência/incapacidade"- "disability" significa

- (A) incapacidade (inability) para se envolver em qualquer atividade remunerada substancial em razão de qualquer deficiência - impairment física ou mental medicamente determinável que pode ser esperado que resulte na morte ou tenha durado ou que se possa esperar que dure por um período contínuo de não menor que 12 meses, ou

- (B) cegueira; e o termo "cegueira" significa acuidade visual central de 20/200 ou menos no melhor olho com o uso de uma lente corretiva. Um olho que é acompanhado por uma limitação nos campos da visão tal que o mais amplo diâmetro do campo visual subtende um ângulo não maior que 20 graus deve ser considerado para os propósitos deste parágrafo como tendo uma acuidade visual central de 20/200 ou menos. As provisões de parágrafos (2)(A), (2)(B), (3), (4), (5), e (6) da seção 423(d) deste título devem ser aplicados para os propósitos de determinar se um indivíduo está sob uma incapacidade/deficiência (is under a disability) dentro do significado da primeira sentença deste parágrafo da mesma maneira como eles são aplicados para os propósitos do parágrafo (1) de tal seção. Nada neste subcapítulo deve ser construído como autorizando o Comissário da Securidade Social ou qualquer outro funcionário ou empregado dos Estados Unidos a interferir de qualquer maneira com a prética da medicina ou com os relacionamentos entre os médicos e seus pacientes, ou exerce qualquer supervisão ou controle sobre a administração ou operação de qualquer hospital.

\section{Aporte Suplementar da Seguridade [Supplemental Security Income (SSI)]}

Título XVI da lei de Seguridade Social (Social Security Act)

(a) (2) Um indivíduo deve ser considerado como sendo cego para os propósitos deste subcapítulo se ele tem acuidade visual central de 20/200 ou menos no melhor olho com o uso de lentes corretivas. Um olho que é acompanhado por uma limitação nos 
campos da visão tal que o diâmetro mais amplo do campo visual subtende um ângulo não maior que 20 graus deve ser considerado para os propósitos da primeira sentença desta subseção como tendo uma acuidade visual central de 20/200 ou menos. Um indivíduo deve também ser considerado como sendo cego para os propósitos deste subcapítulo se ele é cego como definido sob um plano do Estado aprovado sob o subcapítulo X ou XVI deste capítulo como em efeito para Outubro de 1972 e recebido ajuda sob tal plano (com base na cegueira) para Dezembro de 1973, por tanto tempo quanto ele tenha sido continumente cego como assim definido.

(3) (A) Exceto como apresentado no subparágrafo (C), um indivíduo deve ser considerado como sendo deficiente - disabled para os propósitos deste subcapítulo se ele for incapaz de se envolver em qualquer atividade que lhe proporcione ganho substancial em razão de qualquer deficiência - impairment física ou mental medicamente determinável que pode ser esperado que resulte em morte ou que tenha durado ou que seja esperado que dure por um período contínuo de não menos que doze meses.

(B) Para os propósitos do subparágrafo (A), um indivíduo deve ser determinado como estando sob uma condição de deficiência ou incapacidade (to be under a disability) somente se a sua deficiência ou deficiências (impairment or impairments) física ou mental são de tal gravidade que ele não é somente incapaz de fazer o seu trabalho prévio, mas não pode ou não consegue, considerando sua idade, educação e experiência profissional, envolver-se em qualquer outro tipo de trabalho com remuneração substancial que existe na economia nacional, independente se tal trabalho existe na área imediata na qual ele vive, ou se existe uma vaga específica de emprego para ele, ou se ele seria contratado se ele se candidatasse para o trabalho. Para os propósitos da sentença precedente (com respeito a qualquer indivíduo), "trabalho que existe na economia nacional" significa trabalho que existe em números significantes seja na região onde tal indivíduo vive ou em várias regiões do país.

(C) (i) Um indivíduo abaixo da idade de 18 anos deve ser considerado deficiente disabled para os propósitos deste subcapítulo se aquele indivíduo tem uma deficiência-impairment física ou mental medicamente determinável, que resulta em limitações funcionais significantes e graves, e que se pode esperar que resulte em morte ou que tenha durado ou possa ser esperado que dure por um período contínuo de não menos que 12 meses.

(ii) Não obstante a cláusula (i), nenhum indivíduo abaixo da idade de 18 anos que esteja envolvido em atividade substancial remunerada (determinada de acordo com regulações prescritas conforme o subparágrafo (E)) pode ser considerado como sendo deficiente-disabled.

(D) Para os propósitos deste parágrafo, uma deficiência - impairment física ou mental é uma deficiência - impairment que resulta de anormalidades anatômicas, fisiológicas ou psicológicas que são demonstráveis por técnicas diagnósticas clínicas e laboratoriais medicamente aceitáveis.

(E) O Comissário da Seguridade Social deve, pelas regulações, prescrever os critérios para determinar quando serviços realizados ou ganhos derivados destes serviços 
demonstram uma capacidade (ability) de um indivíduo de se envolver em atividade remunerada substancial.

(F) Não obstante as provisões dos subparágrafos (A) até (E), um indivíduo deve também ser considerado como sendo deficiente - disabled para os propósitos deste subcapítulo se ele é permanentemente e totalmente deficiente - disabled como definido sob um plano do Estado aprovado sob o subcapítulo XIV ou XVI deste capítulo como em efeito para Outubro de 1972 e recebeu ajuda soib tal plano (com base na incapacidade/deficiência - disability) para Dezembro de 1973 (e por pelo menos um mês antes de Julho de 1973), por quanto tempo quanto ele esteja continuamente deficiente - disabled como assim definido.

(G) Ao determinar se a deficiência ou deficiências - impairment or impairments física ou mental de um indivíduo são de uma gravidade médica suficiente que tal deficiência ou deficiências - impairment or impairments poderiam ser a base da eligibilidade sob esta seção, o Comissário da Securidade Social deve considerar o efeito combinado de todas deficiências-impairments do indivíduo sem considerar se alguma tal deficiência-impairment, se considerada separadamente, seria de tal gravidade. Se o Comissário da Seguridade Social encontra uma combinação de deficiências-impairments medicamente grave, o impacto combinado das deficiênciasimpairments deve ser considerado durante o processo de determinação da incapacidade-disability.

\section{VII) RELACIONADAS A SERVIÇOS SOCIAIS}

41. Cuidados à Saúde Indígena Projeto de Demonstração de Cuidados com base domiciliar e comunitária (Indian Health Care Home- And Community-Based Care Demonstration Project)

(2) O termo "funcionalmente deficiente"-"functionally disabled" significa um indivíduo que que está determinado para requerer serviços domiciliares e comunitários com base em uma avaliação que usa critérios (incluindo, na organização tribal ou no arbítrio da tribo, atividades da vida diária) desenvolvidos pela tribo ou organização tribal.

42. Cuidados Domiciliares e Comunitários para Indivíduos Idosos Funcionalmente Deficientes (Home And Community Care For Functionally Disabled Elderly Individuals)

(c) Determinações de incapacidade-disability funcional

(1) Em geral

Nesta seção, um indivíduo é "funcionalmente deficiente"-"functionally disabled" se o indivíduo -

(A) é incapaz (unable) de realizar sem assistência substancial de um outro indivíduo pelo menos 2 das 3 seguintes atividades da vida diária: toilete, transferência e alimentação; ou

(B) tem um diagnóstico primário ou secundário de doença de Alzheimer e é: 
- (i) incapaz (unable) para realizar sem assistência humana substancial (incluindo pistas físicas ou verbais) ou supervisão em pelo menos 2 das 5 seguintes atividades de vida diária: banho, vestuário, toilete, transferência e alimentação; ou

- (ii) cognitivamente deficiente-impaired de modo tal que requer supervisão substancial de um outro indivíduo porque ele ou ela se envolve em comportamentos inapropriados que representam sérios riscos à saúde ou segurança a si ou aos outros.

\section{Lei dos Americanos Idosos de 1965 (Older Americans Act of 1965)}

(8) O termo "incapacidade"- "disability" significa (exceto quando tal termo é usado na frase "deficiência/incapacidade grave"- "severe disability", "deficiências/incapacidades do desenvolvimento"- "developmental disabilities", "deficiência/incapacidade mental ou física"- "physical or mental disability", deficiências/incapacidades mental e física"- "physical and mental disabilities", ou "deficiências/incapacidades físicas"- "physical disabilities") uma deficiência/incapacidade-disability atribuível a deficiência-impairment mental ou física, ou uma combinação de deficiências-impairments mental e física, que resulta em limitações funcionais substanciais em 1 ou mais das seguintes áreas de atividades maiores da vida:
(A) auto-cuidados,
(B) linguagem receptiva e expressiva,
(C) aprendizagem,
(D) mobilidade,
(E) auto-determinação,
(F) capacidade para vida independente,
(G) auto-suficiência econômica,
(H) funcionamento cognitivo, e
(I) ajustamento emocional.

(9) O termo "deficiência/incapacidade grave"- "severe disability" significa uma deficiência/incapacidade-disability grave, crônica atribuível a deficiência-impairment mental ou física, ou uma combinação de deficiências-impairments mental e física, que -
(A) é provável que continue indefinidamente; e
(B) resulte em limitação funcional substancial em 3 ou mais das atividades maiores da vida especificadas nos subparágrafos $(\mathrm{A})$ até $(\mathrm{G})$ do parágrafo $(8)$.

44. Título IV da lei dos Americanos Idosos de 1965 (Title IV of the Older Americans Act of 1965). 
Programas de Demonstração para Indivíduos Idosos com Deficiências/Incapacidades do Desenvolvimento (Demonstration Programs For Older Individuals With Developmental Disabilities)

Como usado nesta seção:

(1) Deficiência/incapacidade do desenvolvimento-Developmental disability

O termo "deficiência/incapacidade do desenvolvimento"- "developmental disability" tem o significado dado ao termo na seção 6001(5)* deste título.

* Seção 6001(5) deste título, referido na subseção (a)(1), foi subseqüentemente emendada, e a seção 6001(5) não mais define o termo "deficiência/incapacidade do desenvolviemnto"-“developmental disability". Contudo, tal termo está definido em outro local naquela seção.

45. Título II da Lei de Tratamento e Prevenção ao Abuso Infantil (Title II of the Child Abuse Prevention and Treatment Act).

Recurso para a Família Baseado na Comunidade e Subvenções de Apoio (Community-Based Family Resource And Support Grants)

(1) Crianças com deficiências/incapacidades-disabilities

O termo "crianças com deficiências/incapacidades"- "children with disabilities" tem o mesmo significadodado a tal termo na seção 1401(a)(2) do título 20.

46. Lei do Estado para o desenvolvimento de Subvenções para o cuidado de dependentes (State Dependent Care Development Grants Act)

(3) o termo "deficiência/incapacidade do desenvolvimento"-"developmental disability” tem o mesmo significado como na seção 6001(7)* deste título;

*Seção 6001(7) deste título foi subseqüentemente emendada, e a seção 6001(7) não mais define o termo "deficiência/incapacidade do desenvolvimento"- "developmental disability”. Contudo, tal termo é definido em outra parte naquela seção.

\section{VII) RELACIONADAS A VETERANOS E FORÇAS ARMADAS}

\section{Empregados e Organização do Governo (Government organization and employees)}

(2) "veterano deficiente"- "disabled veteran" significa um indivíduo que serviu na ativa (on active duty) nas forças armadas, foi afastado desta sob condições honrosas, e foi estabelecida a atual existência de uma deficiência/incapacidade-disability ligada ao serviço ou está recebendo compensação, benefícios de aposentadoria por deficiência/incapacidade (disability retirement), ou pensão por um estatuto público administrado pelo Departamento de Assuntos de Veteranos (Department of Veterans Affairs) ou um departamento militar.

48. Compensação especial para alguns aposentados de serviços uniformizados gravemente deficientes/incapacitados (Special compensation for certain severely disabled uniformed services retirees) 
(d) Qualificação da Deficiência/Incapacidade definida como ligada ao serviço (Qualifying Service-Connected Disability Defined).

Nesta seção, o termo "qualificação de deficiência/incapacidade ligada ao serviço""qualifying service-connected disability" significa uma deficiência/incapacidade ligada ao serviço que -

(1) foi adquirida ou agravada no desempenho de tarefa como um membro de um serviço uniformizado, como determinado pelo Secretário interessado; e

(2) está avaliada como não menos que 70 por cento incapacitante -

- (A) pelo Secretário interessado como da data na qual o membro é aposentado dos serviços uniformizados; ou

- (B) pelo Secretário de Assuntos de Veteranos dentro de quatro anos seguindo a data na qual o membro é aposentado dos serviços uniformizados.

49. Tecnologia Assistiva, dispositivos de tecnologia assistiva e serviços de tecnologia assistiva (Assistive technology, assistive technology devices, and assistive technology services)

(b) Nesta seção, os termos "tecnologia assistiva", "dispositivo de tecnologia assistiva", "serviço de tecnologia assistiva", e "deficiência/incapacidade""disability" tem os significados dados àqueles termos na seção 3 da Lei de Tecnologia Assistiva de 1998 (Assistive Technology Act of 1998) (29 U.S.C. 3002).

50. Pensão por deficiência/incapacidade ou morte não ligada ao serviço ou por serviço (Pension for non-service-connected disability or death or for service)

Para os propósitos deste capítulo, uma pessoa deve ser considerada como sendo permanentemente e totalmente deficiente-disabled se tal pessoa é inempregável como um resultado da deficiência/incapacidade de modo razoavelmente certo de que continue ao longo da vida da pessoa deficiente-disabled, ou está sofrendo com:

(1) qualquer deficiência/incapacidade-disability que é suficiente para tornar impossível para a média das pessoas seguir uma ocupação substancialmente lucrativa (gainful occupation), mas somente se é razoavelmente certo que tal deficiência/incapacidade-disability continuará ao longo da vida da pessoa deficientedisabled; ou

(2) qualquer doença ou distúrbio determinado pelo Secretário como sendo de tal natureza ou extensão para justificar como determinação que pessoas sofrendo destas são total e permanentemente deficientes-disabled.

51.Cuidado médico, hospitalar, de enfermaria e domiciliares para veteranos (Hospital, nursing home, domiciliary, and medical care for veterans )

O termo "deficiência/incapacidade"-"disability" significa uma doença, lesão, ou outro defeito físico ou mental.

52. Assistência educacional a sobreviventes e dependentes (Survivors' and dependents' educational assistance) 
O termo "deficiência/incapacidade total em natureza"- "total disability permanent in nature" significa qualquer deficiência/incapacidade-disability avaliada como total para os propósitos de compensação por incapacidade (disability compensation) que é baseada em uma deficiência-impairment razoavelmente certa que continue ao longo da vida da pessoa deficiente-disabled.

\section{Lei de Empréstimo para Pequenos Negócios de Veteranos de 1981 (Veterans' Small Business Loan Act of 1981)}

O termo "veterano deficiente"-“disabled veteran" significa

(A) um veterano que tem direito a compensação sob leis administradas pelo Secretário por uma deficiência/incapacidade-disability avaliada como de 30 por cento ou mais, ou

(B) um veterano cuja dispensa ou liberação da ativa (active duty) foi por uma deficiência/incapacidade adquirida ou agravada na linha de ação (line of duty).

\section{Serviço de colocação, treinamento e aconselhamento para o Emprego para veteranos (Job counseling, training, and placement service for veterans)}

O termo "veterano deficiente especial"-"special disabled veteran" tem o mesmo significado oferecido na seção 4211(1) deste título.

O termo "veterano deficiente"-"disabled veteran" tem o mesmo significado oferecido na seção 4211(3) deste título.

\section{Emprego e Treinamento de veteranos (Employment and training of veterans)}

(1) O termo "veterano deficiente especial"- "special disabled veteran" significa -

(A) um veterano que tem o direito a compensação (ou aquele que tem o direito ao recebimento de pagamento por aposentadoria militar que teria direito a compensação) sob leis administradas pelo Secretário por uma deficiência/incapacidade-disability

- (i) avaliada como de 30 por cento ou mais, ou

- (ii) avaliada como de 10 ou 20 por cento no caso de um veterano que tenha sido determinado sob a seção 3106 deste título como tendo uma grave desvantagem/deficiência para o emprego (serious employment handicap); ou

(B) uma pessoa que foi dispensada ou liberada da ativa (active duty) por causa de uma deficiência/incapacidade-disability ligada ao serviço.

O termo "veterano deficiente"- "disabled veteran" significa

(A) um veterano que tem o direito a compensação (ou aquele que tem o direito ao recebimento de pagamento por aposentadoria militar teria direito a compensação who but for the receipt of military retired pay would be entitled to compensation) sob leis administradas pelo Secretário, ou

(B) uma pessoa que foi dispensada ou liberada da ativa (active duty) por causa de uma deficiência/incapacidade-disability ligada ao serviço. 


\section{IX) MISCELÂNEA}

\section{Lei do Selo Alimentar de 1977 (Food Stamp Act of 1977)}

(r) "Membro deficiente ou idoso"-"Elderly or disabled member" significa um membro de uma família que -

(1) tem sessenta anos de idade ou mais;

(2)(A) recebe benefícios de renda suplementar da seguridade security sob o título XVI da Lei de Seguridade Social (Social Security Act) (42 U.S.C. 1381 et seq.), ou benefícios suplementares administrados pelo Estado ou pelo nível Federal do tipo descrito na seção 212(a) da Lei Pública 93-66 (42 U.S.C. 1382 note), ou

(B) recebe assistência suplementar administrada pelo Estado ou pelo nível Federal do tipo descrito na seção 1616(a) da Lei da Seguridade Social (Social Security Act) (42 U.S.C. 1382e(a)), recebimento de benefício financeiro de seguridade suplementar como como receita pendente para assistência temporária (interim assistance pending receipt of supplemental security income), assistência médica relacionada à deficiência/incapacidade (disability-related medical assistance) sob o título XIX da lei de Seguridade Social (Social Security Act) (42 U.S.C. 1396 et seq.), ou benefícios de assistência geral do Estado com base na deficiência/incapacidade (disability-based State general assistance benefits), se o Secretário determinar que tais benefícios estão condicionados à evidência de critérios de deficiência/incapacidade-disability ou cegueira pelo menos como estritos àqueles usados sob o título XVI da Lei de Seguridade Social (Social Security Act);

(3) recebe pagamentos por deficiência/incapacidade-disability ou cegueira-blindness sob o título I, II, X, XIV, ou XVI da Lei de Seguridade Social (Social Security Act) (42 U.S.C. 301 et seq., 401 et seq., 1201 et seq., 1351 et seq., 1381 et seq.) ou recebe benefícios de aposentadoria por deficiência/incapacidade-disability de uma agência governamental devido a uma deficiência/incapacidade-disability considerada permanente sob a seção 221(i) da Lei de Seguridade Social (Social Security Act) (42 U.S.C. 421(i));

(4) é um veterano que -

(A) tem uma deficiência/incapacidade-disability relacionada ou não relacionada ao serviço que é avaliada como total sob o título 38; ou

(B) é considerado em necessidade de ajuda regular e atendimento ou permanentemente asilado (housebound) sob tal título;

(5) é uma esposa sobrevivente de um veterano e -

(A) é considerada em necessidade de ajuda regular e atendimento ou permanentemente asilada (housebound) sob o título 38; ou

(B) tem o direito a compensação por uma morte ligada ao serviço ou benefícios de pensão por uma morte não relacionada ao serviço sob o título 38 , e tem uma 
deficiência/incapacidade-disability considerada permanente sob a seção 221(i) da Lei de Seguridade Social (Social Security Act) (42 U.S.C. 421(i));

(6) é um filho (child) de um veterano e -

(A) é considerado permanentemente incapaz de auto-sustento sob a seção 1314 do título 38; ou

(B) tem direito a compensação por uma morte ligada ao serviço ou benefícios de pensão por uma morte não ligada ao serviço sob o título 38 , e tem uma deficiência/incapacidade-disability considerada permanente sob a seção 221(i) da Lei de Seguridade Social (Social Security Act) (42 U.S.C. 421(i)); ou

(7) é um indivíduo recebendo uma anuidade sob a seção 2(a)(1)(iv) ou 2(a)(1)(v) da lei de Aposentadoria da Ferrovia de 1974(Railroad Retirement Act of 1974) (45 U.S.C. 231a(a)(1)(iv) ou 231a(a)(1)(v)), se o serviço do indivíduo como um empregado sob a Lei de Aposentadoria da Ferrovia de 1974 (Railroad Retirement Act of 1974) (45 U.S.C. 231 et seq.), após 31 de Dezembro de 1936, tenha sido incluído no termo "emprego"- "employment" como definido na Lei da Seguridade Social (Social Security Act) (42 U.S.C. 301 et seq.), e se um pedido para benefícios por deficiência/incapacidade-disability foi preenchido. 7 U.S.C. §2012(r)

\section{Lei de Pequenos negócios (Small Business Act)}

(f) "Indivíduo Deficiente"- "Handicapped individual” definido

Para os propósitos da seção 636 deste título, o termo "indivíduo deficiente""handicapped individual" significa um indivíduo -

(1) que tem uma deficiência-impairment física, mental, ou emocional, defeito, enfermidade, doença, deficiência ou incapacidade de uma natureza permanente que em qualquer maneira limita a seleção de qualquer tipo de emprego para o qual a pessoa seria de outro modo qualificada ou qualificável; ou

(2) que é um veterano que ficou deficiente ou incapacitado em serviço (servicedisabled).

(c) Programas para indivíduos cegos e deficientes-handicapped

(1) Como usado nesta subseção:

(C) O termo "indivíduo deficiente"-"handicapped individual" tem o mesmo significado dado a tal termo na seção 632(f) deste título.

58. Limitações para os Direitos de Reprodução/Cópia em direitos exclusivos: reprodução para o cego e outras pessoas com deficiências/incapacidades (Copyright - Limitations on exclusive rights: reproduction for blind or other people with disabilities)

Para os propósitos desta seção, o termo -

(2) "cego e outras pessoas com deficiências/incapacidades"- "blind or other persons with disabilities" significa indivíduos que são elegíveis ou que podem ser 
qualificados de acordo com a Lei intitulada "Uma lei para fornecer livros para o adulto cego"- "An Act to provide books for the adult blind", aprovada em 3 de Março de 1931 (2 U.S.C. 135a; 46 Stat. 1487) para receber livros e outras publicações produzidos em formatos especializados; 17 U.S.C. §121(c)(2)

\section{Lei da Tecnologia Assistiva de 1998 (Assistive Technology Act of 1998)}

\section{(8) Deficiência/Incapacidade-Disability}

O termo "deficiência/incapacidade"- "disability" significa uma condição de um indivíduo que é considerada uma deficiência/incapacidade-disability ou desvantagemhandicap para os propósitos de qualquer lei Federal outra além deste capítulo ou para os propósitos da lei do Estado no qual o indivíduo reside.

(9) Indivíduo com uma deficiência/incapacidade-disability; indivíduos com deficiências/incapacidades-disabilities

(A) Indivíduo com uma deficiência/incapacidade-disability

O termo "indivíduo com uma deficiência"-"individual with a disability" significa qualquer indivíduo de qualquer idade, raça, ou etnia -

- (i) que tem uma deficiência/incapacidade-disability; e

- (ii) que é ou seria capacitado (enabled) por um dispositivo de tecnologia assistiva ou um serviço de tecnologia assistiva para minimizar a deterioração na funcionalidade (functioning), para manter um nível de funcionalidade (functioning), ou para adquirir um nível maior de funcionalidade (functioning) em qualquer atividade maior da vida (major life activity).

\section{Lei Federal de Segurança e Saúde em Minas de 1977 (Federal Mine Safety and Health Act of 1977)}

(1) O termo "deficiência/incapacidade total"- "total disability" tem o significado dado a ele pelas regulações do Secretário da Saúde e Serviços Humanos* (Health and Human Services*) para pedidos sob a parte B deste subcapítulo, e pelas regulações do Secretário do Trabalho para pedidos sob a parte $\mathrm{C}$ deste subcapítulo, assunto para as relevantes provisões das subseções (b) e (d) da seção 923 deste título, exceto que -

(A) no caso de um mineiro residente (living miner), tais regulações devem prover que um mineiro deve ser considerado totalmente deficiente-disabled quando a pneumoconiose o impede de se envolver em emprego remunerado requerendo as habilidades e destreza comparáveis àqueles de qualquer emprego em uma mina ou minas nas quais ele trabalhou previamente com alguma regularidade e acima de um período substancial de tempo;

(B) tais regulações devem prover que

- (i) o emprego de um mineiro falecido em uma mina à época da morte não deve ser usado como evidência conclusiva de que o mineiro não estava totalmente deficientedisabled; e 
- (ii) no caso de um mineiro residente (living miner), se existirem circunstâncias modificadas de emprego indicativas de capacidade (ability) reduzida para realizar o seu trabalho usual na mina de carvão, tal emprego de mineiro em uma mina não deve ser usado como evidência conclusiva de que o mineiro não está totalmente deficientedisabled;

(C) tais regulações não devem prover critérios mais restritivos que aqueles aplicáveis sob a seção 423(d) do título 42; e

(D) o Secretário do Trabalho, em consulta com o Diretor do Instituto Nacional para Segurança e Saúde Ocupacional (National Institute for Occupational Safety and Health), deve estabelecer critérios para todos os testes médicos apropriados sob esta subseção que acuradamente refletem deficiência/incapacidade-disability total em mineiros de carvão como definido no subparágrafo (A).

* Como no original. Provavelmente deveria ser "Comissário da Seguridade Social"

61. Lei da Acessibilidade ao Voto para Idosos e Deficientes (Voting Accessibility for the Elderly and Handicapped Act)

(4) "deficiente"-"handicapped" significa ter uma deficiência/incapacidade-disability física temporária ou permanente;

62. Lei do Serviço Voluntário Doméstico de 1973 (Domestic Volunteer Service Act of 1973)

(11) exceto como apresentado na seção 5057 deste título, o termo "indivíduo com uma deficiência/incapacidade"- "individual with a disability" tem o significado dado ao termo na seção 705(20)(B) do título 29;

63. Lei da Proteção Nacional À Criança de 1993 (National Child Protection Act of 1993)

(7) o termo "indivíduos com deficiências/incapacidade"-"individuals with disabilities" significa pessoas com uma deficiência-impairment mental ou física que requer assistência para realizar uma ou mais tarefas da vida diária;

64. Lei da Conservação de Energia em Edifícios Existentes de 1976 (Energy Conservation in Existing Buildings Act of 1976)

(5) O termo "pessoa deficiente"-“handicapped person” significa qualquer indivíduo

(A) que é um indivíduo com uma deficiência/incapacidade-disability, como definido na seção 705 do título 29,

(B) que está sob uma deficiência/incapacidade-disability como definido na seção 1614(a)(3)(A) ou 233(d)(1) da Lei de Seguridade Social (Social Security Act) (42 U.S.C. 1382c(a)(3)(A), 423(d)(1)) ou em uma seção 102(7)* da Lei da Construção de Serviços e Facilidade para as Deficiências do desenvolvimento (Developmental Disabilities Services and Facilities Construction Act) (42 U.S.C. 6001(7)), ou

(C) que está recebendo benefícios sob o capítulo 11 ou 15 do título 38. 
*Seção 102(7) de 42 U.S.C. 6001(7) foi subseqüentemente emendada e não mais define o termo "deficiência do desenvolvimento"-"developmental disability". Contudo, tal termo é definido em outra parte naquela seção.

65. Lei de Serviço Nacional e Comunitário de 1990 (National and Community Service Act of 1990)

(12) Indivíduo com uma deficiência/incapacidade-disability

Exceto como apresentado na seção 12635(a) deste título, o termo "indivíduo com uma deficiência/incapacidade"- "individual with a disability" tem o significado dado ao termo na seção 705(20)(B) do título 29.

\section{Lei das Telecomunicações de 1996 (Telecommunications Act of 1996)}

(1) Deficiência/Incapacidade-Disability

O termo "deficiência/incapacidade"- "disability" tem o significado dado a ele pela seção 12102(2)(A) do título 42.

\section{Transporte de Massa (Mass Transportation)}

(5) Indivíduo deficiente-Handicapped individual. -

O termo "indivíduo deficiente"-"handicapped individual" significa um indivíduo que, por causa de doença, lesão, idade, disfunção congênita, ou outra incapacitaçãoincapacity ou deficiência/incapacidade-disability temporária ou permanente (incluindo um indivíduo que é um usuário de cadeira de rodas ou tem capacidade semi-ambulatória - semiambulatory capability), não pode usar efetivamente, sem facilitadores especiais-special facilities, planejamento, ou projeto, serviços de transporte de massa ou uma facilidade para transporte de massa (mass transportation service or a mass transportation facility).

(b) Autoridade para modificar "indivíduo deficiente"-“Handicapped Individual". -

O Secretário pode por regulação modificar a definição do termo "indivíduo deficiente"-"handicapped individual" na subseção (a)(5) como se aplica à seção $5307(d)(1)(D)$. 
Anexo 2 -TABELA DE CÓDIGOS DA CID-10 DA RESOLUÇÃo CONJUNTA

SECRETARIA DA SAÚDE / SECRETARIA DE TRANSPORTES

METROPOLITANOS N. 2, DE 30 DE OUTUBRO DE 2003 - ESTADO DE

\section{SÃO PAULO}

\begin{tabular}{|c|c|c|c|c|}
\hline Código & Diagnósticos & $\begin{array}{l}\text { Observações/ } \\
\text { ressalvas }\end{array}$ & $\begin{array}{l}\text { Acompa- } \\
\text { nhante }\end{array}$ & Tempo \\
\hline B & \multicolumn{4}{|c|}{ Algumas doenças infecciosas e parasitárias } \\
\hline B91 & \begin{tabular}{|l|} 
Seqüelas de \\
Poliomielite
\end{tabular} & $\begin{array}{l}\text { Se for bilateral de membros } \\
\text { é com acompanhante }\end{array}$ & Não & 4anos \\
\hline B92 & Seqüela de hanseníase & $\begin{array}{l}\text { Somente com deformidade } \\
\text { nos membros }\end{array}$ & Não & 4anos \\
\hline $\mathrm{E}$ & \multicolumn{4}{|c|}{ Doenças endócrinas nutricionais e metabólicas } \\
\hline E23.0 & $\begin{array}{l}\begin{array}{l}\text { Hipopituitarismo } \\
\text { (Nanismo) }\end{array} \\
\end{array}$ & & Não & 4anos \\
\hline E34.3 & $\begin{array}{l}\text { Nanismo não } \\
\text { classificado em outra } \\
\text { parte }\end{array}$ & & Não & 4anos \\
\hline $\mathrm{F}$ & \multicolumn{4}{|c|}{ Transtornos Mentais e Comportamentais } \\
\hline F00 & $\begin{array}{l}\text { Demência na Doença } \\
\text { de Alzheimer }\end{array}$ & $\begin{array}{l}\text { Com importante } \\
\text { comprometimento cognitivo } \\
\text { e da independência }\end{array}$ & Sim & 2 2anos \\
\hline F01 & Demência Vascular & $\begin{array}{l}\text { Com importante } \\
\text { comprometimento cognitivo } \\
\text { e da independência }\end{array}$ & Sim & 2 anos \\
\hline F02.3 & $\begin{array}{l}\text { Demência na doença } \\
\text { de Parkinson }\end{array}$ & $\begin{array}{l}\text { Com importante } \\
\text { comprometimento cognitivo } \\
\text { e da independência }\end{array}$ & Sim & 2anos \\
\hline F04 & $\begin{array}{l}\text { Síndrome amnésica } \\
\text { orgânica não induzida } \\
\text { pelo álcool ou por } \\
\text { outras substâncias } \\
\text { psicoativas }\end{array}$ & $\begin{array}{l}\text { Com importante } \\
\text { comprometimento cognitivo } \\
\text { e da independência }\end{array}$ & Sim & 1ano \\
\hline F06 & $\begin{array}{l}\text { Outros transtornos } \\
\text { mentais devidos a } \\
\text { lesão e disfunção } \\
\text { cerebral e doença } \\
\text { física }\end{array}$ & $\begin{array}{l}\text { Com importante } \\
\text { comprometimento cognitivo } \\
\text { e da independência }\end{array}$ & Sim & 1ano \\
\hline F07 & $\begin{array}{l}\text { Transtornos de } \\
\text { personalidade e do } \\
\text { comportamento } \\
\text { devidos a doença, a } \\
\text { lesão e a disfunção } \\
\text { cerebral }\end{array}$ & $\begin{array}{l}\text { Com importante } \\
\text { comprometimento cognitivo } \\
\text { e da independência }\end{array}$ & Sim & 1ano \\
\hline F19 & Transtornos mentais e & Com importante & Sim & 1ano \\
\hline
\end{tabular}




\begin{tabular}{|c|c|c|c|c|c|c|}
\hline & $\begin{array}{l}\text { comportamentais } \\
\text { devidos ao uso de } \\
\text { múltiplas drogas e ao } \\
\text { uso de outras } \\
\text { substâncias } \\
\text { psicoativas }\end{array}$ & \multicolumn{2}{|c|}{$\begin{array}{l}\text { comprometimento cognitivo } \\
\text { e da independência }\end{array}$} & & & \\
\hline F20 & Esquizofrenia & \multicolumn{2}{|c|}{$\begin{array}{l}\text { Com importante } \\
\text { comprometimento cognitivo } \\
\text { e da independência }\end{array}$} & \multicolumn{2}{|l|}{ Sim } & 2anos \\
\hline $\mathrm{F} 21$ & $\begin{array}{l}\text { Transtorno } \\
\text { esquizotípico }\end{array}$ & \multicolumn{2}{|c|}{$\begin{array}{l}\text { Com importante } \\
\text { comprometimento cognitivo } \\
\text { e da independência }\end{array}$} & \multicolumn{2}{|l|}{ Sim } & 2anos \\
\hline F24 & $\begin{array}{l}\text { Transtorno delirante } \\
\text { induzido }\end{array}$ & \multicolumn{2}{|c|}{$\begin{array}{l}\text { Com importante } \\
\text { comprometimento cognitivo } \\
\text { e da independência }\end{array}$} & \multicolumn{2}{|l|}{ Sim } & 1ano \\
\hline $\mathrm{F} 25$ & $\begin{array}{l}\text { Transtornos } \\
\text { esquizoafetivos }\end{array}$ & \multicolumn{2}{|c|}{$\begin{array}{l}\text { Com importante } \\
\text { comprometimento cognitivo } \\
\text { e da independência }\end{array}$} & \multicolumn{2}{|l|}{ Não } & 2anos \\
\hline F28 & $\begin{array}{l}\text { Outros transtornos } \\
\text { psicóticos não- } \\
\text { orgânicos } \\
\end{array}$ & \multicolumn{2}{|c|}{$\begin{array}{l}\text { Com importante } \\
\text { comprometimento cognitivo } \\
\text { e da independência }\end{array}$} & \multicolumn{2}{|l|}{ Sim } & 2anos \\
\hline F29 & $\begin{array}{l}\text { Psicose não orgânica } \\
\text { não especificada }\end{array}$ & \multicolumn{2}{|c|}{$\begin{array}{l}\text { Com importante } \\
\text { comprometimento cognitivo } \\
\text { e da independência }\end{array}$} & \multicolumn{2}{|l|}{ Sim } & 2anos \\
\hline F70 & Retardo Mental Leve & \multicolumn{2}{|c|}{$\begin{array}{l}\text { Na idade adulta, com } \\
\text { avaliação psicológica }\end{array}$} & \multicolumn{2}{|l|}{ Sim } & 2anos \\
\hline F71 & $\begin{array}{l}\text { Retardo Mental } \\
\text { Moderado }\end{array}$ & & & \multicolumn{2}{|l|}{ Sim } & 2anos \\
\hline F72 & Retardo Mental Grave & & & \multicolumn{2}{|l|}{ Sim } & 4anos \\
\hline F73 & $\begin{array}{l}\text { Retardo Mental } \\
\text { Profundo }\end{array}$ & & & \multicolumn{2}{|l|}{ Sim } & 4anos \\
\hline F79 & $\begin{array}{l}\text { Retardo Mental não } \\
\text { especificado }\end{array}$ & & & \multicolumn{2}{|l|}{ Sim } & 4anos \\
\hline F83 & $\begin{array}{l}\text { Transtornos } \\
\text { específicos mistos do } \\
\text { desenvolvimento }\end{array}$ & & & \multicolumn{2}{|l|}{ Sim } & 4anos \\
\hline F84 & $\begin{array}{l}\text { Transtornos globais do } \\
\text { desenvolvimento }\end{array}$ & & & \multicolumn{2}{|l|}{ Sim } & 4anos \\
\hline F90 & $\begin{array}{l}\text { Transtornos } \\
\text { hipercinéticos }\end{array}$ & & & \multicolumn{2}{|l|}{ Sim } & 4anos \\
\hline $\mathrm{G}$ & \multicolumn{6}{|c|}{ Doenças do Sistema Nervoso } \\
\hline G04 & \multicolumn{2}{|l|}{$\begin{array}{l}\text { Encefalite, mielite e } \\
\text { encefalomielite }\end{array}$} & & & Sim & 1ano \\
\hline G09 & \multirow{2}{*}{\multicolumn{2}{|c|}{$\begin{array}{l}\text { Seqüelas de doenças inflamatórias } \\
\text { do sistema nervoso central }\end{array}$}} & \multicolumn{2}{|c|}{$\begin{array}{l}\text { Somente com } \\
\text { limitação motora ou } \\
\text { cognitiva }\end{array}$} & Sim & 4anos \\
\hline G10 & & & & & Sim & 4anos \\
\hline
\end{tabular}




\begin{tabular}{|c|c|c|c|c|}
\hline G11 & Ataxia hereditária & & Sim & 4anos \\
\hline G12 & $\begin{array}{l}\text { Atrofia muscular espinal e } \\
\text { síndromes correlatas }\end{array}$ & & Sim & 4anos \\
\hline G20 & Doença de Parkinson & & Sim & 4anos \\
\hline G21 & Parkinsonismo adquirido & & Sim & 4anos \\
\hline G25.4 & Coréia induzida por droga & & Sim & 1ano \\
\hline G25.5 & Outras formas de Coréia & & Sim & 1ano \\
\hline G25.8 & $\begin{array}{l}\text { Outras doenças extrapiramidais e } \\
\text { transtornos do movimento, } \\
\text { especificados }\end{array}$ & & Sim & 4anos \\
\hline G25.9 & $\begin{array}{l}\text { Doenças extrapiramidais e } \\
\text { transtornos do movimento, não } \\
\text { especificados }\end{array}$ & & Sim & 4anos \\
\hline G30 & Doença de Alzheimer & & Sim & 4anos \\
\hline G31 & $\begin{array}{l}\text { Outras doenças degenerativas do } \\
\text { sistema nervoso, não classificadas } \\
\text { em outra parte }\end{array}$ & & Sim & 4anos \\
\hline G35 & Esclerose Múltipla & & Sim & 1ano \\
\hline G36 & $\begin{array}{l}\text { Outras desmielinizações } \\
\text { disseminadas agudas }\end{array}$ & & Sim & 1ano \\
\hline G37 & $\begin{array}{l}\text { Outras doenças desmielinizantes do } \\
\text { sistema nervoso central }\end{array}$ & & Sim & 1ano \\
\hline G46 & $\begin{array}{l}\text { Síndromes vasculares cerebrais que } \\
\text { ocorrem em doenças } \\
\text { cerebrovasculares }\end{array}$ & $\begin{array}{l}\text { Com repercussão } \\
\text { motora }\end{array}$ & Sim & 1ano \\
\hline G54 & $\begin{array}{l}\text { Transtornos das raízes e dos plexos } \\
\text { nervosos }\end{array}$ & $\begin{array}{l}\text { Se for bilateral é com } \\
\text { acompanhante }\end{array}$ & Não & 1ano \\
\hline G55.0 & $\begin{array}{l}\text { Compressões das raízes e dos } \\
\text { plexos nervosos em doenças } \\
\text { neoplásicas }\end{array}$ & $\begin{array}{l}\text { Com repercussão } \\
\text { motora }\end{array}$ & Não & 1ano \\
\hline G55.1 & $\begin{array}{l}\text { Compressões das raízes e dos } \\
\text { plexos nervosos em transtornos dos } \\
\text { discos intervertebrais }\end{array}$ & $\begin{array}{l}\text { Com repercussão } \\
\text { motora }\end{array}$ & Não & 1ano \\
\hline G55.2 & $\begin{array}{l}\text { Compressões das raízes e dos } \\
\text { plexos nervosos na espondilose }\end{array}$ & $\begin{array}{l}\text { Com repercussão } \\
\text { motora }\end{array}$ & Não & 1ano \\
\hline G60 & Neuropatia Hereditária e Idiopática & Eletroneuromiografia & Sim & 4anos \\
\hline G61 & Polineuropatia inflamatória & Eletroneuromiografia & Sim & 1ano \\
\hline G62 & Outras polineuropatias & Eletroneuromiografia & Sim & 1ano \\
\hline G63 & $\begin{array}{l}\text { Polineuropatia em doenças } \\
\text { classificadas em outra parte }\end{array}$ & Eletroneuromiografia & Sim & 1ano \\
\hline G70 & $\begin{array}{l}\text { Miastenia gravis e outros } \\
\text { transtornos neuromusculares }\end{array}$ & & Sim & 2anos \\
\hline G71 & $\begin{array}{l}\text { Transtornos primários dos } \\
\text { músculos }\end{array}$ & & Sim & 2anos \\
\hline G80 & Paralisia Cerebral & & Sim & 4anos \\
\hline G81 & Hemiplegia & & Sim & 4anos \\
\hline G82 & Paraplegia e tetraplegia & & Sim & 4anos \\
\hline
\end{tabular}




\begin{tabular}{|c|c|c|c|c|c|}
\hline G83 & \multicolumn{2}{|c|}{ Outras síndromes paralíticas } & & Sim & 2anos \\
\hline G90 & \multicolumn{2}{|c|}{$\begin{array}{l}\text { Transtornos do Sistema Nervoso } \\
\text { Autônomo }\end{array}$} & & Sim & 2anos \\
\hline G91 & \multicolumn{2}{|l|}{ Hidrocefalia } & & Sim & 1ano \\
\hline G92 & \multicolumn{2}{|l|}{ Encefalopatia Tóxica } & $\begin{array}{l}\text { Remeter a causas } \\
\text { externas T36 a T50 } \\
\text { Somente com sequiela } \\
\text { motora ou cognitiva }\end{array}$ & Sim & 1 ano \\
\hline G93.1 & \multicolumn{2}{|c|}{$\begin{array}{l}\text { Lesão encefálica anóxica, não } \\
\text { classificada em outra parte }\end{array}$} & (1) & Sim & 2anos \\
\hline G93.4 & \multicolumn{2}{|c|}{ Encefalopatia não especificada } & & Sim & 1ano \\
\hline $\mathrm{H}$ & \multicolumn{5}{|c|}{$\begin{array}{l}\text { Doenças do Olho e Anexos / Doenças dos Ouvidos e das Apófises } \\
\text { Mastóides }\end{array}$} \\
\hline H53.4 & $\begin{array}{l}\text { Defeitos do campo } \\
\text { Visual }\end{array}$ & \multicolumn{2}{|c|}{ Com ângulo até $5-10^{\circ}$} & Sim & 4anos \\
\hline H54.0 & $\begin{array}{l}\text { Cegueira, ambos os } \\
\text { olhos }\end{array}$ & & & Sim & 4anos \\
\hline H54.1 & $\begin{array}{l}\text { Cegueira em um olho } \\
\text { e visão subnormal em } \\
\text { outro }\end{array}$ & \multicolumn{2}{|c|}{ Que não melhora com correção } & Sim & 4anos \\
\hline H54.2 & $\begin{array}{l}\text { Visão subnormal em } \\
\text { ambos os olhos }\end{array}$ & \multicolumn{2}{|c|}{ Que não melhora com correção } & Sim & 4anos \\
\hline H54.3 & $\begin{array}{l}\text { Perda não qualificada } \\
\text { da visão em ambos os } \\
\text { olhos }\end{array}$ & \multicolumn{2}{|c|}{ Que não melhora com correção } & Sim & 4anos \\
\hline H90 & $\begin{array}{l}\text { Perda de audição por } \\
\text { transtorno de } \\
\text { condução e/ou } \\
\text { neurossensorial } \\
\end{array}$ & \multicolumn{2}{|c|}{$\begin{array}{l}\text { Nas freqüências de 500, } 1000 \text { e } \\
2000 \mathrm{~Hz}\end{array}$} & Não & 4anos \\
\hline \multicolumn{6}{|c|}{$\begin{array}{l}\text { Para os alunos matriculados e que freqüentam as escolas especiais para deficientes } \\
\text { auditivos, será fornecido o Documento de Identificação de Passageiro Especial - } \\
\text { Pessoa com Deficiência, mediante a apresentação do comprovante de matrícula e de } \\
\text { freqüência regular em escola especial para deficientes auditivos. }\end{array}$} \\
\hline \multicolumn{6}{|c|}{$\begin{array}{l}\text { Para os demais deficientes auditivos, será fornecido o Documento de Identificação } \\
\text { de Passageiro Especial - Pessoa com Deficiência, somente nos casos de deficiência } \\
\text { auditiva severa e profunda, de acordo com a classificação do Bureau International } \\
\text { d'Audiophonologie - BIAP (acima de } 70 \text { decibéis). }\end{array}$} \\
\hline \multicolumn{6}{|c|}{$\begin{array}{l}\text { Deficiência Visual: } \\
\text { Laudo médico com Acuidade Visual (A/V), com perda mínima de } 80 \% \text { da visão } \\
\text { bilateral com a melhor correção, ou } \\
\text { Nos casos de Campo Visual Tubular, a campimetria constando perda bilateral com } \\
\text { ângulo de 5-10 }\end{array}$} \\
\hline $\mathrm{I}$ & \multicolumn{5}{|c|}{ Doenças do Aparelho Circulatório } \\
\hline $\mathrm{I} 02$ & Coréia Reumática & & & Sim & 2anos \\
\hline I60 & $\begin{array}{l}\text { Hemorragia } \\
\text { subaracnóide }\end{array}$ & $\begin{array}{l}\text { Soment } \\
\text { sensoria }\end{array}$ & $\begin{array}{l}\text { quando existir seqüela } \\
\text { ou motora }\end{array}$ & Sim & 1ano \\
\hline
\end{tabular}




\begin{tabular}{|c|c|c|c|c|}
\hline I61 & $\begin{array}{l}\text { Hemorragia } \\
\text { intracerebral }\end{array}$ & $\begin{array}{l}\text { Somente quando existir seqüela } \\
\text { sensorial ou motora }\end{array}$ & Sim & 1ano \\
\hline I63 & Infarto cerebral & $\begin{array}{l}\text { Somente quando existir seqüela } \\
\text { sensorial ou motora }\end{array}$ & Sim & 1ano \\
\hline I64 & $\begin{array}{l}\text { Acidente vascular } \\
\text { cerebral, não } \\
\text { especificado como } \\
\text { hemorrágico ou } \\
\text { isquêmico }\end{array}$ & $\begin{array}{l}\text { Somente quando existir seqüela } \\
\text { sensorial ou motora }\end{array}$ & Sim & 1ano \\
\hline I67 & $\begin{array}{l}\text { Outras doenças } \\
\text { cerebrovasculares }\end{array}$ & $\begin{array}{l}\text { Somente quando existir seqüela } \\
\text { sensorial ou motora }\end{array}$ & Sim & 1ano \\
\hline I69 & $\begin{array}{l}\text { Seqüelas de doenças } \\
\text { cerebrovasculares }\end{array}$ & $\begin{array}{l}\text { Somente quando existir seqüela } \\
\text { sensorial ou motora }\end{array}$ & Sim & 1ano \\
\hline I89 & $\begin{array}{l}\text { Outros transtornos não } \\
\text { infecciosos dos vasos } \\
\text { linfáticos e dos gânglios } \\
\text { linfáticos }\end{array}$ & Elefantíase severa & Não & 1ano \\
\hline $\mathrm{M}$ & \multicolumn{4}{|c|}{ Doenças do Sistema Osteomuscular e do Tecido Conjuntivo } \\
\hline M05 & Artrite reumatóide & $\begin{array}{l}\text { Somente em articulações de } \\
\text { membros }\end{array}$ & Não & 2anos \\
\hline M06.4 & $\begin{array}{l}\text { Poliartropatia } \\
\text { inflamatória }\end{array}$ & & Não & 1ano \\
\hline M08 & Artrite Juvenil & & Não & 2anos \\
\hline M12.5 & Artropatia traumática & $\begin{array}{l}\text { Somente de grandes } \\
\text { articulações }\end{array}$ & Não & 2anos \\
\hline M15 & Poliartrose & $\begin{array}{l}\text { Com comprometimento } \\
\text { importante da deambulação }\end{array}$ & Não & 4anos \\
\hline M16 & $\begin{array}{l}\text { Coxartrose (artrose do } \\
\text { quadril) }\end{array}$ & $\begin{array}{l}\text { Com comprometimento } \\
\text { importante da deambulação }\end{array}$ & Não & 4anos \\
\hline M17 & $\begin{array}{l}\text { Gonartrose (artrose do } \\
\text { joelho) }\end{array}$ & $\begin{array}{l}\text { Com comprometimento } \\
\text { importante da deambulação }\end{array}$ & Não & 4anos \\
\hline M19 & Outras artroses & $\begin{array}{l}\text { Com comprometimento } \\
\text { importante da deambulação } \\
\text { Somente de grandes } \\
\text { articulações }\end{array}$ & Não & 2anos \\
\hline M21.5 & $\begin{array}{l}\text { Mão e pé em garra e } \\
\text { mão e pé tortos } \\
\text { adquiridos }\end{array}$ & & Não & 4anos \\
\hline M21.8 & $\begin{array}{l}\text { Outras deformidades } \\
\text { adquiridas especificadas } \\
\text { dos membros }\end{array}$ & & Não & 2anos \\
\hline M32 & $\begin{array}{l}\text { Lupus eritematoso } \\
\text { disseminado (sistêmico) }\end{array}$ & $\begin{array}{l}\text { Somente de grandes } \\
\text { articulações ou punho }\end{array}$ & Não & 1ano \\
\hline M34.0 & $\begin{array}{l}\text { Esclerose sistêmica } \\
\text { progressiva }\end{array}$ & & Não & 2anos \\
\hline M40 & Cifose e Lordose & $\begin{array}{l}\text { Somente em casos visíveis (em } \\
\text { uso de colete) }\end{array}$ & Não & 1ano \\
\hline
\end{tabular}




\begin{tabular}{|c|c|c|c|c|c|}
\hline M41 & Escoliose & \multicolumn{2}{|c|}{ Somente com limitação motora } & Não & 1ano \\
\hline M42 & \begin{tabular}{|l|}
$\begin{array}{l}\text { Osteocondrose da } \\
\text { coluna vertebral }\end{array}$ \\
\end{tabular} & \multicolumn{2}{|c|}{ com limitação motora } & Não & 2anos \\
\hline M45 & Espondilite ancilosante & \multicolumn{2}{|c|}{ com limitação motora } & Não & 4anos \\
\hline M47.1 & $\begin{array}{l}\text { Outras espondiloses } \\
\text { com mielopatia }\end{array}$ & \multicolumn{2}{|c|}{ com limitação motora } & Não & 1ano \\
\hline M50.0 & $\begin{array}{l}\text { Transtornos dos discos } \\
\text { cervicais com } \\
\text { mielopatia }\end{array}$ & \multicolumn{2}{|c|}{ com limitação motora } & Não & 1ano \\
\hline M51.0 & $\begin{array}{l}\text { Transtornos de discos } \\
\text { lombares e de outros } \\
\text { discos intervertebrais } \\
\text { com mielopatia }\end{array}$ & \multicolumn{2}{|c|}{ com limitação motora } & Não & 1ano \\
\hline M67.0 & $\begin{array}{l}\text { Tendão de Aquiles curto } \\
\text { (adquirido) }\end{array}$ & \multicolumn{2}{|c|}{$\begin{array}{l}\text { Com comprometimento } \\
\text { importante da deambulação }\end{array}$} & Não & 4anos \\
\hline M75.1 & $\begin{array}{l}\text { Síndrome do Manguito } \\
\text { Rotador }\end{array}$ & \multicolumn{2}{|c|}{$\begin{array}{l}\text { Com lesão anatômica } \\
\text { comprovada }\end{array}$} & Não & 1ano \\
\hline M80 & $\begin{array}{l}\text { Osteoporose com fratura } \\
\text { patológica }\end{array}$ & \multicolumn{2}{|c|}{ Somente em ossos grandes } & Sim & 1ano \\
\hline M86 & Osteomielite & \multicolumn{2}{|c|}{$\begin{array}{l}\text { De ossos longos, com limitação } \\
\text { importante de função }\end{array}$} & Não & 1ano \\
\hline M87.0 & $\begin{array}{l}\text { Necrose asséptica } \\
\text { idiopática do osso }\end{array}$ & \multicolumn{2}{|c|}{$\begin{array}{l}\text { Somente em membros } \\
\text { inferiores }\end{array}$} & Não & 4anos \\
\hline M87.2 & $\begin{array}{l}\text { Osteonecrose devida a } \\
\text { traumatismo anterior }\end{array}$ & & & Não & 4anos \\
\hline M88 & $\begin{array}{l}\text { Doença de Paget do } \\
\text { osso (osteíte } \\
\text { deformante) }\end{array}$ & & & Não & 4anos \\
\hline M91 & $\begin{array}{l}\text { Osteocondrose Juvenil } \\
\text { do Quadril e da Pelve }\end{array}$ & & & Não & 4anos \\
\hline $\mathrm{P}$ & \multicolumn{5}{|c|}{ Algumas afecções originadas no período Neonatal } \\
\hline P14 & \multicolumn{3}{|c|}{$\begin{array}{l}\text { Lesões ao nascer do sistema nervoso } \\
\text { periférico }\end{array}$} & Sim & 1ano \\
\hline $\mathrm{P} 20$ & \multicolumn{3}{|l|}{ Hipóxia intra-uterina } & Sim & 4anos \\
\hline $\mathrm{P} 21$ & Asfixia ao nascer & & & Sim & 4anos \\
\hline Q & \multicolumn{5}{|c|}{ Malformações congênitas, deformidades e anomalias cromossômicas } \\
\hline Q00 & \multicolumn{3}{|c|}{ Anencefalia e malformações similares } & Sim & 4anos \\
\hline Q01 & \multicolumn{3}{|l|}{ Encefalocele } & Sim & 4anos \\
\hline $\mathrm{Q} 02$ & \multicolumn{3}{|l|}{ Microcefalia } & Sim & 4anos \\
\hline Q03 & \multicolumn{3}{|l|}{ Hidrocefalia congênita } & Sim & 4anos \\
\hline Q05.2 & \multicolumn{3}{|c|}{ Espinha bífida lombar com hidrocefalia } & Sim & 4anos \\
\hline Q05.3 & \multicolumn{3}{|c|}{ Espinha bífida sacra com hidrocefalia } & Sim & 4anos \\
\hline Q65.0 & \multicolumn{2}{|c|}{ Luxação congênita unilateral do quadril } & $\begin{array}{l}\text { Somente na } \\
\text { fase adulta }\end{array}$ & Não & 4anos \\
\hline Q65.1 & \multicolumn{2}{|c|}{ Luxação congênita bilateral do quadril } & $\begin{array}{l}\text { Somente na } \\
\text { fase adulta }\end{array}$ & Não & 4anos \\
\hline Q66 & \multicolumn{2}{|l|}{ Pé torto congênito } & & Não & 4anos \\
\hline
\end{tabular}




\begin{tabular}{|c|c|c|c|c|c|}
\hline Q71 & \multicolumn{2}{|c|}{ Defeitos, por redução, do membro superior } & $\begin{array}{l}\text { Se for } \\
\text { bilateral, é } \\
\text { com } \\
\text { acompanhante }\end{array}$ & Não & 4anos \\
\hline Q72 & \multicolumn{2}{|c|}{ Defeitos, por redução, do membro inferior } & & Não & 4anos \\
\hline Q74.0 & \multicolumn{2}{|c|}{$\begin{array}{l}\text { Outras malformações congênitas dos } \\
\text { membros superiores, inclusive da cintura } \\
\text { escapular }\end{array}$} & & Não & 4anos \\
\hline Q74.2 & \multicolumn{2}{|c|}{$\begin{array}{l}\text { Outras malformações congênitas dos } \\
\text { membros inferiores, inclusive da cintura } \\
\text { pélvica }\end{array}$} & & Não & 4anos \\
\hline Q78.0 & \multicolumn{2}{|l|}{ Osteogênese imperfeita } & & Sim & 4anos \\
\hline Q78.6 & \multicolumn{2}{|l|}{ Esostosis congênitas múltiplas } & & Não & 4anos \\
\hline Q87.1 & \multicolumn{2}{|c|}{$\begin{array}{l}\text { Síndromes com malformações congênitas } \\
\text { associadas predominantemente com o } \\
\text { nanismo }\end{array}$} & & Não & 4anos \\
\hline Q87.2 & \multicolumn{2}{|c|}{$\begin{array}{l}\text { Síndromes com malformações congênitas } \\
\text { afetando predominantemente os membros }\end{array}$} & & Não & 4anos \\
\hline Q87.4 & \multicolumn{2}{|l|}{ Síndrome de Marfan } & & Sim & 4anos \\
\hline Q87.5 & \multicolumn{2}{|c|}{$\begin{array}{l}\text { Síndromes com malformações congênitas } \\
\text { com outras alterações do esqueleto }\end{array}$} & & Sim & 4anos \\
\hline Q90 & \multicolumn{3}{|l|}{ Síndrome de Down } & Sim & 4anos \\
\hline $\mathrm{R}$ & \multicolumn{5}{|c|}{$\begin{array}{l}\text { Sintomas, sinais e achados anormais de exames clínicos e de laboratório } \\
\text { não classificados em outra parte }\end{array}$} \\
\hline R26 & \multicolumn{3}{|l|}{$\begin{array}{l}\text { Anormalidades da marcha e da } \\
\text { mobilidade }\end{array}$} & Não & 1ano \\
\hline $\mathrm{S}$ & \multicolumn{5}{|c|}{$\begin{array}{l}\text { Lesões, envenenamentos e algumas outras conseqüências de causas } \\
\text { externas }\end{array}$} \\
\hline S14 & $\begin{array}{l}\text { Traumatismo dos nervos e da } \\
\text { medula espinhal no nível cervical }\end{array}$ & & & Sim & 2anos \\
\hline S47 & $\begin{array}{l}\text { Lesão por esmagamento do } \\
\text { ombro e do braço }\end{array}$ & & & Não & 4anos \\
\hline S48 & $\begin{array}{l}\text { Amputação traumática do ombro } \\
\text { e do braço }\end{array}$ & & & Não & 4anos \\
\hline S57 & $\begin{array}{l}\text { Lesão por esmagamento do } \\
\text { antebraço }\end{array}$ & & & Não & 4anos \\
\hline S58 & $\begin{array}{l}\text { Amputação traumática do } \\
\text { cotovelo e do antebraço }\end{array}$ & & & Não & 4anos \\
\hline S67 & $\begin{array}{l}\text { Lesão por esmagamento do } \\
\text { punho e da mão }\end{array}$ & & & Não & 4anos \\
\hline S68.0 & $\begin{array}{l}\text { Amputação traumática do polegar } \\
\text { (completa) }\end{array}$ & & & Não & 4anos \\
\hline S68.2 & $\begin{array}{l}\text { Amputação traumática de dois ou } \\
\text { mais dedos (completa) }\end{array}$ & $\begin{array}{l}\text { Somente } \\
\text { função d }\end{array}$ & $\begin{array}{l}\text { com perda da } \\
\text { e pinça }\end{array}$ & Não & 4anos \\
\hline S68.4 & $\begin{array}{l}\text { Amputação traumática da mão no } \\
\text { nível do punho }\end{array}$ & & & Não & 4anos \\
\hline S68.9 & Amputação traumática do punho & & & Não & 4anos \\
\hline
\end{tabular}




\begin{tabular}{|c|c|c|c|c|}
\hline & e da mão, nível não especificado & & & \\
\hline S72 & Fratura do fêmur & $\begin{array}{l}\text { Somente com } \\
\text { encurtamento de } \\
\text { membro que leve a } \\
\text { dificuldade na } \\
\text { deambulação - } \\
\text { escanograma com } \\
\text { dismetria > } 3 \mathrm{~cm} \text { ou em } \\
\text { uso de aparelho fixador } \\
\text { externo }\end{array}$ & Não & 1 ano \\
\hline S77 & $\begin{array}{l}\text { Lesão por esmagamento do } \\
\text { quadril e da coxa }\end{array}$ & & Não & 4anos \\
\hline S78 & $\begin{array}{l}\text { Amputação traumática do quadril } \\
\text { e da coxa }\end{array}$ & & Sim & 4anos \\
\hline S82.1 & $\begin{array}{l}\text { Fratura da extremidade proximal } \\
\text { da tíbia }\end{array}$ & $\begin{array}{l}\text { Somente em uso de } \\
\text { aparelho fixador externo }\end{array}$ & Não & 1 ano \\
\hline S82.2 & Fratura da diáfise da tíbia & $\begin{array}{l}\text { Somente em uso de } \\
\text { aparelho fixador externo }\end{array}$ & Não & 1 ano \\
\hline S82.3 & $\begin{array}{l}\text { Fratura da extremidade distal da } \\
\text { tíbia }\end{array}$ & $\begin{array}{l}\text { Somente em uso de } \\
\text { aparelho fixador externo }\end{array}$ & Não & 1 ano \\
\hline S82.4 & Fratura do perônio (Fíbula) & $\begin{array}{l}\text { Somente em uso de } \\
\text { aparelho fixador externo }\end{array}$ & Não & 1 ano \\
\hline S82.7 & Fraturas múltiplas da perna & $\begin{array}{l}\text { Somente em uso de } \\
\text { aparelho fixador externo }\end{array}$ & Não & 1 ano \\
\hline S88 & Amputação traumática da perna & & Não & 4anos \\
\hline S97 & $\begin{array}{l}\text { Lesão por esmagamento do } \\
\text { tornozelo e pé }\end{array}$ & & Não & 4anos \\
\hline S98 & $\begin{array}{l}\text { Amputação traumática do } \\
\text { tornozelo e pé }\end{array}$ & & Não & 4anos \\
\hline $\mathrm{T}$ & \multicolumn{4}{|c|}{$\begin{array}{l}\text { Lesões, envenenamentos e algumas outras conseqüências de causas } \\
\text { externas }\end{array}$} \\
\hline T02.1 & $\begin{array}{l}\text { Fratura envolvendo tórax com } \\
\text { parte inferior do dorso e da pelve }\end{array}$ & & Não & 1 ano \\
\hline T02.4 & $\begin{array}{l}\text { Fraturas envolvendo regiões } \\
\text { múltiplas de ambos os membros } \\
\text { superiores }\end{array}$ & & Não & 1 ano \\
\hline T02.5 & $\begin{array}{l}\text { Fraturas envolvendo regiões } \\
\text { múltiplas de ambos os membros } \\
\text { inferiores }\end{array}$ & & Não & 1 ano \\
\hline T02.6 & $\begin{array}{l}\text { Fraturas envolvendo regiões } \\
\text { múltiplas dos membros } \\
\text { superiores com inferiores }\end{array}$ & & Não & 1 ano \\
\hline T02.7 & $\begin{array}{l}\text { Fraturas envolvendo tórax com } \\
\text { parte inferior do dorso e da pelve } \\
\text { com membros }\end{array}$ & & Não & 1ano \\
\hline T04.4 & $\begin{array}{l}\text { Traumatismos por esmagamento } \\
\text { envolvendo regiões múltiplas dos }\end{array}$ & & Não & 1 ano \\
\hline
\end{tabular}




\begin{tabular}{|c|c|c|c|c|}
\hline & $\begin{array}{l}\text { membros superiores com } \\
\text { inferiores }\end{array}$ & & & \\
\hline T04.7 & $\begin{array}{l}\text { Traumatismos por esmagamento } \\
\text { do tórax com abdome, parte } \\
\text { inferior do dorso, pelve e } \\
\text { membros }\end{array}$ & & Não & 1 ano \\
\hline T05 & $\begin{array}{l}\text { Amputações traumáticas } \\
\text { envolvendo múltiplas regiões do } \\
\text { corpo }\end{array}$ & & Sim & 4anos \\
\hline T11.6 & $\begin{array}{l}\text { Amputação traumática de } \\
\text { membro superior, nível não } \\
\text { especificado }\end{array}$ & & Não & 4anos \\
\hline T13.6 & $\begin{array}{l}\text { Amputação traumática de } \\
\text { membro inferior, nível não } \\
\text { especificado }\end{array}$ & & Não & 4anos \\
\hline $\mathrm{T} 21$ & Queimadura e corrosão do tronco & $\begin{array}{l}\text { Somente com limitação } \\
\text { motora }\end{array}$ & Não & 1 ano \\
\hline $\mathrm{T} 22$ & $\begin{array}{l}\text { Queimadura e corrosão do ombro } \\
\text { e de membro superior, exceto } \\
\text { punho e mão }\end{array}$ & $\begin{array}{l}\text { Somente com limitação } \\
\text { motora }\end{array}$ & Não & 1 ano \\
\hline $\mathrm{T} 23$ & $\begin{array}{l}\text { Queimadura e corrosão do punho } \\
\text { e da mão }\end{array}$ & Somente com Atrofia & Não & 1 ano \\
\hline $\mathrm{T} 24$ & $\begin{array}{l}\text { Queimadura e corrosão do quadril } \\
\text { e de membro inferior, exceto } \\
\text { tornozelo e pé }\end{array}$ & $\begin{array}{l}\text { Somente com limitação } \\
\text { motora }\end{array}$ & Não & 1 ano \\
\hline $\mathrm{T} 25$ & $\begin{array}{l}\text { Queimadura e corrosão do } \\
\text { tornozelo e do pé }\end{array}$ & $\begin{array}{l}\text { Somente com limitação } \\
\text { motora }\end{array}$ & Não & 1 ano \\
\hline T87 & $\begin{array}{l}\text { Complicações próprias de } \\
\text { reimplante e amputação }\end{array}$ & & Não & 4anos \\
\hline T90.5 & $\begin{array}{l}\text { Sequiela de traumatismo } \\
\text { intracraniano }\end{array}$ & $\begin{array}{l}\text { Somente com limitação } \\
\text { motora ou cognitiva } \\
\text { Se tiver seqüela } \\
\text { cognitiva, é com } \\
\text { acompanhante }\end{array}$ & Não & 2anos \\
\hline T91.1 & $\begin{array}{l}\text { Seqüela de fratura de coluna } \\
\text { vertebral }\end{array}$ & $\begin{array}{l}\text { Somente com limitação } \\
\text { motora }\end{array}$ & Não & 2anos \\
\hline T92.6 & $\begin{array}{l}\text { Seqüela de esmagamento e } \\
\text { amputação traumática de membro } \\
\text { superior }\end{array}$ & & Não & 4anos \\
\hline T93.1 & Seqüela de fratura de fêmur & $\begin{array}{l}\text { Somente com } \\
\text { encurtamento de } \\
\text { membro que leve a } \\
\text { dificuldade na } \\
\text { deambulação - } \\
\text { escanograma com } \\
\text { dismetria > } 3 \mathrm{~cm}\end{array}$ & Não & 1 ano \\
\hline T93.6 & $\begin{array}{l}\text { Seqüela de esmagamento e } \\
\text { amputação traumática de membro }\end{array}$ & & Não & 4anos \\
\hline
\end{tabular}




\begin{tabular}{|c|c|c|c|c|}
\hline & inferior & & & \\
\hline T95.3 & $\begin{array}{l}\text { Seqüelas de queimadura, corrosão } \\
\text { e geladura de membro inferior }\end{array}$ & & Não & 4anos \\
\hline $\mathrm{Z}$ & \multicolumn{4}{|c|}{$\begin{array}{l}\text { Fatores que influenciam o estado de saúde e o contato com serviços de } \\
\text { saúde }\end{array}$} \\
\hline$\overline{Z 89}$ & Ausência adquirida dos membros & & Não & 4anos \\
\hline & \multicolumn{4}{|c|}{ Doenças orgânicas, não exatamente caracterizadas como deficiências } \\
\hline B20.0 & $\begin{array}{l}\text { Doença pelo HIV resultando em } \\
\text { infecções micobacterianas } \\
\text { (resultando em tuberculose) }\end{array}$ & & Não & 1ano \\
\hline B20.1 & $\begin{array}{l}\text { Doença pelo HIV resultando em } \\
\text { outras infecções bacterianas }\end{array}$ & $\begin{array}{l}\text { Somente com doença } \\
\text { oportunista: A15 até } \\
\text { A19; B58 e B59; J13 até } \\
\text { J18; e J65; C46 }\end{array}$ & Não & 1ano \\
\hline B20.2 & $\begin{array}{l}\text { Doença pelo HIV resultando em } \\
\text { doença citomegálica }\end{array}$ & $\begin{array}{l}\text { Somente com doença } \\
\text { oportunista: A15 até } \\
\text { A19; B58 e B59; J13 até } \\
\text { J18; e J65; C46 }\end{array}$ & Não & 1ano \\
\hline B20.3 & $\begin{array}{l}\text { Doença pelo HIV resultando em } \\
\text { outras infecções virais }\end{array}$ & $\begin{array}{l}\text { Somente com doença } \\
\text { oportunista: A15 até } \\
\text { A19; B58 e B59; J13 até } \\
\text { J18; e J65; C46 }\end{array}$ & Não & 1ano \\
\hline B20.4 & $\begin{array}{l}\text { Doença pelo HIV resultando em } \\
\text { candidíase }\end{array}$ & $\begin{array}{l}\text { Somente com doença } \\
\text { oportunista: A15 até } \\
\text { A19; B58 e B59; J13 até } \\
\text { J18; e J65; C46 }\end{array}$ & Não & 1ano \\
\hline B20.5 & $\begin{array}{l}\text { Doença pelo HIV resultando em } \\
\text { outras micoses }\end{array}$ & $\begin{array}{l}\text { Somente com doença } \\
\text { oportunista: A15 até } \\
\text { A19; B58 e B59; J13 até } \\
\text { J18; e J65; C46 }\end{array}$ & Não & 1ano \\
\hline B20.6 & $\begin{array}{l}\text { Doença pelo HIV resultando em } \\
\text { pneumonia por Pneumocystis } \\
\text { carinii }\end{array}$ & & Não & 1ano \\
\hline B20.7 & $\begin{array}{l}\text { Doença pelo HIV resultando em } \\
\text { infecções múltiplas }\end{array}$ & $\begin{array}{l}\text { Somente com doença } \\
\text { oportunista: A15 até } \\
\text { A19; B58 e B59; J13 até } \\
\text { J18; e J65; C46 }\end{array}$ & Sim & 1ano \\
\hline B20.8 & $\begin{array}{l}\text { Doença pelo HIV resultando em } \\
\text { outras doenças infecciosas e } \\
\text { parasitárias }\end{array}$ & $\begin{array}{l}\text { Somente com doença } \\
\text { oportunista: A15 até } \\
\text { A19; B58 e B59; J13 até } \\
\text { J18; e J65; C46 }\end{array}$ & Não & 1ano \\
\hline B20.9 & $\begin{array}{l}\text { Doença pelo HIV resultando em } \\
\text { doença infecciosa ou parasitária } \\
\text { não especificada }\end{array}$ & $\begin{array}{l}\text { Somente com doença } \\
\text { oportunista: A15 até } \\
\text { A19; B58 e B59; J13 até } \\
\text { J18; e J65; C46 }\end{array}$ & Não & 1ano \\
\hline
\end{tabular}




\begin{tabular}{|c|c|c|c|c|}
\hline B21.0 & $\begin{array}{l}\text { Doença pelo HIV resultando em } \\
\text { sarcoma de Kaposi }\end{array}$ & & Não & 1ano \\
\hline B21.1 & $\begin{array}{l}\text { Doença pelo HIV resultando em } \\
\text { linfoma de Burkitt }\end{array}$ & $\begin{array}{l}\text { Somente com doença } \\
\text { oportunista: A15 até } \\
\text { A19; B58 e B59; J13 até } \\
\text { J18; e J65; C46 }\end{array}$ & Não & 1ano \\
\hline B21.2 & $\begin{array}{l}\text { Doença pelo HIV resultando em } \\
\text { outros tipos de linfoma não- } \\
\text { Hodgkin }\end{array}$ & $\begin{array}{l}\text { Somente com doença } \\
\text { oportunista: A15 até } \\
\text { A19; B58 e B59; J13 até } \\
\text { J18; e J65; C46 }\end{array}$ & Não & 1ano \\
\hline B21.3 & $\begin{array}{l}\text { Doença pelo HIV resultando em } \\
\text { outras neoplasias malignas dos } \\
\text { tecidos linfático, hematopoiético } \\
\text { e correlatos }\end{array}$ & $\begin{array}{l}\text { Somente com doença } \\
\text { oportunista: A15 até } \\
\text { A19; B58 e B59; J13 até } \\
\text { J18; e J65; C46 }\end{array}$ & Não & 1ano \\
\hline B21.7 & $\begin{array}{l}\text { Doença pelo HIV resultando em } \\
\text { múltiplas neoplasias malignas }\end{array}$ & $\begin{array}{l}\text { Somente com doença } \\
\text { oportunista: A15 até } \\
\text { A19; B58 e B59; J13 até } \\
\text { J18; e J65; C46 }\end{array}$ & Sim & 1ano \\
\hline B21.8 & $\begin{array}{l}\text { Doença pelo HIV resultando em } \\
\text { outras neoplasias malignas }\end{array}$ & $\begin{array}{l}\text { Somente com doença } \\
\text { oportunista: A15 até } \\
\text { A19; B58 e B59; J13 até } \\
\text { J18; e J65; C46 }\end{array}$ & Sim & 1ano \\
\hline B21.9 & $\begin{array}{l}\text { Doença pelo HIV resultando em } \\
\text { neoplasia maligna não } \\
\text { especificada }\end{array}$ & $\begin{array}{l}\text { Somente com doença } \\
\text { oportunista: A15 até } \\
\text { A19; B58 e B59; J13 até } \\
\text { J18; e J65; C46 } \\
\end{array}$ & Sim & 1ano \\
\hline B22.0 & $\begin{array}{l}\text { Doença pelo HIV resultando em } \\
\text { encefalopatia (Demência pelo } \\
\text { HIV) }\end{array}$ & & Sim & 1ano \\
\hline B22.1 & $\begin{array}{l}\text { Doença pelo HIV resultando em } \\
\text { pneumonite intersticial linfática }\end{array}$ & $\begin{array}{l}\text { Somente com doença } \\
\text { oportunista: A15 até } \\
\text { A19; B58 e B59; J13 até } \\
\text { J18; e J65; C46 }\end{array}$ & Não & 1ano \\
\hline B22.2 & $\begin{array}{l}\text { Doença pelo HIV resultando em } \\
\text { síndrome de emaciação }\end{array}$ & $\begin{array}{l}\text { Somente com doença } \\
\text { oportunista: A15 até } \\
\text { A19; B58 e B59; J13 até } \\
\text { J18; e J65; C46 }\end{array}$ & Não & 1ano \\
\hline B22.7 & $\begin{array}{l}\text { Doença pelo HIV resultando em } \\
\text { doenças múltiplas classificadas } \\
\text { em outra parte }\end{array}$ & $\begin{array}{l}\text { Somente com doença } \\
\text { oportunista: A15 até } \\
\text { A19; B58 e B59; J13 até } \\
\text { J18; e J65; C46 }\end{array}$ & Sim & 1ano \\
\hline B23.0 & $\begin{array}{l}\text { Síndrome de Infecção Aguda pelo } \\
\text { HIV }\end{array}$ & $\begin{array}{l}\text { Somente com doença } \\
\text { oportunista: A15 até } \\
\text { A19; B58 e B59; J13 até } \\
\text { J18; e J65; C46 }\end{array}$ & Não & 1ano \\
\hline B23.1 & $\begin{array}{l}\text { Doença pelo HIV resultando em } \\
\text { linfadenopatias generalizadas } \\
\text { (persistentes) }\end{array}$ & 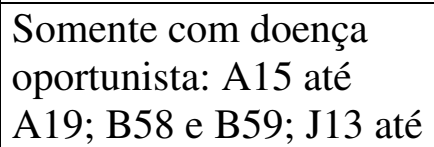 & Não & 1ano \\
\hline
\end{tabular}




\begin{tabular}{|l|l|l|l|l|}
\hline B23.2 & $\begin{array}{l}\text { Doença pelo HIV resultando em } \\
\text { anomalias hematológicas e } \\
\text { imunológicas não classificadas } \\
\text { em outra parte }\end{array}$ & $\begin{array}{l}\text { Somente com doença } \\
\text { oportunista: A15 até } \\
\text { A19; B58 e B59; J13 até } \\
\text { J18; e J65; C46 }\end{array}$ & Não & 1ano \\
\hline B23.8 & $\begin{array}{l}\text { Doença pelo HIV resultando em } \\
\text { outras afecções especificadas }\end{array}$ & $\begin{array}{l}\text { Somente com doença } \\
\text { oportunista: A15 até } \\
\text { A19; B58 e B59; J13 até } \\
\text { J18; e J65; C46 }\end{array}$ & Não & 1ano \\
\hline B24 & $\begin{array}{l}\text { Doença pelo Vírus da } \\
\text { Imunodeficiência Humana (HIV) } \\
\text { não especificada }\end{array}$ & $\begin{array}{l}\text { Somente com doença } \\
\text { oportunista: A15 até } \\
\text { A19; B58 e B59; J13 até } \\
\text { J18; e J65; C46 }\end{array}$ & Não & 1ano \\
\hline $\begin{array}{l}\text { C00 a } \\
\text { C97 }\end{array}$ & $\begin{array}{l}\text { Neoplasias (Tumores) } \\
\text { Malignas(os) }\end{array}$ & $\begin{array}{l}\text { Somente para menores } \\
\text { de 18 anos e em } \\
\text { tratamento de } \\
\text { quimioterapia ou } \\
\text { radioterapia ou } \\
\text { cobaltoterapia }\end{array}$ & Sim & 1ano \\
\hline N18 & Insuficiência Renal Crônica & $\begin{array}{l}\text { Hemodiálise 3X por } \\
\text { semana } \\
\text { Para menores de 18 } \\
\text { anos }\end{array}$ & Sim & 2anos \\
\hline
\end{tabular}




\section{Anexo 3 - AlgoritMo de CODIFICAÇÃo E LISTA NUMÉRICA DE TERMOS CODIFICADOS (ESTUDO NEILS) (SIMEONSSON e} SCARBOROUGH, 2001)

As razões de elegibilidade para serviços de intervenção precoce são codificadas usando os códigos da CID-9 / CID-10 e da ICIDH/CIF e são agrupadas dentro de quatro categorias principais.

Categoria I. Descreve razões de elegibilidade que são baseadas em uma descrição de variação significante no desenvolvimento, forma ou função de sistemas físicos, sensoriais, motores, fisiológicos, neurológicos ou psicológicos. Uma variação significante inclui atraso, perda, restrição, alteração e deficiência do desenvolvimento da função.

Categoria II. Inclui razões de elegibilidade que descrevem uma limitação ou atraso no desempenho nas atividades da vida diária.

Categoria III. As razões de elegibilidade incluídas nesta categoria são aquelas que descrevem condições específicas de saúde, síndromes ou diagnósticos associados com crescimento ou desenvolvimento atrasado ou atípico.

Categoria IV. As razões de elegibilidade capturadas nesta categoria são aquelas que descrevem problemas com fatores ambientais (isto é, falta de, atípico, restrito,etc.) altamente associados com risco para desenvolvimento atrasado ou atípico.

\begin{tabular}{|c|c|c|c|c|}
\hline Lista Alfabética do termo codificado & $\begin{array}{l}\text { Código do } \\
\text { Algoritmo }\end{array}$ & $\begin{array}{l}\text { Código da } \\
\text { CID-10 }\end{array}$ & $\begin{array}{l}\text { Código da } \\
\text { CID-9 }\end{array}$ & $\begin{array}{l}\text { Código } \\
\text { da CIF }\end{array}$ \\
\hline \multicolumn{5}{|l|}{ Categoria I } \\
\hline \multicolumn{5}{|l|}{ A. DESENVOLVIMENTO } \\
\hline $\begin{array}{l}\text { Deficiências no desenvolvimento na } \\
\text { infância precoce }\end{array}$ & A & Z13.4 & V79.3 & \\
\hline $\begin{array}{l}\text { Distúrbio misto do desenvolvimento, } \\
\text { atraso em todas as áreas exceto social- }\end{array}$ & A & F83 & 315.5 & \\
\hline
\end{tabular}




\begin{tabular}{|c|c|c|c|c|}
\hline \begin{tabular}{|l|} 
emocional, os pais geralmente estão \\
preocupados quanto à fala, mas todas \\
as áreas são rebaixadas exceto a motora \\
geral, não passa para a posição em pé, \\
não anda, andando (atraso implícito)
\end{tabular} & & & & \\
\hline $\begin{array}{l}\text { Distúrbio do desenvolvimento, SOE, } \\
\text { Atraso Global, atraso em todas as } \\
\text { áreas, atraso, todas, generalizado, } \\
\text { saindo da curva, balbucios e gritos, } \\
\text { sem palavras, não brinca com outras } \\
\text { crianças, balança o corpo, sorri, } \\
\text { afável), sob risco para atraso no } \\
\text { desenvolvimento, deficiência do } \\
\text { desenvolvimento, falha no teste padrão } \\
\text { de desenvolvimento, falha no teste } \\
\text { padrão de desenvolvimento de Denver, } \\
\text { ou Denver II, MDI 60, MDI 70 - PDI } \\
\text { 76, falha em todas as áreas no teste } \\
\text { Battelle, desenvolvimento atípico, } \\
\text { problemas médicos resultando em } \\
\text { atraso, não anda, fica em pé, engatinha } \\
\text { ou fala. }\end{array}$ & A & F81.9 & 315.9 & \\
\hline $\begin{array}{l}\text { Distúrbio da infância, SOE, retardo } \\
\text { mental, RM, deficiente mental } \\
\text { educável (DME), deficiente mental } \\
\text { treinável (DMT) }\end{array}$ & A & $\begin{array}{l}\text { F79.0 } \\
\text { F79.1 } \\
\text { F79.8 } \\
\text { F79.9 } \\
\text { R41.8 }\end{array}$ & $\begin{array}{c}319 \\
\text { (DSMIV) }\end{array}$ & \\
\hline \multicolumn{5}{|l|}{ Aa. Crescimento Físico } \\
\hline $\begin{array}{l}\text { físico, atrasos físicos, fisicamente } \\
\text { alterado, desenvolvimento físico, }\end{array}$ & $\mathrm{Aa}$ & & $\mathrm{Aa}$ & \\
\hline $\begin{array}{l}\text { Déficit no crescimento, FTT(failure to } \\
\text { thrive), déficit no ganho de peso, } \\
\text { crescimento atrasado, acompanhado } \\
\text { para monitorar crescimento e ganho de } \\
\text { peso }\end{array}$ & $\mathrm{Aa}$ & $\begin{array}{l}\text { E34.3 } \\
\text { R62.0 } \\
\text { R62.8 } \\
\text { R62.9 }\end{array}$ & 783.4 & b530 \\
\hline \multicolumn{5}{|l|}{$\begin{array}{l}\text { B. SISTEMAS SOMÁTICOS } \\
\text { C. SISTEMAS SENSORIAIS }\end{array}$} \\
\hline $\begin{array}{l}\text { Sistemas de Integração Sensorial, } \\
\text { sensório motor, atraso no } \\
\text { processamento de habilidades } \\
\text { sensoriais, distúrbio de integração } \\
\text { sensorial, temas de IS, integração } \\
\text { sensorial atípica }\end{array}$ & $\mathrm{C}$ & & $\mathrm{C}$ & \\
\hline \multicolumn{5}{|l|}{ Ca. Visão/ distúrbios dos olhos } \\
\hline glaucoma & $\mathrm{Ca}$ & H40.9 & 365.9 & \\
\hline $\begin{array}{l}\text { Problemas Visuais: miopia grave, } \\
\text { visão alterada, cego }\end{array}$ & $\mathrm{Ca}$ & $\begin{array}{c}\text { H53 } \\
\text { G73.6 } \\
\text { R44.1 }\end{array}$ & 368 & b210 \\
\hline
\end{tabular}




\begin{tabular}{|c|c|c|c|c|}
\hline Atrofia do nervo óptico & $\mathrm{Ca}$ & $\begin{array}{l}\mathrm{H} 46 \\
\mathrm{H} 47 \\
\mathrm{H} 48\end{array}$ & 377 & \\
\hline Estrabismo & $\mathrm{Ca}$ & $\begin{array}{l}\text { H49.9 } \\
\text { H50.8 } \\
\text { H50.9 }\end{array}$ & 378.9 & \\
\hline Distúrbios do corpo vítreo & $\mathrm{Ca}$ & $\begin{array}{c}\mathrm{H} 43 \\
\mathrm{H} 45.0 \\
\mathrm{H} 45.8\end{array}$ & 379.2 & s2205 \\
\hline Nistagmo, apraxia oculomotora & $\mathrm{Ca}$ & $\begin{array}{c}\text { H51.8 } \\
\text { H55 }\end{array}$ & 379.5 & b2125 \\
\hline \multicolumn{5}{|l|}{ Cb. Audição } \\
\hline $\begin{array}{l}\text { Audição, perda da audição, surdo, } \\
\text { neuropatia auditiva, resposta auditiva }\end{array}$ & $\mathrm{Cb}$ & $\begin{array}{l}\mathrm{H} 91.8 \\
\mathrm{H} 91.9\end{array}$ & 389.9 & $\mathrm{~b} 230$ \\
\hline Hiperacusia & $\mathrm{Cb}$ & H93.2 & 388.4 & \\
\hline \multicolumn{5}{|l|}{ Cc. Vestibular } \\
\hline \multicolumn{5}{|l|}{$\begin{array}{l}\text { D. SISTEMAS MOTORES } \\
\text { Da. Motor Grosseiro }\end{array}$} \\
\hline $\begin{array}{l}\text { Da. Motor Grosseiro } \\
\text { Atraso Motor Grosseiro, motor, atraso } \\
\text { motor, déficits neuro-motores, } \\
\text { planejamento motor, atraso MG, } \\
\text { desenvolvimento motor atípico, motor } \\
\text { grosseiro, sequiência anormal do } \\
\text { desenvolvimento motor, qualidade do } \\
\text { movimento, força muscular e } \\
\text { coordenação, terapia física, controle } \\
\text { pobre da cabeça, psicomotor, atraso } \\
\text { psicomotor, dispraxia }\end{array}$ & $\mathrm{Da}$ & F82 & 315.4 & \\
\hline Anormalidade da Marcha & $\mathrm{Da}$ & R26 & 781.2 & b770 \\
\hline \multicolumn{5}{|l|}{ Db. Motor Fino } \\
\hline $\begin{array}{l}\text { Motor Fino, Terapia Ocupacional, } \\
\text { motor fino perceptual, dureza nos } \\
\text { dedos, coordenação olho-mão }\end{array}$ & $\mathrm{Db}$ & & & $\mathrm{d} 440$ \\
\hline \multicolumn{5}{|l|}{ Dc. Motor oral } \\
\hline $\begin{array}{l}\text { Habilidades Motoras Orais, disfunção, } \\
\text { planejamento motor oral, oral }\end{array}$ & Dc & & $\mathrm{Dc}$ & \\
\hline \multicolumn{5}{|l|}{ Dd. Desenvolvimento da Fala } \\
\hline Afasia & Dd & R47.0 & 784.3 & \\
\hline Disartria & Dd & $\begin{array}{l}\text { R47.1 } \\
\text { R47.8 }\end{array}$ & 784.5 & b320 \\
\hline Apraxia & Dd & $\begin{array}{l}\mathrm{F} 80.2 \\
\mathrm{R} 48.2\end{array}$ & 784.6 & \\
\hline \multicolumn{5}{|l|}{ E.SISTEMAS FISIOLÓGICOS } \\
\hline $\begin{array}{l}\text { Cardíaco, problemas cardíacos, } \\
\text { Coração, distúrbio do coração, }\end{array}$ & $\mathrm{Ea}$ & & & $\mathrm{s} 410$ \\
\hline
\end{tabular}




\begin{tabular}{|c|c|c|c|c|}
\hline $\begin{array}{l}\text { condição cardíaca, ataque cardíaco, } \\
\text { problemas no coração, infarto do } \\
\text { miocárdio }\end{array}$ & & & & \\
\hline Hipertensão pulmonar & $\mathrm{Ea}$ & $\begin{array}{l}\text { I27.0 } \\
\text { I27.1 } \\
\text { I27.8 } \\
\text { I24.9 } \\
\text { I27.9 } \\
\text { I52.1 }\end{array}$ & 416 & b420 \\
\hline Estenose aórtica & $\mathrm{Ea}$ & $\mathrm{I} 35$ & 424.1 & \\
\hline Estenose subaórtica hipertrófica & $\mathrm{Ea}$ & $\mathrm{I} 42.1$ & 425.1 & \\
\hline Cardiomiopatia & $\mathrm{Ea}$ & $\begin{array}{l}\text { I42.0 } \\
\text { I } 42.2 \\
\text { I42.5 } \\
\text { I42.8 } \\
\text { I42.9 } \\
\text { I51.7 }\end{array}$ & 425.4 & $\mathrm{~b} 410$ \\
\hline $\begin{array}{l}\text { Bradicardia, Taquicardia, } \\
\text { supraventricular }\end{array}$ & $\mathrm{Ea}$ & $\begin{array}{l}\text { I47.0 } \\
\text { I47.1 } \\
\text { I49.5 } \\
\text { I49.8 } \\
\text { I49.9 } \\
\text { R00.1 } \\
\text { R00.8 } \\
\text { R01.2 }\end{array}$ & 427.8 & $\mathrm{~b} 4100$ \\
\hline Insuficiência cardíaca congestiva & $\mathrm{Ea}$ & $\begin{array}{c}\mathrm{I} 50 \\
\mathrm{I} 46.9\end{array}$ & 428 & \\
\hline Trombose, perna & $\mathrm{Ea}$ & $\begin{array}{l}\mathrm{I} 80.1 \\
\mathrm{I} 80.2 \\
\mathrm{I} 82.8 \\
\mathrm{I} 86.8\end{array}$ & 453.8 & \\
\hline Sopro cardíaco & $\mathrm{Ea}$ & $\begin{array}{l}\mathrm{R} 01.0 \\
\mathrm{R} 01.1\end{array}$ & 785.2 & \\
\hline \multicolumn{5}{|l|}{ Eb. Respiratório } \\
\hline $\begin{array}{l}\text { Doença Brônquica } \\
\text { (bronquite/bronquiolite) }\end{array}$ & $\mathrm{Eb}$ & $\begin{array}{l}\mathrm{J} 20 \\
\mathrm{~J} 22 \\
\mathrm{~J} 21\end{array}$ & 466 & \\
\hline $\begin{array}{l}\text { Paralisia de Pregas Vocais, Paralisia de } \\
\text { Prega vocal }\end{array}$ & $\mathrm{Eb}$ & $\mathrm{J} 38.0$ & 478.3 & \\
\hline $\begin{array}{l}\text { Estenose glótica, pólipo de prega vocal, } \\
\text { laringe }\end{array}$ & $\mathrm{Eb}$ & $\begin{array}{l}\text { J05.0 } \\
\text { J38.3 } \\
\text { J38.5 } \\
\text { J38.6 } \\
\text { J38.7 } \\
\text { J95.5 }\end{array}$ & 478.7 & \\
\hline $\begin{array}{l}\text { doença da via aérea brônquica ou } \\
\text { reativa, distúrbio }\end{array}$ & $\mathrm{Eb}$ & $\begin{array}{l}\mathrm{J} 45 \\
\mathrm{~J} 46\end{array}$ & 493 & \\
\hline Asma & $\mathrm{Eb}$ & $\mathrm{J} 45.0$ & 493.9 & \\
\hline
\end{tabular}




\begin{tabular}{|c|c|c|c|c|}
\hline & & $\begin{array}{c}\mathrm{J} 45.8 \\
\mathrm{~J} 45.9 \\
\mathrm{~J} 46\end{array}$ & & \\
\hline \multicolumn{5}{|l|}{ Ec. Digestivo } \\
\hline problemas no fígado & Ec & & & s506 \\
\hline $\begin{array}{l}\text { aerofagia (vômitos cíclicos } \\
\text { psicogênicos) }\end{array}$ & Ec & $\begin{array}{l}\text { F45.3 } \\
\text { F45.8 } \\
\text { F50.5 } \\
\text { F54 }\end{array}$ & 306.4 & \\
\hline $\begin{array}{l}\text { edema pulmonar, líquido nos pulmões, } \\
\text { edema pulmonar }\end{array}$ & Ec & $\begin{array}{c}\mathrm{J} 18.2 \\
\mathrm{~J} 81\end{array}$ & 514 & \\
\hline "baba" (salivação excessiva) & Ec & $\begin{array}{l}\mathrm{K} 11.7 \\
\mathrm{R} 68.2\end{array}$ & 527.7 & \\
\hline esofagite & Ec & $\begin{array}{c}\text { K20 } \\
\text { K21.0 } \\
\text { K21.9 } \\
\text { K23.0 } \\
\text { K23.8 }\end{array}$ & 530.1 & \\
\hline $\begin{array}{l}\text { refluxo esofágico (hérnia de fundo } \\
\text { gástrico), Refluxo Gastro-Esofágico, } \\
\text { RGE }\end{array}$ & Ec & $\begin{array}{l}\text { J86.0 } \\
\text { K21.9 } \\
\text { K22.1 } \\
\text { K22.8 } \\
\text { K23.8 } \\
\text { Z90.4 } \\
\text { K22.9 }\end{array}$ & 530.8 & \\
\hline Ruptura do Apêndice & Ec & $\begin{array}{l}\text { K35.0 } \\
\text { K65.0 } \\
\text { K65.8 } \\
\text { K35.1 } \\
\text { K35.9 }\end{array}$ & 540 & \\
\hline Enterocolite necrotizante, ECN & Ec & K55 & 557 & \\
\hline Obstrução Intestinal & Ec & K56 & 560 & s540 \\
\hline Volvo intestinal & Ec & K56.2 & 560.2 & \\
\hline Distúrbios da Vesícula & Ec & $\begin{array}{c}\text { K81 } \\
\text { K82 } \\
\text { K83.0 } \\
\text { K83.1 } \\
\text { K83.8 } \\
\text { K87.0 } \\
\text { Z90.4 }\end{array}$ & 575 & \\
\hline Problemas com a evacuação & Ec & $\begin{array}{c}\text { K58 } \\
\text { K59 } \\
\text { K91 } \\
\text { K93.1 } \\
\text { R19.8 } \\
\text { Z90.3 }\end{array}$ & 564 & b5250 \\
\hline $\begin{array}{l}\text { Intestino curto, Síndrome do intestino } \\
\text { curto }\end{array}$ & Ec & K91.2 & 579.3 & \\
\hline
\end{tabular}




\begin{tabular}{|c|c|c|c|c|}
\hline Disfagia & Ec & R13 & 787.2 & b510 \\
\hline Fígado aumentado & Ec & R16.0 & 789.1 & s560 \\
\hline \multicolumn{5}{|l|}{ Ed. Endócrino/ Metabólico } \\
\hline Hipotiroidismo (congênito) & Ed & $\begin{array}{c}\text { E00 } \\
\text { E03.1 } \\
\text { E07.1 }\end{array}$ & 243 & \\
\hline Hipoglicemia & Ed & $\begin{array}{l}\text { E16.1 } \\
\text { E16.2 }\end{array}$ & 251.2 & \\
\hline Síndrome de Sotos & Ed & $\begin{array}{c}\text { E22 } \\
\text { E23 } \\
\text { E34.4 } \\
\text { E89.3 }\end{array}$ & 253 & \\
\hline Pan-hipopituitarismo & Ed & E23.0 & 253.2 & \\
\hline Puberdade precoce & Ed & $\begin{array}{l}\text { E30.1 } \\
\text { E30.8 }\end{array}$ & 259.1 & \\
\hline Nanismo, estrutura esquelética pequena & Ed & E34.3 & 259.4 & \\
\hline Desnutrição & Ed & $\begin{array}{c}\text { e44.0 } \\
\text { E44.1 } \\
\text { E45 } \\
\text { E46 } \\
\text { E64.0 } \\
\text { R64 }\end{array}$ & 263 & \\
\hline Deficiência de Biotina & Ed & $\begin{array}{l}\text { E53.8 } \\
\text { E53.9 }\end{array}$ & 266.2 & \\
\hline Fraturas & Ed & $\begin{array}{l}\text { D65 } \\
\text { D66 } \\
\text { D67 } \\
\text { D68 }\end{array}$ & 286 & \\
\hline Fenilcetonúria, PKU & Ed & $\begin{array}{l}\text { E70.0 } \\
\text { E70.1 }\end{array}$ & 270.1 & \\
\hline Albinismo, albinismo ocular & Ed & $\begin{array}{l}\text { E70.2 } \\
\text { E70.3 } \\
\text { E70.8 } \\
\text { E70.9 } \\
\text { E72.0 } \\
\text { E72.1 }\end{array}$ & 270.2 & \\
\hline Doença do xarope de bordo & Ed & $\begin{array}{l}\text { E71.0 } \\
\text { E71.1 } \\
\text { E71.2 }\end{array}$ & 270.3 & \\
\hline Doença de acúmulo de glicogênio & Ed & $\begin{array}{c}\text { E71.1 } \\
\text { E73 } \\
\text { E74 }\end{array}$ & 271 & \\
\hline $\begin{array}{l}\text { Intolerância à lactose, deficiência de } \\
\text { beta-galactosidadse }\end{array}$ & Ed & $\begin{array}{c}\text { E73 } \\
\text { E74.3 }\end{array}$ & 271.3 & \\
\hline Distúrbios do metabolismo lipídico & Ed & $\begin{array}{c}\text { E75 } \\
\text { E77.0 } \\
\text { E78 } \\
\text { E88 } \\
\end{array}$ & 272 & \\
\hline
\end{tabular}




\begin{tabular}{|c|c|c|c|c|}
\hline & & $\begin{array}{l}\mathrm{H} 02.6 \\
\mathrm{D} 76.0\end{array}$ & & \\
\hline Intolerância à proteína & Ed & $\begin{array}{l}\text { E75.5 } \\
\text { E78.2 } \\
\text { H02.6 }\end{array}$ & 272.2 & \\
\hline $\begin{array}{l}\text { Doença de Niemann-Pick, Doença de } \\
\text { Wolman, Mucolipidoses }\end{array}$ & Ed & $\begin{array}{l}\text { D76.0 } \\
\text { E74.0 } \\
\text { E75.0 } \\
\text { E75.2 } \\
\text { E75.3 } \\
\text { E75.5 } \\
\text { E75.6 } \\
\text { E77.0 } \\
\text { E78.2 }\end{array}$ & 272.7 & \\
\hline Hipocalcemia & $\mathrm{Ed}$ & $\begin{array}{c}\text { E20.1 } \\
\text { E83.5 } \\
\text { M11 } \\
\text { R89.7 }\end{array}$ & 275.4 & \\
\hline Hipernatremia & $\mathrm{Ed}$ & $\begin{array}{c}\text { E86 } \\
\text { E87 } \\
\text { E88.8 } \\
\text { R60.9 }\end{array}$ & 276 & \\
\hline $\begin{array}{l}\text { Hiperbilirrubinemia(bilirrubina } \\
\text { elevada) }\end{array}$ & Ed & $\begin{array}{c}\text { E80.4 } \\
\text { E80.5 } \\
\text { E80.6 } \\
\text { E80.7 }\end{array}$ & 277.4 & \\
\hline Obesidade, sobrepeso & Ed & $\begin{array}{l}\text { E65 } \\
\text { E66 } \\
\text { E67 } \\
\text { E68 }\end{array}$ & 278 & \\
\hline \multicolumn{5}{|l|}{ Ee. Urológico } \\
\hline Refluxo Uretral & $\mathrm{Ee}$ & N13.7 & 593.7 & \\
\hline Refluxo Bilateral & $\mathrm{Ee}$ & N13.7 & 593.7 & \\
\hline Bexiga Neurogênica & $\mathrm{Ee}$ & N31 & 596.5 & \\
\hline \multicolumn{5}{|c|}{ Ef. Hematológico/ Linfático/ Imunológico } \\
\hline $\begin{array}{l}\text { Distúrbio hematológico, plaquetas } \\
\text { baixas, baixa imunidade }\end{array}$ & Ef & & & $\mathrm{b} 435$ \\
\hline Síndrome de Di George & Ef & $\begin{array}{l}\text { D81.4 } \\
\text { D82.0 } \\
\text { D82.1 } \\
\text { D84.0 } \\
\text { D84.1 } \\
\text { D84.8 }\end{array}$ & 279.1 & \\
\hline Talassemia, beta sickle & Ef & $\begin{array}{c}\text { D56 } \\
\text { D64.8 }\end{array}$ & 282.4 & \\
\hline Anemia falciforme & Ef & $\begin{array}{c}\text { D57 } \\
\text { D58.2 }\end{array}$ & 282.6 & \\
\hline Hemofilia & Ef & D65 & 286 & \\
\hline
\end{tabular}




\begin{tabular}{|c|c|c|c|c|}
\hline & & $\begin{array}{l}\text { D66 } \\
\text { D67 } \\
\text { D68 }\end{array}$ & & \\
\hline Doença de Von Willebrand & Ef & D68.0 & 286.4 & \\
\hline Trombocitopenia & Ef & D69.6 & 287.5 & \\
\hline Síndrome de Job & Ef & D71 & 288.1 & \\
\hline Metemoglobinemia & Ef & D74 & 289.7 & \\
\hline \multicolumn{5}{|l|}{ F. NEUROLÓGICO } \\
\hline $\begin{array}{l}\text { Neurológico, doenças neurológicas, } \\
\text { problemas, exame neurológico } \\
\text { suspeito, neurologicamente alterado, } \\
\text { exame neurológico anormal, queixas } \\
\text { neurológicas }\end{array}$ & $\mathrm{F}$ & & $\mathrm{F}$ & \\
\hline Doença de Tourette & $\mathrm{F}$ & F95 & 307.2 & \\
\hline Distúrbio do Sono & $\mathrm{F}$ & F51 & 307.4 & b130 \\
\hline Enxaqueca & $\mathrm{F}$ & $\begin{array}{l}\mathrm{G} 43 \\
\mathrm{G} 44 \\
\end{array}$ & 346.9 & \\
\hline Miopatia Mitocondrial & $\mathrm{F}$ & $\begin{array}{c}\text { G64 } \\
\text { G71.9 } \\
\text { G72.9 } \\
\text { M62.9 }\end{array}$ & 359.9 & \\
\hline \multicolumn{5}{|l|}{ G. PSICOLÓGICO } \\
\hline \multicolumn{5}{|l|}{ Ga. Intelectual / Cognitivo } \\
\hline Aprendizagem & $\mathrm{Ga}$ & & & d159 \\
\hline Autismo, Síndrome de Asperger & $\mathrm{Ga}$ & F84 & 299 & \\
\hline $\begin{array}{l}\text { Distúrbio Invasivo do } \\
\text { Desenvolvimento, TGD }\end{array}$ & $\mathrm{Ga}$ & F84.8 & 299.8 & \\
\hline Cognitivo, cognição & $\mathrm{Ga}$ & & & b118 \\
\hline Déficit de Atenção & $\mathrm{Ga}$ & F90 & 314 & b140 \\
\hline $\begin{array}{l}\text { Transtorno de Déficit de Atenção com } \\
\text { Hiperatividade (TDAH) }\end{array}$ & $\mathrm{Ga}$ & $\begin{array}{l}\text { F90.0 } \\
\text { F90.9 }\end{array}$ & $\begin{array}{c}314.0 \\
(\mathrm{DSMIV})\end{array}$ & \\
\hline $\begin{array}{l}\text { Atraso no Desenvolvimento com } \\
\text { Hipercinesia }\end{array}$ & $\mathrm{Ga}$ & F90.0 & 314.1 & \\
\hline $\begin{array}{l}\text { Hiperatividade, nível de atividade, } \\
\text { hipercinesia }\end{array}$ & $\mathrm{Ga}$ & F90.9 & 314.9 & \\
\hline \multicolumn{5}{|l|}{ Gb. Afetivo } \\
\hline Crises de birra & $\mathrm{Gb}$ & F91.2 & 312.1 & \\
\hline controle do impulso & $\mathrm{Gb}$ & F92 & 312.3 & b1264 \\
\hline $\begin{array}{l}\text { distúrbio reativo de ligação, distúrbio } \\
\text { emocional }\end{array}$ & $\mathrm{Gb}$ & F93.8 & $\begin{array}{c}313.8 \\
(\mathrm{DSMIV}) \\
313 \\
\end{array}$ & \\
\hline \multicolumn{5}{|l|}{ Gc. Linguagem } \\
\hline $\begin{array}{l}\text { Distúrbio do Desenvolvimento da Fala } \\
\text { ou da Linguagem, atraso no } \\
\text { desenvolvimento da fala, atraso de fala } \\
\text { e linguagem, lentidão para falar }\end{array}$ & $\mathrm{Gc}$ & $\begin{array}{c}\text { F80 } \\
\text { F81.8 }\end{array}$ & 315.3 & \\
\hline Linguagem expressiva, atraso na & Gc & F80 & 315.31 & \\
\hline
\end{tabular}




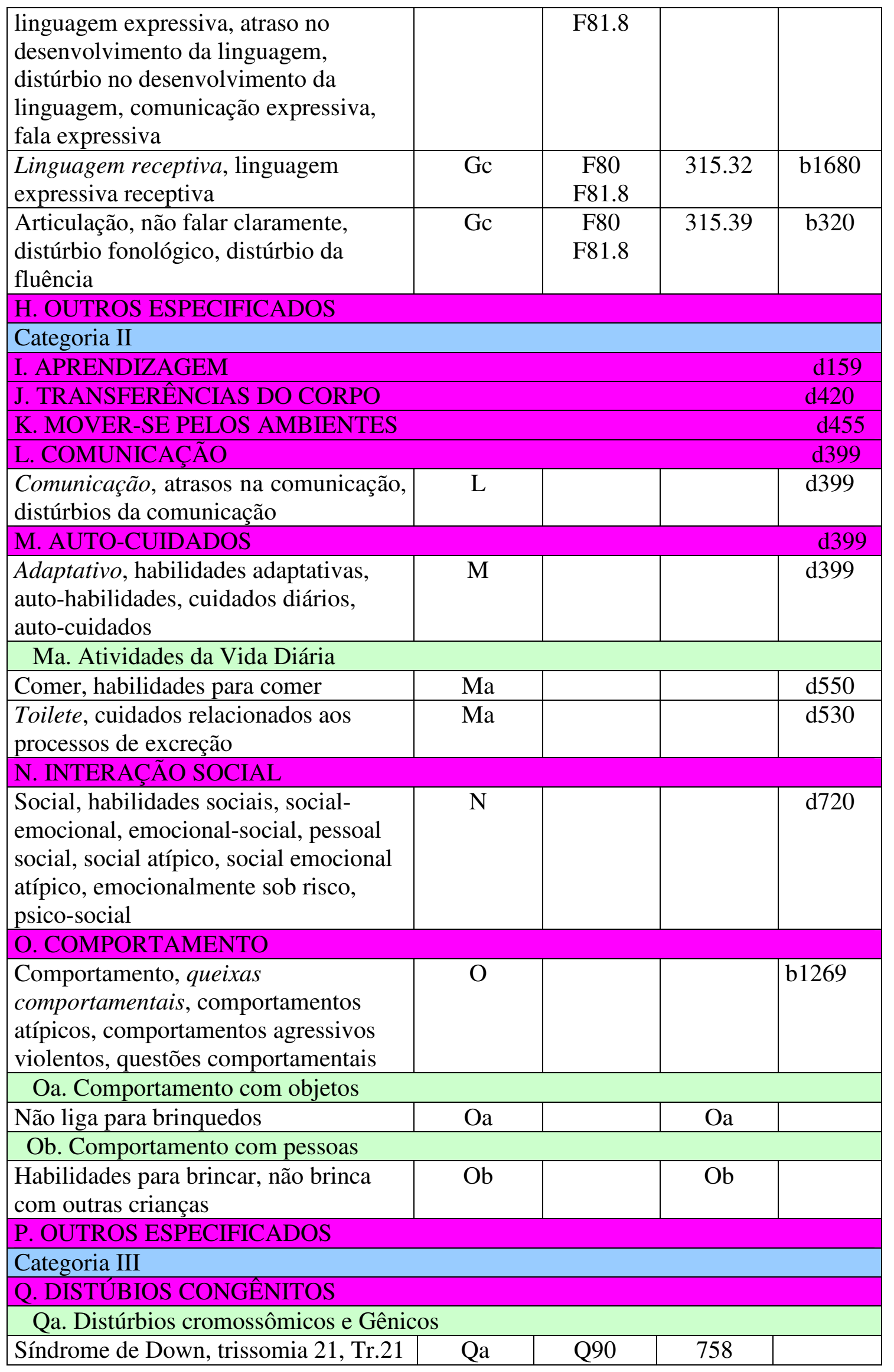




\begin{tabular}{|c|c|c|c|}
\hline $\begin{array}{l}\text { Trissomia } 22 \text {, síndrome cromossômica } \\
\text { genética } 22\end{array}$ & $\mathrm{Qa}$ & $\begin{array}{c}\text { Q90 } \\
\text { Q92.8 }\end{array}$ & 758.01 \\
\hline Trissomia 13 & $\mathrm{Qa}$ & $\begin{array}{l}\text { Q91.4 a } \\
\text { Q91.7 }\end{array}$ & 758.1 \\
\hline Trissomia 18 & $\mathrm{Qa}$ & $\begin{array}{c}\text { Q91.0 a } \\
\text { Q91.3 }\end{array}$ & 758.2 \\
\hline Síndrome Cri-du-chat & $\mathrm{Qa}$ & Q93 & 758.3 \\
\hline Trissomia, trissomia 8, trissomia 2 & $\mathrm{Qa}$ & $\begin{array}{c}\text { Q92 } \\
\text { Q95.3 } \\
\text { Q95.8 } \\
\text { Q99.9 }\end{array}$ & 758.5 \\
\hline $\begin{array}{l}\text { Síndrome de Turner (disgenesia } \\
\text { gonadal) }\end{array}$ & $\mathrm{Qa}$ & $\begin{array}{c}\text { Q87.1 } \\
\text { Q96 } \\
\text { Q99.1 }\end{array}$ & 758.6 \\
\hline Síndrome de Klinefelter & $\mathrm{Qa}$ & $\begin{array}{c}\text { Q98.0 a } \\
\text { Q98.6 } \\
\text { Q99.1 }\end{array}$ & 758.7 \\
\hline Síndrome XXX, XXXXY & $\mathrm{Qa}$ & $\begin{array}{c}\text { Q97 } \\
\text { Q98.1 } \\
\text { Q98.5 } \\
\text { Q98.7 a } \\
\text { Q98.9 } \\
\text { Q99.0 a } \\
\text { Q99.2 }\end{array}$ & 758.81 \\
\hline $\begin{array}{l}\text { Outras anomalias genéticas / } \\
\text { cromossômicas, } 18 p \text { negativo, } \\
\text { anormalidade cromossômica, anomalia } \\
\text { cromossômica, distúrbio genético, } \\
\text { defeito cromossômico, translocação } \\
\text { cromossômica, cariótipo anormal 46XY } \\
\text { 10p, duplicação de novo Xq23, } \\
\text { anomalias genéticas e metabólicas, } \\
\text { duplicação de bandas no braço longo do } \\
\text { cromossomo X, anomalias } \\
\text { cromossômicas múltiplas, síndrome } \\
\text { genética R/O, síndrome } 8 \text { recombinante }\end{array}$ & $\mathrm{Qa}$ & $\begin{array}{l}\text { Q99.8 } \\
\text { Q99.9 }\end{array}$ & 758.9 \\
\hline Baço ausente & $\mathrm{Qa}$ & Q89 & 759 \\
\hline Situs inversus, heterotaxia & $\mathrm{Qa}$ & Q89.3 & 759.3 \\
\hline Esclerose tuberosa & $\mathrm{Qa}$ & Q85.1 & 759.5 \\
\hline Síndrome de Prader-Willi & $\mathrm{Qa}$ & & 759.81 \\
\hline Síndrome de Marfan & $\mathrm{Qa}$ & & 759.82 \\
\hline X frágil & $\mathrm{Qa}$ & & 759.83 \\
\hline $\begin{array}{l}\text { Outras síndromes congênitas } \\
\text { especificadas, síndrome de Beckwith- } \\
\text { Wiedemann, síndrome de Noonan, } \\
\text { síndrome oro-facial digital, síndrome de } \\
\text { Rubinstein-Taybi, síndrome ou } \\
\text { associação VATER, síndrome de }\end{array}$ & $\mathrm{Qa}$ & $\begin{array}{l}\text { E83.0 } \\
\text { Q01.9 } \\
\text { Q04.9 } \\
\text { Q74.0 } \\
\text { Q79.8 } \\
\text { Q86.0 }\end{array}$ & 759.89 \\
\hline
\end{tabular}




\begin{tabular}{|c|c|c|c|c|}
\hline $\begin{array}{l}\text { Angelman, síndrome ou associação } \\
\text { CHARGE, síndrome de Wolf- } \\
\text { Hirschorn, síndrome do crânio em folha } \\
\text { de cravo, , síndrome de Fryns, síndrome } \\
\text { de Hay-Wells, síndrome de Klippel- } \\
\text { Weber, síndrome de Polland, síndrome } \\
\text { de Robinow, síndrome de Smith- } \\
\text { Magenis, síndrome de stickler, } \\
\text { síndrome de Walker-Wahrburg, } \\
\text { síndrome de Williams, síndrome de } \\
\text { Cornélia-De Lange, síndrome de Seckel }\end{array}$ & & $\begin{array}{c}\text { Q86.1 } \\
\text { Q86.2 } \\
\text { Q86.8 } \\
\text { Q87 } \\
\text { Q89.8 }\end{array}$ & & \\
\hline \multicolumn{5}{|l|}{ Qb. Outras anomalias congênitas } \\
\hline Dentes com dupla fileira (row) & $\mathrm{Qb}$ & K00.1 & 520.1 & \\
\hline Alvéolos fendidos & $\mathrm{Qb}$ & $\begin{array}{l}\text { K08.8 } \\
\text { K08.9 } \\
\text { K10.2 }\end{array}$ & 525.8 & \\
\hline Microftalmia, microftalmo & $\mathrm{Qb}$ & Q11.2 & 743.10 & \\
\hline Catarata & $\mathrm{Qb}$ & $\begin{array}{l}\mathrm{Q} 12.0 \mathrm{a} \\
\mathrm{Q} 12.4 \\
\mathrm{Q} 12.8\end{array}$ & 743.3 & \\
\hline $\begin{array}{l}\text { Aniridia, coloboma, anomalias do olho } \\
\text { anterior }\end{array}$ & $\mathrm{Qb}$ & $\begin{array}{l}\text { Q13 } \\
\text { Q15.0 } \\
\text { Q15.8 }\end{array}$ & 743.4 & \\
\hline Coloboma, anomalias do olho anterior & $\mathrm{Qb}$ & & 743.4 & \\
\hline $\begin{array}{l}\text { Ptose bilateral, anomalias das pálpebras, } \\
\text { órbitas, lacrimal }\end{array}$ & $\mathrm{Qb}$ & $\begin{array}{l}\text { Q10.0 a } \\
\text { Q10.6 } \\
\text { Q15.8 }\end{array}$ & 743.6 & \\
\hline $\begin{array}{l}\text { Doença de Norrie, outras anormalidades } \\
\text { especificadas dos olhos }\end{array}$ & $\mathrm{Qb}$ & $\begin{array}{l}\text { Q11.3 } \\
\text { Q15.8 }\end{array}$ & 743.8 & \\
\hline $\begin{array}{l}\text { Displasia septo-óptica, anomalia óptica } \\
\text { não especificada, hipoplasia do nervo } \\
\text { óptico }\end{array}$ & $\mathrm{Qb}$ & $\begin{array}{l}\text { Q10.3 } \\
\text { Q10.6 } \\
\text { Q10.7 } \\
\text { Q12.9 } \\
\text { Q13.2 } \\
\text { Q13.4 } \\
\text { Q14.0 a } \\
\text { Q14.3 } \\
\text { Q14.9 } \\
\text { Q15.8 } \\
\text { Q15.9 }\end{array}$ & 743.9 & \\
\hline $\begin{array}{l}\text { Microtia, outras anomalias especificadas } \\
\text { da orelha }\end{array}$ & $\mathrm{Qb}$ & $\begin{array}{c}\text { Q16.2 } \\
\text { Q16.4 } \\
\text { Q17.1 a } \\
\text { Q17.5 } \\
\text { Q17.8 }\end{array}$ & 744.2 & \\
\hline $\begin{array}{l}\text { Protrusão da orelha, outras anomalias } \\
\text { especificadas da orelha }\end{array}$ & $\mathrm{Qb}$ & & 744.2 & \\
\hline Defeito aórtico septal (DAS) & $\mathrm{Qb}$ & Q20 e Q21 & 745 & \\
\hline
\end{tabular}




\begin{tabular}{|c|c|c|c|c|}
\hline Transposição de grandes artérias & $\mathrm{Qb}$ & $\begin{array}{l}\text { Q20.1 a } \\
\text { Q20.5 }\end{array}$ & 745.1 & \\
\hline Tetralogia de Fallot & $\mathrm{Qb}$ & $\begin{array}{l}\text { Q21.3 } \\
\text { Q21.8 }\end{array}$ & 745.2 & \\
\hline Defeito do Septo Ventricular (DSV) & $\mathrm{Qb}$ & $\begin{array}{l}\text { Q2 } 2.5 \\
\text { Q21.0 } \\
\text { Q21.2 } \\
\text { Q21.8 }\end{array}$ & 745.4 & \\
\hline Forame Oval Patente (FOP) & $\mathrm{Qb}$ & Q21.1 & 745.5 & \\
\hline Defeito do Coxim Endocárdico & $\mathrm{Qb}$ & $\begin{array}{l}\text { Q21.1 } \\
\text { Q21.2 }\end{array}$ & 745.6 & \\
\hline Atresia pulmonar & $\mathrm{Qb}$ & $\begin{array}{l}\text { Q22.0 a } \\
\text { Q22.3 }\end{array}$ & 746.01 & \\
\hline Estenose pulmonar & $\mathrm{Qb}$ & & 746.02 & \\
\hline Atresia Tricúspide & $\mathrm{Qb}$ & Q22.4 & 746.1 & \\
\hline Arco Aórtico Bicúspide & $\mathrm{Qb}$ & Q23.1 & 746.4 & \\
\hline Insuficiência Mitral & $\mathrm{Qb}$ & Q23.3 & 746.6 & \\
\hline $\begin{array}{l}\text { Síndrome do coração esquerdo } \\
\text { hipoplásico }\end{array}$ & $\mathrm{Qb}$ & Q23.4 & 746.7 & \\
\hline Dextro-cardia, dextrocardia cardíaca & $\mathrm{Qb}$ & $\begin{array}{c}\text { Q20.4 a } \\
\text { Q20.9 } \\
\text { Q21.0 } \\
\text { Q22.4 a } \\
\text { Q22.8 } \\
\text { Q23.0 a } \\
\text { Q23.2 } \\
\text { Q23.8 } \\
\text { Q24.0 a } \\
\text { Q24.8 }\end{array}$ & 746.87 & \\
\hline cardiomegalia & $\mathrm{Qb}$ & & 756.89 & \\
\hline $\begin{array}{l}\text { Anomalia cardíaca não especificada, } \\
\text { doença congênita do coração, defeito, } \\
\text { anomalia, anomalia cardíaca, ventrículo } \\
\text { direito hipoplásico, defeito do canal } \\
\text { atrioventricular, síndrome velo- } \\
\text { cardiofacial }\end{array}$ & $\mathrm{Qb}$ & $\begin{array}{l}\text { Q20.8 } \\
\text { Q20.9 } \\
\text { Q22.9 } \\
\text { Q23.8 } \\
\text { Q23.9 } \\
\text { Q24.5 } \\
\text { Q24.8 } \\
\text { Q24.9 } \\
\text { Q2 } 2.9 \\
\end{array}$ & 746.9 & s4100 \\
\hline $\begin{array}{l}\text { Hipoplasia cardiopulmonar (não } \\
\text { fechamento de válvula) }\end{array}$ & $\mathrm{Qb}$ & $\begin{array}{c}\mathrm{P} 29.3 \\
\mathrm{Q} 25 \text { a } \mathrm{Q} 28\end{array}$ & 747 & \\
\hline $\begin{array}{l}\text { Ducto arterioso persistente (DAP), ducto } \\
\text { patente }\end{array}$ & $\mathrm{Qb}$ & $\begin{array}{l}\mathrm{P} 29.3 \\
\mathrm{Q} 25.0\end{array}$ & 747.0 & \\
\hline $\begin{array}{l}\text { Hipoplasia do arco aórtico, coarctação da } \\
\text { aorta }\end{array}$ & $\mathrm{Qb}$ & $\begin{array}{l}\text { Q25.1 } \\
\text { Q25.2 }\end{array}$ & 747.1 & \\
\hline $\begin{array}{l}\text { Arco aórtico interrompido, coarctação de } \\
\text { aorta }\end{array}$ & $\mathrm{Qb}$ & & 747.11 & \\
\hline
\end{tabular}




\begin{tabular}{|c|c|c|c|c|}
\hline $\begin{array}{l}\text { Retorno Venoso Pulmonar Anômalo } \\
\text { Total, anomalias de grandes veias }\end{array}$ & $\mathrm{Qb}$ & $\begin{array}{l}\text { Q26.0 a } \\
\text { Q26.9 }\end{array}$ & 747.4 & \\
\hline Anomalia vascular periférica & $\mathrm{Qb}$ & $\begin{array}{c}\text { Q27.1 a } \\
\text { Q27.9 } \\
\text { Q28.1 }\end{array}$ & 747.6 & \\
\hline Atresia de coana & $\mathrm{Qb}$ & Q30 a Q34 & 748 & \\
\hline $\begin{array}{l}\text { Traqueomalácia, broncomalácia, estenose } \\
\text { traqueal }\end{array}$ & $\mathrm{Qb}$ & $\begin{array}{c}\text { Q31.1 a } \\
\text { Q31.9 } \\
\text { Q32.0 a } \\
\text { Q32.4 } \\
\text { Q34.8 }\end{array}$ & 748.3 & \\
\hline Hipoplasia pulmonar & $\mathrm{Qb}$ & $\begin{array}{l}\text { Q33.2 a } \\
\text { Q33.8 }\end{array}$ & 748.5 & \\
\hline Fenda palatina, submucosa & $\mathrm{Qb}$ & Q35 a Q37 & 749 & s3202 \\
\hline Fenda labial & $\mathrm{Qb}$ & $\begin{array}{l}\text { Q36.0 a } \\
\text { Q36.9 }\end{array}$ & 749.1 & s3204 \\
\hline Língua presa & $\mathrm{Qb}$ & Q38 a Q40 & 750 & s3203 \\
\hline Língua pequena & $\mathrm{Qb}$ & $\begin{array}{l}\text { Q38.2 } \\
\text { Q38.3 }\end{array}$ & 750.1 & s3203 \\
\hline $\begin{array}{l}\text { Fístula esôfago-traqueal (FET), atresia } \\
\text { esofágica }\end{array}$ & $\mathrm{Qb}$ & $\begin{array}{c}\text { Q39.0 a } \\
\text { Q39.4 } \\
\text { Q39.8 }\end{array}$ & 750.3 & \\
\hline Espasmo pilórico & $\mathrm{Qb}$ & Q40.0 & 750.5 & \\
\hline Hérnia hiatal & $\mathrm{Qb}$ & Q40.1 & 750.6 & \\
\hline $\begin{array}{l}\text { Atresia duodenal, atresia de intestino } \\
\text { delgado }\end{array}$ & $\mathrm{Qb}$ & $\begin{array}{l}\text { Q41.0 a } \\
\text { Q41.9 }\end{array}$ & 751.1 & \\
\hline Atresia de intestino grosso, estenose retal & $\mathrm{Qb}$ & $\begin{array}{l}\text { Q42.0 a } \\
\text { Q42.9 }\end{array}$ & 751.2 & \\
\hline Doença de Hirschsprung & $\mathrm{Qb}$ & $\begin{array}{l}\text { Q43.1 } \\
\text { Q43.2 } \\
\text { Q43.8 }\end{array}$ & 751.3 & \\
\hline $\begin{array}{l}\text { Má rotação intestinal, intestino mal } \\
\text { rodado, anomalias da fixação intestinal }\end{array}$ & $\mathrm{Qb}$ & Q43.3 & 751.4 & \\
\hline $\begin{array}{l}\text { Atresia biliar, anomalia da vesícula biliar, } \\
\text { fígado e ductos biliares }\end{array}$ & $\mathrm{Qb}$ & $\begin{array}{l}\text { Q44.0 a } \\
\text { Q44.7 }\end{array}$ & 751.6 & \\
\hline Hepatomegalia & $\mathrm{Qb}$ & & 751.69 & \\
\hline Criptorquidia & $\mathrm{Qb}$ & $\begin{array}{c}\text { Q53.0 a } \\
\text { Q53.9 } \\
\text { Q55.2 }\end{array}$ & 752.5 & s6304 \\
\hline Hipospádia & $\mathrm{Qb}$ & $\begin{array}{c}\text { Q54.0 a } \\
\text { Q54.9 } \\
\text { Q64.0 }\end{array}$ & 752.6 & \\
\hline Micropênis & $\mathrm{Qb}$ & & 752.64 & s6305 \\
\hline Anomalias urinárias congênitas & $\mathrm{Qb}$ & $\begin{array}{c}\text { Q60 a Q64 } \\
\text { N07.9 } \\
\text { P96.0 }\end{array}$ & 753 & \\
\hline Rim policístico, multicístico & $\mathrm{Qb}$ & Q61.0 a & 753.12 & \\
\hline
\end{tabular}




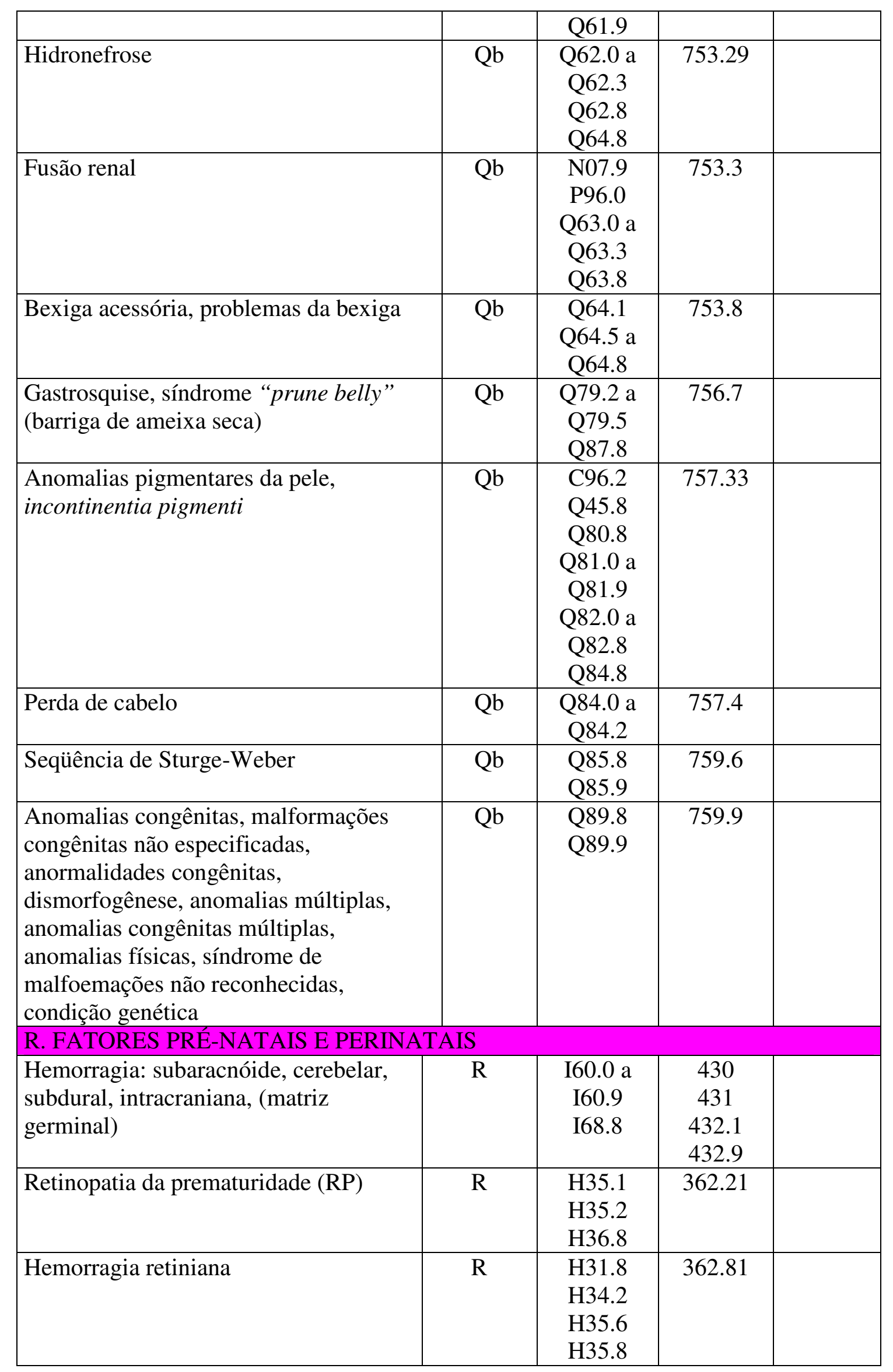




\begin{tabular}{|c|c|c|c|c|}
\hline Descolamento da retina & $\mathrm{R}$ & H31.4 & 363.7 & s2203 \\
\hline $\begin{array}{l}\text { Acidente vascular cerebral, infarto } \\
\text { cerebral, infarto intracraniano }\end{array}$ & $\mathrm{R}$ & $\begin{array}{c}\text { G46.3 a } \\
\text { G46.8 } \\
\text { I63.8 } \\
\text { I64 } \\
\text { I66.3 } \\
\text { I67.8 }\end{array}$ & 436 & \\
\hline $\begin{array}{l}\text { Pós-termo, parto tardio, gravidez } \\
\text { prolongada }\end{array}$ & $\mathrm{R}$ & $\mathrm{O} 48$ & 645 & \\
\hline Deficiência (ou insuficiência) umbilical & $\mathrm{R}$ & $\begin{array}{c}\text { O69.0 a } \\
\text { O69.9 }\end{array}$ & 663 & \\
\hline $\begin{array}{l}\text { Hipertensão (materna) (relacionada a } \\
\text { prematuridade) }\end{array}$ & $\mathrm{R}$ & $\begin{array}{c}\text { P00.0 a } \\
\text { P00.9 } \\
\text { P04.1 a } \\
\text { P04.9 }\end{array}$ & 760 & \\
\hline Mãe com HIV & $\mathrm{R}$ & P00.2 & 760.2 & \\
\hline $\begin{array}{l}\text { Exposição pré-natal a drogas, exposição } \\
\text { tóxica }\end{array}$ & $\mathrm{R}$ & $\begin{array}{l}\text { P04.1 a } \\
\text { P04.9 }\end{array}$ & 760.7 & \\
\hline $\begin{array}{l}\text { Síndrome alcoólica fetal (SAF), } \\
\text { exposição alcoólica pré-natal }\end{array}$ & $\mathrm{R}$ & $\begin{array}{c}\text { P04.1 a } \\
\text { P04.9 }\end{array}$ & 760.71 & \\
\hline Exposição pré-natal a heroína & $\mathrm{R}$ & $\begin{array}{l}\text { P04.1 a } \\
\text { P04.9 }\end{array}$ & 760.72 & \\
\hline Exposição pré-natal a cocaína/crack & $\mathrm{R}$ & $\begin{array}{l}\text { P04.1 a } \\
\text { P04.9 }\end{array}$ & 760.75 & \\
\hline Exposição pré-natal a medicação & $\mathrm{R}$ & $\begin{array}{l}\text { P04.1 a } \\
\text { P04.9 }\end{array}$ & 760.79 & \\
\hline Gravidez múltipla & $\mathrm{R}$ & $\mathrm{P} 01.5$ & 761.5 & \\
\hline Separação placentária & $\mathrm{R}$ & $\begin{array}{l}\mathrm{P} 01.8 \\
\mathrm{P} 02.1\end{array}$ & 762.1 & \\
\hline Circular de cordão ao redor do pescoço & & $\mathrm{P} 02.5$ & 762.5 & \\
\hline Parto pélvico & & $\begin{array}{c}\text { P03.0 a } \\
\text { P03.9 } \\
\text { P04.0 } \\
\text { O83.0 }\end{array}$ & 763 & \\
\hline $\begin{array}{l}\text { Complicação não especificada do } \\
\text { trabalho de parto e parto afetando o } \\
\text { recém-nascido } \\
\text { Trauma de parto, problemas ao } \\
\text { nascimento, Apgar baixo, escores } \\
\text { baixos, depressão perinatal/neonatal, } \\
\text { nascido por cesareana de emergência, } \\
\text { nascido com sofrimento fetal, parto } \\
\text { difícil sem batimento cardíaco no } 6^{\circ} \\
\text { minuto, falta de oxigênio ao } \\
\text { nascimento, nascimento traumático, } \\
\text { parto traumático, ressuscitação } \\
\text { completa }\end{array}$ & $\mathrm{R}$ & $\begin{array}{l}\mathrm{P} 03.8 \\
\mathrm{P} 03.9\end{array}$ & 763.9 & \\
\hline Pequeno para Idade Gestacional, PIG & $\mathrm{R}$ & P05.0 a & 764 & \\
\hline
\end{tabular}




\begin{tabular}{|c|c|c|c|c|}
\hline & & P05.9 & & \\
\hline $\begin{array}{l}\text { Retardo de Crescimento Intra-Uterino, } \\
\text { RCIU }\end{array}$ & $\mathrm{R}$ & P05.9 & 764.9 & \\
\hline $\begin{array}{l}\text { Prematuro, prematuridade, extrema, } \\
\text { baixo peso ao nascer, muito baixo peso } \\
\text { ao nascer }\end{array}$ & $\mathrm{R}$ & $\begin{array}{l}\text { P07.0 a } \\
\text { P07.3 }\end{array}$ & 765 & \\
\hline $\begin{array}{l}\text { Grande para idade gestacional, pesado } \\
\text { (macrossômico) }\end{array}$ & $\mathrm{R}$ & P08.1 & 766.1 & b530 \\
\hline Hemorragia Cerebral e Sub-dural & $\mathrm{R}$ & $\begin{array}{c}\text { P10.0 } \\
\text { P10.1 } \\
\text { P10.4 a } \\
\text { P10.9 } \\
\text { P11.0 a } \\
\text { P11.9 } \\
\text { P12.0 a } \\
\text { P12.9 } \\
\text { P13.0 a } \\
\text { P13.9 } \\
\text { P14.0 a } \\
\text { P14.9 } \\
\text { P15.0 a } \\
\text { P15.9 } \\
\text { P52.4 } \\
\text { P52.8 } \\
\text { P91.8 }\end{array}$ & 767 & \\
\hline Paralisia Facial & $\mathrm{R}$ & P11.3 & 767.5 & \\
\hline $\begin{array}{l}\text { Paralisia de Plexo Braquial, paralisia de } \\
\text { Erb }\end{array}$ & $\mathrm{R}$ & $\begin{array}{l}\text { P14.0 a } \\
\text { P14.3 }\end{array}$ & 767.6 & \\
\hline $\begin{array}{l}\text { Distúrbio da Membrana Hialina, } \\
\text { Síndrome do Desconforto Respiratório } \\
\text { (SDR), aguda }\end{array}$ & $\mathrm{R}$ & $\mathrm{P} 22.0$ & 769 & \\
\hline Pneumonia (perinatal) & $\mathrm{R}$ & & 770 & \\
\hline Aspiração de mecônio & $\mathrm{R}$ & $\begin{array}{l}\text { P24.0 a } \\
\text { P24.9 }\end{array}$ & 770.1 & \\
\hline Displasia broncopulmonar (DBP) & $\mathrm{R}$ & $\begin{array}{l}\text { P27.0 a } \\
\text { P27.9 }\end{array}$ & 770.7 & \\
\hline $\begin{array}{l}\text { Outros problemas respiratórios após o } \\
\text { nascimento }\end{array}$ & $\mathrm{R}$ & $\begin{array}{c}\text { P21.9 } \\
\text { P22.8 } \\
\text { P22.9 } \\
\text { P28.2 a } \\
\text { P28.8 }\end{array}$ & 770.8 & \\
\hline Pulmões imaturos, não desenvolvidos & $\mathrm{R}$ & P28.9 & 770.9 & \\
\hline Rubéola Congênita & $\mathrm{R}$ & $\begin{array}{c}\text { A33 } \\
\text { P35.0 a } \\
\text { P35.9 } \\
\text { P36.0 a } \\
\text { P36.9 } \\
\text { P37.0 a }\end{array}$ & 771 & \\
\hline
\end{tabular}




\begin{tabular}{|c|c|c|c|}
\hline & & $\begin{array}{c}\text { P37.9 } \\
\text { P38 } \\
\text { P39.0 a } \\
\text { P39.9 }\end{array}$ & \\
\hline $\begin{array}{l}\text { Doença por Citomegalovírus, infecção, } \\
\text { CMV, vírus ao nascimento }\end{array}$ & $\mathrm{R}$ & P35.1 & 771.1 \\
\hline Outras infecções congênitas & $\mathrm{R}$ & $\begin{array}{c}\text { P35.2 a } \\
\text { P35.9 } \\
\text { P37.0 a } \\
\text { P37.9 }\end{array}$ & 771.2 \\
\hline Outras infecções perinatais & $\mathrm{R}$ & $\begin{array}{c}\text { P36.0 a } \\
\text { P36.9 } \\
\text { P38 } \\
\text { P39.2 a } \\
\text { P39.9 }\end{array}$ & 771.8 \\
\hline $\begin{array}{l}\text { Hemorragia Intraventricular, } I V H, \\
\text { sangramento cerebral }\end{array}$ & $\mathrm{R}$ & $\begin{array}{c}\text { P10.2 } \\
\text { P52.0 a } \\
\text { P52.5 }\end{array}$ & 772.1 \\
\hline Sistema imune imaturo & $\mathrm{R}$ & $\begin{array}{c}\text { P55.0 a } \\
\text { P55.9 } \\
\text { P56.0 } \\
\text { P57.0 } \\
\text { P61.4 } \\
\end{array}$ & 773 \\
\hline Doença Hemolítica ABO & $\mathrm{R}$ & P55.1 & 773.1 \\
\hline Hidropsia imune & $\mathrm{R}$ & P56.0 & 773.3 \\
\hline Acidose & $\mathrm{R}$ & P77.4 & 775.7 \\
\hline Íleo & $\mathrm{R}$ & $\begin{array}{c}\text { P75 } \\
\text { P76.0 a } \\
\text { P76.9 } \\
\text { P77 } \\
\text { P78.0 a } \\
\text { P78.9 }\end{array}$ & 777 \\
\hline Hidropsia fetal & $\mathrm{R}$ & $\begin{array}{l}\text { P56.9 } \\
\text { P80.0 a } \\
\text { P80.9 } \\
\text { P81.0 a } \\
\text { P81.9 } \\
\text { P83.0 a } \\
\text { P83.9 } \\
\end{array}$ & 778 \\
\hline Hidrocele & $\mathrm{R}$ & P83.5 & 778.6 \\
\hline $\begin{array}{l}\text { Convulsões, convulsões neonatais, } \\
\text { ataques, transtorno convulsivo, EEG } \\
\text { anormal } \\
\text { Convulsões } \\
\text { Tremor } \\
\text { Epilepsia } \\
\text { Espasmos infantis }\end{array}$ & $\mathrm{R}$ & $\begin{array}{c}\text { P29.0 a } \\
\text { P29.2 } \\
\text { P29.4 a } \\
\text { P29.9 } \\
\text { P90 } \\
\text { P91.0 a } \\
\text { P91.9 } \\
\text { P92.0 a }\end{array}$ & $\begin{array}{c}781 \\
780.3 \\
345.9 \\
345.6\end{array}$ \\
\hline
\end{tabular}




\begin{tabular}{|c|c|c|c|c|}
\hline & & $\begin{array}{c}\text { P92.9 } \\
\text { P93 } \\
\text { P94.1 a } \\
\text { P94.9 } \\
\text { P95 } \\
\text { P96.0 a } \\
\text { P96.9 }\end{array}$ & & \\
\hline $\begin{array}{l}\text { Abstinência de droga no lactente, } \\
\text { nascido adicto a metadona, abstinência } \\
\text { de droga em recém-nascido }\end{array}$ & $\mathrm{R}$ & $\begin{array}{l}\text { P96.1 } \\
\text { P96.2 }\end{array}$ & 779.5 & \\
\hline $\begin{array}{l}\text { Hipertonia, tônus muscular aumentado } \\
\text { ou anormal, problemas persistentes de } \\
\text { tônus, rigidez nos membros e hipotonia, } \\
\text { tônus reduzido, síndrome da hipotonia } \\
\text { cerebral, clônus atípico nos tornozelos }\end{array}$ & $\mathrm{R}$ & $\begin{array}{c}\text { P29.0 a } \\
\text { P29.2 } \\
\text { P29.4 a } \\
\text { P29.9 } \\
\text { P91.1 a } \\
\text { P91.8 } \\
\text { P94.1 a } \\
\text { P94.9 } \\
\text { P95 } \\
\text { P96.0 } \\
\text { P96.3 } \\
\text { P96.5 } \\
\text { P96.8 } \\
\end{array}$ & 779.8 & \\
\hline Icterícia & $\mathrm{R}$ & $\mathrm{R} 17$ & 782.4 & \\
\hline $\begin{array}{l}\text { Problemas com alimentação e sucção, } \\
\text { dificuldades na alimentação, sucção não } \\
\text { nutritiva, sucção podre ao seio, sonda } \\
\text { nasogástrica (SNG), alimentado por } \\
\text { sonda, nutrição parenteral(NPO) } \\
\end{array}$ & $\mathrm{R}$ & R63.3 & 783.3 & b510 \\
\hline Estridor (problema na respiração) & $\mathrm{R}$ & R06.1 & 786.1 & b440 \\
\hline Cólica & $\mathrm{R}$ & $\begin{array}{c}\text { R10.0 a } \\
\text { R10.4 } \\
\text { R16.0 } \\
\text { R16.1 } \\
\text { R19.0 } \\
\text { R19.3 } \\
\text { R18 } \\
\text { R19.8 }\end{array}$ & 789 & \\
\hline Anoxia, hipoxemia, hipóxico, hipóxia & $\mathrm{R}$ & & 799 & \\
\hline \multicolumn{5}{|l|}{ S. INFECÇÕES } \\
\hline Rotavírus & $\mathrm{S}$ & $\begin{array}{l}\text { A08.0 a } \\
\text { A08.3 }\end{array}$ & 008.61 & \\
\hline $\begin{array}{l}\text { Infecções intestinais mal definidas } \\
\text { (inner intestinitis) }\end{array}$ & $\mathrm{S}$ & $\begin{array}{c}\text { A09 } \\
\text { M02.1 }\end{array}$ & 009 & \\
\hline Neisseria meningitidis & $\mathrm{S}$ & $\begin{array}{l}\text { A39.0 } \\
\text { A39.8 }\end{array}$ & 036.0 & \\
\hline AIDS, HIV & $\mathrm{S}$ & $* *$ & 042. & \\
\hline Polio & $\mathrm{S}$ & A80.3 & 045.9 & \\
\hline
\end{tabular}




\begin{tabular}{|c|c|c|c|c|}
\hline & & A80.9 & & \\
\hline RSV, vírus respiratório sincicial & $\mathrm{S}$ & $* *$ & 079.6 & \\
\hline Sífilis congênita & $\mathrm{S}$ & $\begin{array}{l}\text { A50.2 } \\
\text { A50.9 }\end{array}$ & 090.9 & \\
\hline Meningite bacteriana & $\mathrm{S}$ & $\begin{array}{l}\text { G00.9 } \\
\text { G04.2 } \\
\text { G06.2 } \\
\end{array}$ & 320.9 & \\
\hline $\begin{array}{l}\text { Meningite, infecção do SNC, infecção } \\
\text { cerebral }\end{array}$ & $\mathrm{S}$ & $\begin{array}{c}\text { G03.2 a } \\
\text { G03.9 }\end{array}$ & 322.9 & \\
\hline Otite média, infecção da orelha média & $\mathrm{S}$ & H66.9 & 382.9 & \\
\hline Doença de Kawasaki & $\mathrm{S}$ & M30.3 & 446.1 & \\
\hline bronquiolite & $\mathrm{S}$ & $\begin{array}{l}\mathrm{J} 18.0 \\
\mathrm{~J} 21.0 \\
\mathrm{~J} 21.8 \\
\mathrm{~J} 21.9 \\
\end{array}$ & 466.19 & \\
\hline Sinusite, infecção do seio da face & $\mathrm{S}$ & $\begin{array}{l}\mathrm{J} 32.9 \\
\mathrm{~J} 34.8\end{array}$ & 473.9 & \\
\hline Pneumonia devida a vírus parainfluenza & $\mathrm{S}$ & $\mathrm{J} 12.2$ & 480.2 & \\
\hline Bronquite & $\mathrm{S}$ & $\begin{array}{c}\text { J20.9 } \\
\text { J40 } \\
\text { J98.0 }\end{array}$ & 490 & \\
\hline Hepatite & $\mathrm{S}$ & $\begin{array}{c}\text { K65.8 } \\
\text { K71.0 a } \\
\text { K71.9 } \\
\text { K75.2 } \\
\text { K75.3 } \\
\text { K75.8 } \\
\text { K75.9 }\end{array}$ & 573.3 & \\
\hline \multicolumn{5}{|l|}{ T. OUTRAS DOENÇAS / LESÕES } \\
\hline Doença Crônica & $\mathrm{T}$ & & $\mathrm{T}$ & \\
\hline Anemia & $\mathrm{T}$ & $\begin{array}{l}\text { D58.2 } \\
\text { D63.0 } \\
\text { D63.8 } \\
\text { D64.8 } \\
\text { D64.9 }\end{array}$ & 285.9 & \\
\hline $\begin{array}{l}\text { Aderências (pós-operatórias, intestinais, } \\
\text { etc) }\end{array}$ & $\mathrm{T}$ & $\begin{array}{c}\text { K66.0 a } \\
\text { K66.9 } \\
\text { K65.8 } \\
\text { R18 }\end{array}$ & 568 & \\
\hline Eczema & $\mathrm{T}$ & $\begin{array}{l}\text { L23.9 } \\
\text { L24.9 } \\
\text { L25.9 } \\
\text { L28.0 } \\
\text { L30.0 } \\
\text { L30.4 } \\
\text { L30.8 } \\
\text { L30.9 }\end{array}$ & 692.9 & \\
\hline Diarréia & $\mathrm{T}$ & R19.4 & 787.91 & \\
\hline
\end{tabular}




\begin{tabular}{|c|c|c|c|c|}
\hline & & R19.8 & & \\
\hline Fratura de crânio & $\mathrm{T}$ & $\begin{array}{c}\text { S02.9 } \\
\text { S07.1 a } \\
\text { S07.9 } \\
\text { S09.9 }\end{array}$ & 803 & \\
\hline Clavícula fraturada & $\mathrm{T}$ & S42.0 & 810 & \\
\hline Pedra no rim & $\mathrm{T}$ & $\begin{array}{l}\text { S62.0 } \\
\text { S62.1 } \\
\text { S62.8 }\end{array}$ & 814 & \\
\hline Braço quebrado & $\mathrm{T}$ & $\begin{array}{c}\text { S42.7 } \\
\text { S52.8 } \\
\text { T02.2 } \\
\text { T10 }\end{array}$ & 818 & \\
\hline Luxação do quadril & $\mathrm{T}$ & S73.0 & 835 & \\
\hline $\begin{array}{l}\text { Lesão cerebral, lesão difusa global do } \\
\text { cérebro, lesão cerebral traumática }\end{array}$ & $\mathrm{T}$ & $\begin{array}{l}\text { S06.2 } \\
\text { S06.3 } \\
\text { S06.8 }\end{array}$ & 851 & \\
\hline $\begin{array}{l}\text { Queimaduras: profunda até a parede } \\
\text { abdominal / queimaduras }\end{array}$ & $\mathrm{T}$ & $* *$ & 942.5 & \\
\hline Queimaduras & $\mathrm{T}$ & $\begin{array}{c}\mathrm{T} 27.3 \\
\mathrm{~T} 29.1 \mathrm{a} \\
\mathrm{T} 29.7 \\
\text { T30.0 a } \\
\text { T30.7 } \\
\text { L59.0 }\end{array}$ & 949 & \\
\hline Alergias alimentares & $\mathrm{T}$ & T78.4 & 995.3 & \\
\hline \multicolumn{5}{|c|}{ U. DOENÇAS CRÔNICAS / NEOPLASIAS } \\
\hline $\begin{array}{l}\text { Doença pulmonar, doença pulmonar } \\
\text { crônica }\end{array}$ & $\mathrm{U}$ & & & $\begin{array}{c}\mathrm{s} 40230 \\
\mathrm{~s} 4301\end{array}$ \\
\hline Insuficiência renal, problemas nos rins & $\mathrm{U}$ & & 170.1 & s6100 \\
\hline Tumor de Wilms & $\mathrm{U}$ & $\begin{array}{c}\text { C64 } \\
\text { C65 } \\
\text { C66 } \\
\text { C68.0 a } \\
\text { C68.9 } \\
\end{array}$ & 189 & \\
\hline Retinoblastoma & $\mathrm{U}$ & C69.2 & 190.5 & \\
\hline Tumor cerebral, neuroblastoma & $\mathrm{U}$ & $\begin{array}{c}\text { C71.0 a } \\
\text { C71.9 }\end{array}$ & 191 & \\
\hline Tumores espinhais & $\mathrm{U}$ & $\begin{array}{l}\text { C72.0 } \\
\text { C72.1 }\end{array}$ & 192.2 & \\
\hline Leucemia & $\mathrm{U}$ & C95.9 & 208.9 & \\
\hline Hemangioma & $\mathrm{U}$ & $\begin{array}{l}\text { D18.0 } \\
\text { D18.1 }\end{array}$ & 228 & \\
\hline Higroma cístico & $\mathrm{U}$ & D18.1 & 228.1 & \\
\hline Tumor fibroso no pescoço & $\mathrm{U}$ & $\begin{array}{l}\text { D15.9 } \\
\text { D19.7 } \\
\text { D36.7 } \\
\end{array}$ & 229.8 & \\
\hline
\end{tabular}




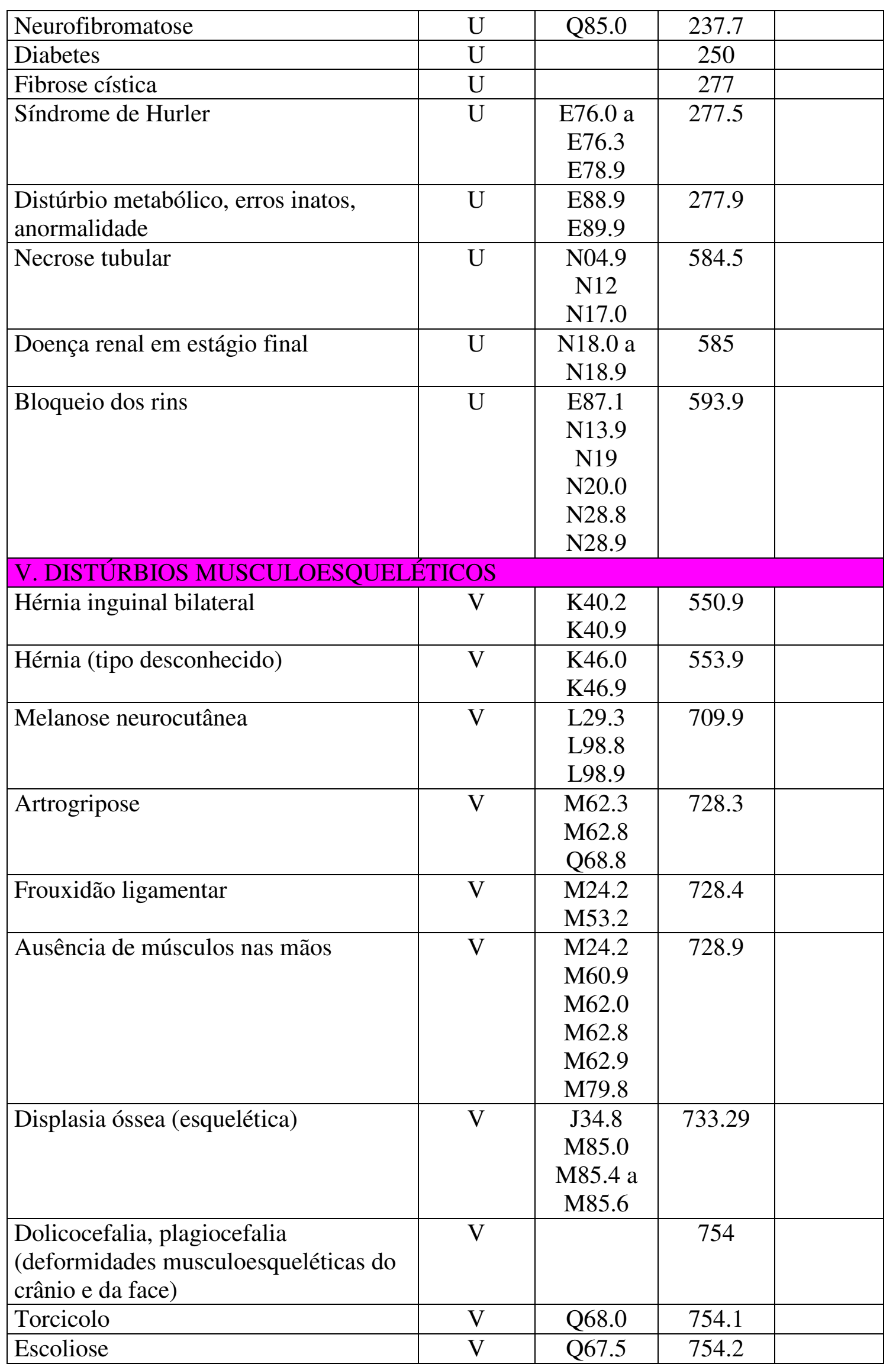




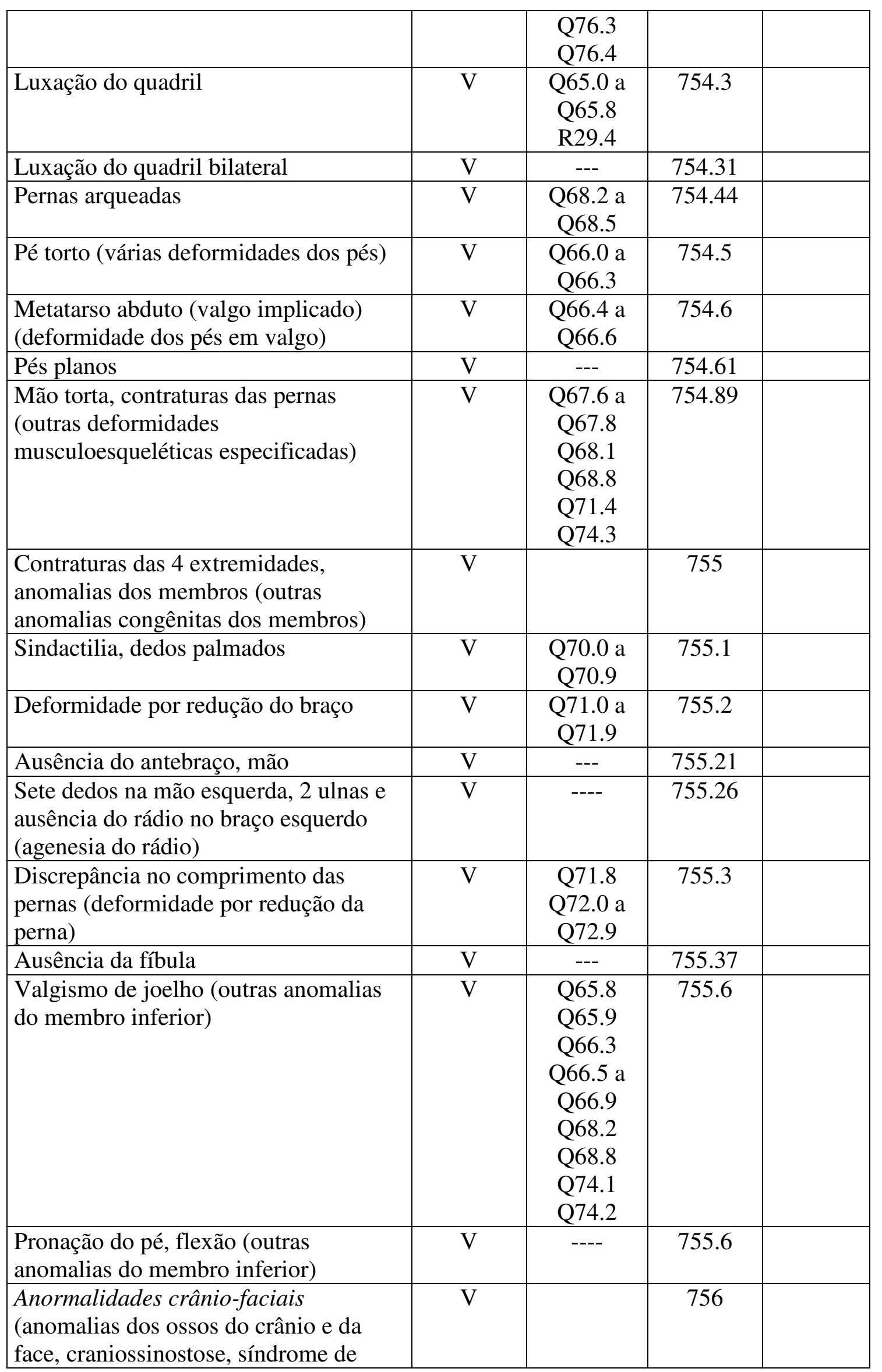




\begin{tabular}{|c|c|c|c|}
\hline \multicolumn{4}{|l|}{$\begin{array}{l}\text { Goldenhar, síndrome de Hallerman- } \\
\text { Streiff, macrocefalia, síndrome de } \\
\text { Pierre-Robin, anomalias múltiplas do } \\
\text { crânio, achados anormais/dismórficos, } \\
\text { assimetria cranial facial) }\end{array}$} \\
\hline $\begin{array}{l}\text { Agenesia sacral (ausência congênita de } \\
\text { vértebra) }\end{array}$ & $\mathrm{V}$ & $\begin{array}{c}\text { M43.1 } \\
\text { M43.2 } \\
\text { Q67.5 } \\
\text { Q76.0 a } \\
\text { Q76.2 } \\
\text { Q76.4 }\end{array}$ & 756.1 \\
\hline Ausência de costela (missing rib) & $\mathrm{V}$ & $\begin{array}{l}\text { Q67.8 } \\
\text { Q76.6 a } \\
\text { Q76.9 }\end{array}$ & 756.3 \\
\hline $\begin{array}{l}\text { Acondroplasia, hipocondroplasia } \\
\text { (condrodistrofia) }\end{array}$ & $\mathrm{V}$ & $\begin{array}{c}\text { Q77.0 a } \\
\text { Q77.4 } \\
\text { Q77.8 } \\
\text { Q78.4 } \\
\text { Q78.6 } \\
\text { Q78.9 }\end{array}$ & 756.4 \\
\hline $\begin{array}{l}\text { Osteogênese imperfeita } \\
\text { (osteodistrofias) }\end{array}$ & $\mathrm{V}$ & $\begin{array}{c}\text { M89.9 } \\
\text { Q75.8 } \\
\text { Q77.5 } \\
\text { Q77.6 } \\
\text { Q77.8 } \\
\text { Q77.9 } \\
\text { Q78.0 a } \\
\text { Q78.3 } \\
\text { Q78.8 } \\
\text { Q78.9 } \\
\text { Q79.8 }\end{array}$ & 756.5 \\
\hline $\begin{array}{l}\text { Hérnia diafragmática, hérnia } \\
\text { diafragmática congênita (anomalias do } \\
\text { diafragma) }\end{array}$ & $\mathrm{V}$ & $\begin{array}{l}\text { Q79.0 } \\
\text { Q79.1 }\end{array}$ & 756.6 \\
\hline Onfalocele & $\mathrm{V}$ & $\begin{array}{l}Q^{2} 79.2^{\mathrm{a}} \\
\mathrm{Q} 79.5 \\
\mathrm{Q} 87.8\end{array}$ & 756.79 \\
\hline Amioplasia congênita & $\mathrm{V}$ & $\begin{array}{c}\text { Q68.0 } \\
\text { Q74.0 } \\
\text { Q74.1 } \\
\text { Q77.2 } \\
\text { Q78.5 } \\
\text { Q78.8 } \\
\text { Q79.1 } \\
\text { Q79.4 a } \\
\text { Q79.8 } \\
\text { Q77.2 } \\
\text { Q77.3 }\end{array}$ & 756.89 \\
\hline
\end{tabular}




\begin{tabular}{|c|c|c|c|c|}
\hline & & Q87.8 & & \\
\hline $\begin{array}{l}\text { Outras alterações musculoesqueléticas: } \\
\text { displasia espondiloepifisária congênita, } \\
\text { defeito ortopédico, deficiência, } \\
\text { malformação ortopédica de ossos e } \\
\text { articulações, anomalias esqueléticas, } \\
\text { questões ortopédicas }\end{array}$ & $\mathrm{V}$ & $\begin{array}{l}\text { Q78.8 } \\
\text { Q79.9 }\end{array}$ & 756.9 & \\
\hline $\begin{array}{l}\text { Cotovelo de enfermeira, luxação de } \\
\text { cotovelo }\end{array}$ & $\mathrm{V}$ & $\begin{array}{l}\text { S53.0 } \\
\text { S53.1 }\end{array}$ & 832 & \\
\hline \multicolumn{5}{|c|}{ W. DISTÚRBIOS DO SITEMA NERVOSO CENTRAL } \\
\hline Encefalite & $\mathrm{W}$ & $\begin{array}{l}\text { G04.9 } \\
\text { G37.3 } \\
\text { G37.4 } \\
\text { G93.4 }\end{array}$ & 323.9 & \\
\hline $\begin{array}{l}\text { Leucodistrofia, distúrbio da substância } \\
\text { branca, distúrbio da mielinização, } \\
\text { atraso na mielinização, Pelizaeus- } \\
\text { Merzbacher }\end{array}$ & $\mathrm{W}$ & & 330 & \\
\hline Gangliosidose, Tay-Sachs & $\mathrm{W}$ & $\begin{array}{l}\text { E75.0 } \\
\text { E75.1 } \\
\text { E75.4 }\end{array}$ & 330.1 & \\
\hline Doença ou síndrome de Leigh & $\mathrm{W}$ & G31.8 & 330.8 & \\
\hline Ataxia cerebelar, aguda & $\mathrm{W}$ & $\begin{array}{l}\text { G11.3 } \\
\text { G11.9 } \\
\text { G60.0 }\end{array}$ & 334.3 & \\
\hline Atrofia muscular espinhal & $\mathrm{W}$ & $\begin{array}{c}\text { G12.0 a } \\
\text { G12.9 }\end{array}$ & 335.1 & \\
\hline Esclerose múltipla & $\mathrm{W}$ & G35 & 340 & \\
\hline Hemiparesia, hemiplegia & $\mathrm{W}$ & G81.9 & 342.9 & \\
\hline Diplegia congênita, espástica & $\mathrm{W}$ & G80 & 343 & \\
\hline Quadriplegia espástica & $\mathrm{W}$ & $\begin{array}{l}\text { G80.8 } \\
\text { G82.5 }\end{array}$ & 343.2 & \\
\hline Paralisia cerebral, PC & $\mathrm{W}$ & $\begin{array}{l}\text { G80.0 } \\
\text { G80.9 }\end{array}$ & 343.9 & \\
\hline Paraplegia & $\mathrm{W}$ & $\begin{array}{l}\text { G82.0 a } \\
\text { G82.2 } \\
\text { G83.8 }\end{array}$ & 344.1 & \\
\hline Cisto subaracnóide & $\mathrm{W}$ & & 348 & \\
\hline $\begin{array}{l}\text { Encefalopatia isquêmica hipóxica, EIH, } \\
\text { distúrbio cerebral isquêmico } \\
\text { encefalopático }\end{array}$ & $\mathrm{W}$ & G93.1 & 348.1 & \\
\hline Encefalopatia & $\mathrm{W}$ & $\begin{array}{l}\text { G40.9 } \\
\text { G93.4 } \\
\text { G93.8 } \\
\text { G96.9 }\end{array}$ & 348.3 & \\
\hline Leucomalácia periventricular, LPV & $\mathrm{W}$ & $\begin{array}{l}\text { G31.9 } \\
\text { G93.9 }\end{array}$ & 348.9 & \\
\hline
\end{tabular}




\begin{tabular}{|c|c|c|c|}
\hline Paralisia oculofacial de Möebius & $\mathrm{W}$ & $\begin{array}{l}\text { G46.3 } \\
\text { G52.7 } \\
\text { G53.2 } \\
\text { I66.8 } \\
\text { Q87.0 }\end{array}$ & 352.6 \\
\hline $\begin{array}{l}\text { Síndrome / doença de Charcot-Marie- } \\
\text { Tooth }\end{array}$ & $\mathrm{W}$ & $\begin{array}{l}\text { G58.9 } \\
\text { G60.0 }\end{array}$ & 356.1 \\
\hline Neuropatia periférica & $\mathrm{W}$ & $\begin{array}{l}\text { G58.9 } \\
\text { G60.0 } \\
\text { G60.3 } \\
\text { G60.9 } \\
\text { G62.9 } \\
\text { G96.8 }\end{array}$ & 356.9 \\
\hline Distrofia muscular & $\mathrm{W}$ & $\begin{array}{l}\text { G71.0 } \\
\text { G71.2 } \\
\text { G71.9 }\end{array}$ & 359.1 \\
\hline Distrofia miotônica & $\mathrm{W}$ & G71.1 & 359.2 \\
\hline Encefalomalácia (artérias cerebrais) & $\mathrm{W}$ & $\begin{array}{c}\text { G46.0 a } \\
\text { G46.2 } \\
\text { G93.8 } \\
\text { I63.5 } \\
\text { I63.8 } \\
\text { I63.9 } \\
\text { I66.0 a } \\
\text { I66.9 }\end{array}$ & 434.9 \\
\hline Encefalopatia hipotônica & $\mathrm{W}$ & I67.4 & 437.2 \\
\hline $\begin{array}{l}\text { Espinha bífida com hidrocefalia ou } \\
\text { obstrução de Arnold-Chiari }\end{array}$ & $\mathrm{W}$ & $\begin{array}{l}\text { Q05.0 a } \\
\text { Q05.9 } \\
\text { Q07.0 }\end{array}$ & 741 \\
\hline $\begin{array}{l}\text { Espinha bífida: meningomielocele, } \\
\text { mielomeningocele, defeito de tubo } \\
\text { neural, medula estirada (sem menção de } \\
\text { hidrocefalia) }\end{array}$ & $\mathrm{W}$ & $\begin{array}{l}\text { Q05.5 a } \\
\text { Q05.9 }\end{array}$ & 741.9 \\
\hline Encefalocele & $\mathrm{W}$ & & 742 \\
\hline $\begin{array}{l}\text { Microcefalia, microencefalia, } \\
\text { desenvolvimento do crescimento } \\
\text { cerebral mais lento que o normal }\end{array}$ & $\mathrm{W}$ & Q02 & 742.1 \\
\hline $\begin{array}{l}\text { (deformidades por redução do cérebro) } \\
\text { agenesia do corpo caloso (ausência), } \\
\text { deficiência do corpo caloso, } \\
\text { holoprosencefalia, lissencefalia, } \\
\text { lissencéfalo }\end{array}$ & $\mathrm{W}$ & $\begin{array}{l}\text { Q04.0 a } \\
\text { Q04.3 }\end{array}$ & 742.2 \\
\hline $\begin{array}{l}\text { (hidrocefalia congênita) estenose do } \\
\text { aqueduto de Sylvius, Dandy-Walker, } \\
\text { hidrocefalia, hidrocefálico, hidrocefalia } \\
\text { congênita, hidranencefalia }\end{array}$ & $\mathrm{W}$ & $\begin{array}{l}\text { Q03.0 a } \\
\text { Q03.9 } \\
\text { Q04.3 }\end{array}$ & 742.3 \\
\hline $\begin{array}{l}\text { (outras anomalias cerebrais } \\
\text { especificadas) atrofia cerebral, cisto no }\end{array}$ & $\mathrm{W}$ & $\begin{array}{l}\text { Q04.4 a } \\
\text { Q04.9 }\end{array}$ & 742.4 \\
\hline
\end{tabular}




\begin{tabular}{|c|c|c|c|c|}
\hline $\begin{array}{l}\text { cérebro, macroencefalia, cisto } \\
\text { porencefálico, porencefalia, } \\
\text { esquizencefalia, megaencefalia } \\
\text { (megalencefalia) }\end{array}$ & & & & \\
\hline $\begin{array}{l}\text { (anomalias não especificadas do } \\
\text { cérebro / SNC) anormalidade cerebral, } \\
\text { anormalidade do desenvolvimento } \\
\text { cerebral, displasia cleidocraniana, } \\
\text { anormalidade do SNC, malformação do } \\
\text { cerebelo, suspeita de anomalia } \\
\text { estrutural do cérebro, cefalização }\end{array}$ & $\mathrm{W}$ & $\begin{array}{l}\text { Q04.8 } \\
\text { Q04.9 } \\
\text { Q06.1 } \\
\text { Q06.9 } \\
\text { Q07.8 } \\
\text { Q07.9 }\end{array}$ & 742.9 & \\
\hline \multicolumn{5}{|l|}{ X. OUTROS ESPECIFICADOS } \\
\hline \multicolumn{5}{|l|}{ Xa. Hospitalização / tratamento médico } \\
\hline $\begin{array}{l}\text { Hospitalizado } 8 \text { dias, UTI Neonatal, } \\
\text { insulto biomédico grave, hospitalizado } \\
\text { por longo tempo, história de problemas } \\
\text { médicos, problemas médicos ao } \\
\text { nascimento, evolução médica } \\
\text { complicada, cirurgia ao nascimento, } \\
\text { devido a permanência no hospital, } \\
\text { numerosas cirurgias na cabeça } \\
\text { Diagnóstico médico, complicações, } \\
\text { diagnóstico de frágil do ponto de vista } \\
\text { médico, dependente de tecnologia } \\
\text { médica }\end{array}$ & $\mathrm{Xa}$ & & $\mathrm{Xa}$ & \\
\hline $\begin{array}{l}\text { Respiração: história de suporte } \\
\text { ventilatório, em ventilador, oxigênio, } \\
\mathrm{O}^{2} \text {, problema respiratório pulmonar, } \\
\text { colapso de pulmão e falência } \\
\text { respiratória, ventilação, ventilação } \\
\text { assistida, problemas respiratórios }\end{array}$ & $\mathrm{Xa}$ & & $\mathrm{i} 409$ & \\
\hline \multicolumn{5}{|l|}{ Categoria IV } \\
\hline \multicolumn{5}{|l|}{ Y. AMBIENTE FÍSICO } \\
\hline $\begin{array}{l}\text { Ambiente, ambientalmente sob risco, } \\
\text { elegível para cuidados médicos }\end{array}$ & Y & & $\mathrm{Y}$ & \\
\hline \multicolumn{5}{|l|}{ Ya. Produtos / Objetos / Materiais } \\
\hline Transplante cardíaco & $\mathrm{Ya}$ & Z94.1 & V42.1 & \\
\hline Ileostomia & $\mathrm{Ya}$ & Z93.2 & V44.2 & e1151 \\
\hline $\begin{array}{l}\text { Traqueostomia, colocação de tubo } \\
\text { traqueal }\end{array}$ & $\mathrm{Ya}$ & $\begin{array}{c}\text { Z93.0 a } \\
\text { Z93.9 }\end{array}$ & V44 & e1151 \\
\hline Gastrostomia, tubo gástrico & $\mathrm{Ya}$ & Z93.1 & V44.1 & $\mathrm{e} 1151$ \\
\hline Colostomia & $\mathrm{Ya}$ & Z93.3 & V44.3 & $\mathrm{e} 1151$ \\
\hline Sonda jejunal & $\mathrm{Ya}$ & Z93.4 & V44.4 & $\mathrm{e} 1151$ \\
\hline $\begin{array}{l}\text { Derivação Ventrículo-peritoneal } \\
\text { (DVP), derivação colocada na cabeça } \\
\text { (quando claramente associada com } \\
\text { hidrocefalia) hidrocefalia e derivação }\end{array}$ & $\mathrm{Ya}$ & $\mathrm{Z} 98.2$ & V45.2 & e1151 \\
\hline Marcapasso & $\mathrm{Ya}$ & Z45.0 & V53.31 & e1151 \\
\hline
\end{tabular}




\begin{tabular}{|c|c|c|c|c|}
\hline $\begin{array}{l}\text { Dispositivos ortopédicos (órteses, } \\
\text { contensores, etc) }\end{array}$ & $\mathrm{Ya}$ & Z46.7 & V53.7 & \\
\hline Cadeira de rodas & $\mathrm{Ya}$ & Z46.8 & V53.8 & \\
\hline Transfusão de sangue & $\mathrm{Ya}$ & Z51.3 & V58.2 & \\
\hline \multicolumn{5}{|l|}{ Yb. Ambiente imediato } \\
\hline Trauma psicológico & $\mathrm{Yb}$ & Z91.4 & V15.49 & \\
\hline $\begin{array}{l}\text { Envenenamento por chumbo, chumbo } \\
\text { elevado }\end{array}$ & $\mathrm{Yb}$ & $\begin{array}{l}\text { M10.1 } \\
\text { N14.3 } \\
\text { T56.0 }\end{array}$ & 984.9 & \\
\hline Afogado na banheira & $\mathrm{Yb}$ & T75.1 & 994.1 & \\
\hline Sem teto, vivendo em albergue & $\mathrm{Yb}$ & & V60 & \\
\hline Moradia inadequada & $\mathrm{Yb}$ & Z59.1 & V60.1 & \\
\hline $\begin{array}{l}\text { Alimentação, recursos materiais e } \\
\text { vestimentas inadequados }\end{array}$ & $\mathrm{Yb}$ & $\begin{array}{l}\text { Z59.6 } \\
\text { Z59.8 } \\
\text { Z59.9 }\end{array}$ & V60.2 & \\
\hline \multicolumn{5}{|l|}{ Z. AMBIENTE SOCIAL } \\
\hline $\begin{array}{l}\text { Social: situação, fatores de risco, } \\
\text { apoios, falta de suporte }\end{array}$ & $\mathrm{Z}$ & $\begin{array}{c}\text { Z60.3 a } \\
\text { Z60.9 }\end{array}$ & V62.4 & \\
\hline \multicolumn{5}{|l|}{ Za. Membros da Família e Cuidadores } \\
\hline $\begin{array}{l}\text { Muitos fatores de risco familiares, } \\
\text { ausência de estimulação no lar, pobre } \\
\text { situação doméstica, mãe adolescente, } \\
\text { educação e idade jovem da mãe, pai } \\
\text { adolescente, mãe ou pais surdos, mãe } \\
\text { sobrecarregada por separação recente, } \\
\text { mudança recente para a custódia do } \\
\text { pai, pai ou mãe solteiro sob muito } \\
\text { estresse, múltiplos traumas ou perdas, } \\
\text { perdas }\end{array}$ & $\mathrm{Za}$ & & & e310 \\
\hline Abuso ou negligência da criança & $\mathrm{Za}$ & $\begin{array}{c}\text { T74.0 } \\
\text { T74.1 } \\
\text { T74.3 a } \\
\text { T74.9 }\end{array}$ & 995.5 & \\
\hline $\begin{array}{l}\text { Negligência da criança - nutricional, } \\
\text { desnutrição }\end{array}$ & $\mathrm{Za}$ & & 995.52 & \\
\hline Síndrome do bebê sacudido & $\mathrm{Za}$ & & 995.55 & \\
\hline Lactente abandonado, enjeitado & $\mathrm{Za}$ & $\begin{array}{l}\text { Z76.1 } \\
\text { Z76.2 } \\
\text { Z00.1 }\end{array}$ & V20 & \\
\hline $\begin{array}{l}\text { Problemas pais/criança; vínculo, } \\
\text { cuidados parentais, ligação insegura, } \\
\text { problemas na ligação }\end{array}$ & $\mathrm{Za}$ & $\begin{array}{c}\text { Z61.6 } \\
\text { Z62.0 a } \\
\text { Z62.9 } \\
\text { Z63.8 }\end{array}$ & V61.2 & $\mathrm{d} 7600$ \\
\hline Cuidado substituto, criança adotada & $\mathrm{Za}$ & --- & V61.29 & \\
\hline Mãe ou pais com doença crônica & $\mathrm{Za}$ & $\begin{array}{l}\mathrm{Z} 63.6 \\
\mathrm{Z} 63.7\end{array}$ & V61.4 & \\
\hline Mãe ou pais que têm distúrbio mental & $\mathrm{Za}$ & Z60.1 & V61.8 & \\
\hline
\end{tabular}




\begin{tabular}{|c|c|c|c|c|}
\hline $\begin{array}{l}\text { ou comportamental, irmãos com } \\
\text { deficiência do desenvolvimento }\end{array}$ & & $\begin{array}{c}\text { Z61.0 a } \\
\text { Z61.2 } \\
\text { Z61.4 } \\
\text { Z63.2 a } \\
\text { Z63.4 } \\
\text { Z63.7 } \\
\text { Z63.8 }\end{array}$ & & \\
\hline $\begin{array}{l}\text { Abuso de drogas ou outras substâncias } \\
\text { pelos pais, abuso de substâncias no lar }\end{array}$ & $\mathrm{Za}$ & Z63.9 & V61.9 & \\
\hline Violência doméstica & $\mathrm{Za}$ & $\begin{array}{c}\text { Z60.0 } \\
\text { Z61.3 } \\
\text { Z61.5 } \\
\text { Z61.7 a } \\
\text { Z61.9 } \\
\text { Z62.2 } \\
\text { Z64.4 } \\
\text { Z65.2 } \\
\text { Z65.4 a } \\
\text { Z65.8 } \\
\text { Z72.2 } \\
\text { Z73.0 a } \\
\text { Z73.5 }\end{array}$ & V62.8 & \\
\hline \multicolumn{5}{|l|}{ AA. AMBIENTE CULTURAL } \\
\hline \multicolumn{5}{|c|}{ BB. AMBIENTE COMUNITÁRIO / INFRAESTRUTURA } \\
\hline \multicolumn{5}{|l|}{ BBa. Educação } \\
\hline $\begin{array}{l}\text { Educação especial, educação especial } \\
\text { na infância precoce (ECSE Early } \\
\text { Childhood Special Education), } \\
\text { educação acadêmica, pré-acadêmica, } \\
\text { instituição especial }\end{array}$ & $\mathrm{BBa}$ & & $\mathrm{BBa}$ & \\
\hline \multicolumn{5}{|l|}{ BBb. Serviços sociais } \\
\hline $\begin{array}{l}\text { Envolvimento com dispositivos de } \\
\text { serviços sociais (DSS), relato, } \\
\text { envolvimento de proteção das crianças }\end{array}$ & $\mathrm{BBb}$ & & $\mathrm{BBb}$ & \\
\hline \multicolumn{5}{|l|}{ BBc. Serviços de saúde } \\
\hline $\begin{array}{l}\text { Cuidados médicos limitados, sem } \\
\text { cuidados de pré-natal, sem médico ou } \\
\text { imunização }\end{array}$ & $\mathrm{BBc}$ & & $\mathrm{BBc}$ & \\
\hline
\end{tabular}

